\title{
Effect of breathing, posture, and air velocity on breathing zone gas concentrations for human subjects in a wind tunnel
}

Ahmed R. El-Sotouhy

West Virginia University

Follow this and additional works at: https://researchrepository.wvu.edu/etd

\section{Recommended Citation}

El-Sotouhy, Ahmed R., "Effect of breathing, posture, and air velocity on breathing zone gas concentrations for human subjects in a wind tunnel" (2008). Graduate Theses, Dissertations, and Problem Reports. 4369. https://researchrepository.wvu.edu/etd/4369

This Dissertation is protected by copyright and/or related rights. It has been brought to you by the The Research Repository @ WVU with permission from the rights-holder(s). You are free to use this Dissertation in any way that is permitted by the copyright and related rights legislation that applies to your use. For other uses you must obtain permission from the rights-holder(s) directly, unless additional rights are indicated by a Creative Commons license in the record and/ or on the work itself. This Dissertation has been accepted for inclusion in WVU Graduate Theses, Dissertations, and Problem Reports collection by an authorized administrator of The Research Repository @ WVU.

For more information, please contact researchrepository@mail.wvu.edu. 


\title{
Effect of Breathing, Posture, and Air Velocity on Breathing Zone Gas Concentrations for Human Subjects in a Wind Tunnel
}

\author{
Ahmed R. El-Sotouhy \\ Dissertation \\ Submitted to the \\ College of Engineering and Mineral Resources \\ at \\ West Virginia University \\ in partial fulfillment of the requirements \\ for the degree of \\ Doctor of Philosophy \\ in
}

Occupational Safety and Health / Industrial and Management Systems Engineering

Steven E. Guffey, Ph.D., WVU-IMSE, Committee Chair

Warren Myers, Ph.D., WVU-IMSE

Wafik Iskander, Ph.D., WVU-IMSE

Michael McCawley, Ph.D., WVU-CEE

Christopher Coffey, Ph.D., NIOSH

Department of Industrial and Management Systems Engineering

Morgantown, West Virginia

2008

Keywords: Industrial Hygiene - Human Subjects - Personal Air Sampling - Indoor Air Quality - Exposure - Breathing Zone - Wind Tunnel - Cross Draft Velocities Tracer Gases

Copyrights 2008 Ahmed R. El-Sotouhy 


\title{
ABSTRACT
}

\section{Effect of Breathing, Posture, and air velocity on Breathing Zone Gas Concentrations for Human Subjects in a Wind Tunnel}

\begin{abstract}
Ahmed R. El-Sotouhy
Industrial hygienists generally place air-sampling probes on the mid to upper torso of workers when attempting to determine inhaled concentrations. There is no convincing evidence that concentrations measured on the chest are equal to inhaled concentrations. To determine how well surrogate locations matched concentrations at the mouth $\left(\mathrm{C}_{\text {mouth }}\right)$, low concentrations of ethanol in nitrogen were released between the hands of standing and seated human subjects while they moved children's blocks back and forth over the source.

In all cases, each of four subjects stood or sat with their backs to the airflow in a wind tunnel because previous studies had established that facing downstream produced exposures that were more than 100 times the exposures when facing upstream or sideways to the flow with the source in the subjects' hands. Sampling probes were placed at the subject's mouth, nose, forehead, neck, both collars, center chest and both lapels. Airflow was drawn to $3 \mathrm{~L} \mathrm{Teflon}^{\mathrm{TM}}$ sampling bags at $0.15 \mathrm{Lpm}$. Concentrations were measured using a gas chromatograph with a photo-ionization detector, which was calibrated daily over the range of sample concentrations. Subjects were tested at wind tunnel cross-draft velocities of 11.3, 27.2, 47.5, 81.5, and $103.5 \mathrm{ft} / \mathrm{min}$ while either exhaling through a tube or not and either sitting or standing.

The results showed that posture and wind tunnel velocity have highly significant effect on sampling location concentration $(\mathrm{p}<0.01)$. Exhaling through a tube was less important $(\mathrm{p}<0.04)$. As with a previous manikin study, concentrations varied in an inverted-V with velocity. Concentrations across the chest were as much as $22 \%$ higher than $\mathrm{C}_{\text {mouth }}$ when seated and $70 \%$ higher than $\mathrm{C}_{\text {mouth }}$ when standing. Concentrations at the neck and collar were much closer to $\mathrm{C}_{\text {mouth }}$ but still deviated by as much as $10 \%$. Levels at the forehead were generally lower than $\mathrm{C}_{\text {mouth }}$ but were highly correlated to it. Levels adjacent to the tip of the nose deviated the least $7 \%$, as might be expected. Based on the study, the best surrogate to mouth location are the collars with an over estimation of $7 \%$.

Previous studies raise strong concerns about the accuracy of samples taken anywhere below the collar when the subject is close to the source and airflow is from the rear. The dramatic effects of posture on concentrations suggest that exposure studies should include both sitting and standing as well as variations of each. The effects of body size and shape and hair length should be investigated in future studies.
\end{abstract}




\section{ACKNOWLEDGEMENTS}

This work was supported by the Industrial and Management Systems Engineering Department (IMSE), the National Institute for Occupational Safety and Health (NIOSH) grant number (1RO1 OHO4081-01), as well as the NEETC funding through WVUNRCCE - WRI Project (Office of Supported Research).

I would like to extend my sincere appreciation and deep gratitude to Dr. Steve Guffey for making this accomplishment possible. I would like to thank him for having confidence and faith and willingness to spend all that time with me and giving me the opportunity to work on this project. Through his care and keen efforts, I have passed many difficulties and achieved immensely.

I would like to extend my thanks to Dr. John Quaranta at the National Research Center of Coal Mining and Energy (NRCCE) of West Virginia University - Water Research Institute (WRI) Project for finding me the needed funds through NEETC Agency to complete my research.

I would like to thank specifically Dr. Wafik Iskander for all the support and kindness he showed to me during my study in the department. I would like to take this opportunity to extent my gratitude to Dr. Warren Myers for all his supportive actions for me to succeed and fulfill my academic aims. I present my gratitude to Dr. Michael McCawley and Dr. Christopher Coffey, for sharing their technical expertise with me and for serving on my committee. 
I would also like to thank everyone who has assisted me on this project, including Mr. Dalton and all my colleagues in the exposure assessment project: Santosh, Sumeeth, Vivek, Amit, \& El Nahas. Special thanks go for Jeremy Slagly for all the support he gave to my family and me.

My deepest thanks and gratitude go out to my parents Reda El-Sotouhy and Kariman Badr, and to Eng. Heba El-Sotouhy, my sister, and all my family back home. You supported and stood by my side through all the difficulties of this project. Without your true care, love, funding and prayers I would have not accomplished what I have now. I dedicate this degree to you and I kiss your hands forever.

Finally great thanks to my wonderful wife Dalia Nawar and my children Omar, Marwan and Jameela for being with me during these hard studying years standing by my side. I love you and cherish your love for me. 


\title{
ABBREVIATIONS
}

\author{
BZ Breathing Zone \\ CFD Computational Fluid Dynamics \\ $\mathrm{C}_{\text {c.chest }}$ Concentration at center chest location, ppm \\ $\mathrm{C}_{\text {l.lapel }} \quad$ Concentration at left lapel location, ppm \\ $\mathrm{C}_{\text {r.lapel }}$ Concentration at right lapel location, $\mathrm{ppm}$ \\ $\mathrm{C}_{\text {neck }} \quad$ Concentration at neck location, ppm \\ $\mathrm{C}_{\text {l.collar }}$ Concentration at left collar location, ppm \\ $\mathrm{C}_{\text {r.collar }}$ Concentration at right collar location, $\mathrm{ppm}$ \\ $\mathrm{C}_{\text {mouth }} \quad$ Concentration at mouth location, $\mathrm{ppm}$ \\ $\mathrm{C}_{\text {nose }} \quad$ Concentration at nose location, $\mathrm{ppm}$ \\ $\mathrm{C}_{\text {forehead }}$ Concentration at forehead location, ppm \\ fpm feet per min \\ $\mathrm{mV} \quad$ Milli volt \\ mVS milli volt second \\ NIOSH National Institute for Occupational Safety and Health \\ OSHA Occupational Safety and Health Administration \\ ppm parts per million \\ Re Reynolds number \\ V wind tunnel velocity, fpm
}




\section{TABLE OF CONTENT}

ABSTRACT

ACKNOWLEDGEMENTS

iii

ABBREVIATIONS

v

TABLE OF CONTENT

vi

LIST OF FIGURES

ix

LIST OF TABLES

xiv

CHAPTER 1: INTRODUCTION

1

1.1 Background, \& Problem Statement

1.2 Practical Need for the Proposed Research 3

1.3 PROBLEM STATEMENT 4

1.4 Research ObJectives $\quad 5$

Chapter 2: LITERATURE REVIEW

2.1 INTRODUCTION $\quad 6$

$\begin{array}{ll}2.2 \text { HUMAN STUDIES } & 7\end{array}$

2.3 MANIKIN STUDIES

2.3.1 MANIKINS: UNHEATED AND NON-BREATHING 8

2.3.2 MANIKIN VERSUS HUMAN SUBJECTS

2.3.3 HEATED MANIKIN 13

2.4 Computational Fluid Dynamics Studies (CFD) 14

2.5 Typical Cross-draft Velocities $\quad 15$

CHAPTER 3: RESEARCH DESIGN, METHODS, APPARATUS AND PROCEDURES $\quad 17$

3.1 Research Design and Methods 17

3.1.1 INTRODUCTION 17

$\begin{array}{ll}\text { 3.1.2 EXPERIMENTAL DESIGN } & 17\end{array}$ 
3.2.1 WIND TUNNEL

3.2.2 Temperature, Humidity and Barometric Measurements 21

3.2.3 System for Generation And Dispersion of Tracer Gas Mixture 22

3.2.3 SAMPLING LOCATIONS 23

3.2.4 GAS AND VAPOR SAMPLING SYSTEM

3.2.5 GAS AND VAPOR ANALYSIS $\quad 25$

3.3 Procedures 26

3.3.1 Procedures for Operating the Tracer Gas Release System 26

3.3.1.1 Procedures for ethanol liquid preparation for usage in tracer gas pump: 26

3.3.1.2. Procedures for setting and controlling the nitrogen gas release system 26

3.3.1.3. Procedures for setting electric heating element (evaporation device) system $\quad 27$

3.3.1.4 Procedures for setting tracer gas pump system 27

3.3.1.5 Sampling procedures for checking the concentration levels of tracer gas generated 28

3.3.2 PROCEDURES FOR SAMPLING SYSTEM $\quad 29$

3.3.2.1 Procedures for sampling lines preparation for sampling 29

3.3.2.1.1 Leak detection procedure for sampling line 30

3.3.2.2 Procedures for sampling lines preparation for sampling 30

3.3.2.2.1 Leak detection procedure for sampling bags 32

3.3.2.3 Low flow pumps set procedures for operation: 33

3.3.2.3.1 Leak detection procedure for sampling pumps 33

3.3.3 ADJUSTMENT OF FAN SPEED 34

3.3.4 Procedures for Analyzing Ethanol Sampling Bags 34

3.3.5 Procedures For GC Calibration

CHAPTER 4: RESULTS OF STUDY $\quad 38$

4.1 Effects of Independent Variables on Concentration at Mouth Location $\left(\mathrm{C}_{\text {моuтн }}\right)$

4.1.1 VELOCITY

4.1.2 SUBJECT $\quad 46$

$\begin{array}{ll}\text { 4.1.3 POSTURE } & 48\end{array}$

4.1.4 BREATHING

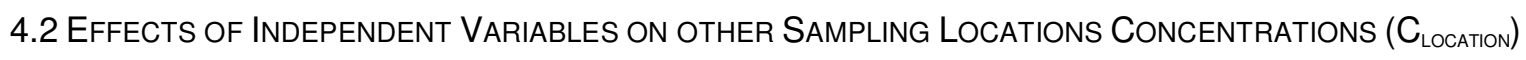

4.2.1 EFFECT OF VELOCITY $\quad 67$

4.2.2 SUBJECTS

$\begin{array}{ll}\text { 4.2.3 POSTURE } & 70\end{array}$

4.2.4 BREATHING

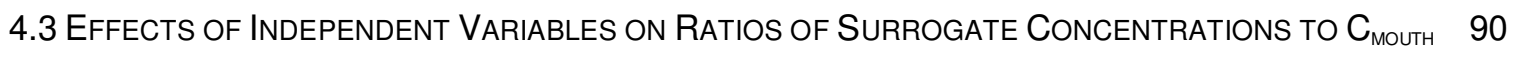




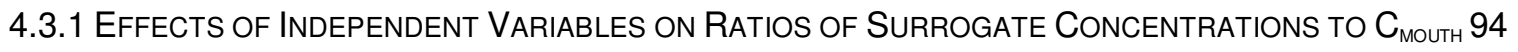
CHAPTER 5: DISCUSSION 97

5.1 ANALYSIS AND DisCUSSION OF $\mathrm{C}_{\text {MOUTH }}$ RESULTS 99

5.1.1 ANALYSIS OF VARIANCE (ANOVA) FOR $\mathrm{C}_{\text {MOUTH }}$ 99

5.2 Comparison of DiffERENCES In CONCENTRATIONS OBSERVEd AT DifFERENT SAMPLING LOCATIONS

5.3 CONCENTRATIONS AT DifFERENT Locations

5.3.1 EFFECTS OF INDEPENDENT VARIABLES ON $\mathrm{C}_{\text {Location }}$

5.4 RATIOS OF CONCENTRATIONS TO $\mathrm{C}_{\text {MOUTH }}$ AT DIFFERENT LOCATIONS

5.4.1 ANOVA FOR CRATIO

5.5 MANIKIN 120

CHAPTER 6: CONCLUSIONS AND RECOMMENDATIONS

6.1 CONCLUSIONS

6.2 RECOMmEndations

6.3 CAVEATS

6.4 IMPACT OF THE STUDY

6.5 RECOMMENDATIONS FOR FUtURE WORK 


\section{LIST OF FIGURES}

Figure 1.1: Sampling BZ.

Figure 3.1 Wind tunnel 20

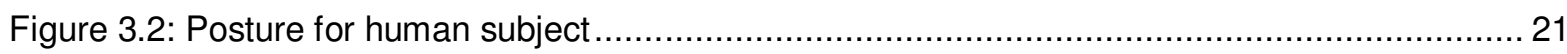

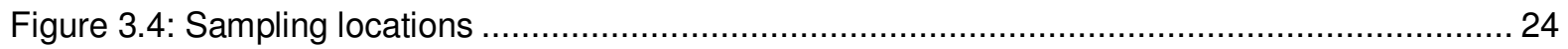

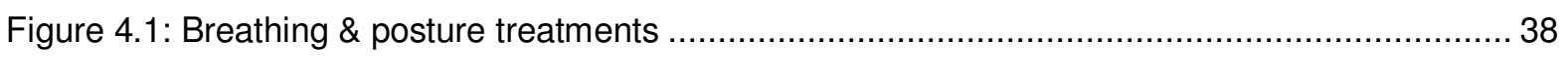

Figure 4.2: Scatter and mean plot of $C_{\text {mouth }}$ Vs. velocity for subjects standing .............................43

Figure 4.3: Scatter and mean plot of $C_{\text {mouth }}$ vs. velocity for subjects sitting ….......................... 43

Figure 4.4: Scatter and mean plot of $C_{\text {mouth }}$ vs. velocity for subjects standing and exhaling through a tube. 44

Figure 4.5: Scatter and mean plot of $C_{\text {mouth }}$ vs. velocity for subjects sitting and exhaling through a tube

Figure 4.6 Mouth average concentration for the four subjects ............................................... 45

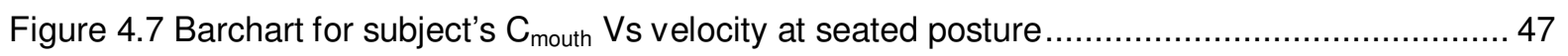

Figure 4.8 Barchart for subject's $C_{\text {mouth }}$ Vs velocity at standing posture .................................... 48

Figure 4.9: Barchart showing breathing treatment effects on each subject's $C_{\text {mouth }}$ Vs velocity at standing posture treatment......

Figure 4.10: Barchart showing breathing treatment effects on subject's $C_{\text {mouth }}$ Vs velocity at sitting posture treatment (Note : A, B, C, and D are human subjects). 49 
Figure 4.11: Scatter and mean plots of $C_{\text {adj.nose }}$ plotted against wind tunnel velocity for same treatment conditions.

Figure 4.12: Scatter and mean plots of $\mathrm{C}_{\text {forehead }}$ plotted against wind tunnel velocity for same treatment conditions per subject

Figure 4.13: Scatter and mean plots of $C_{\text {neck }}$ plotted against wind tunnel velocity for same treatment conditions per subject

Figure 4.14: Scatter and mean plots of $C_{\text {I.collar }}$ plotted against wind tunnel velocity for same treatment conditions per subject

Figure 4.15: Scatter and mean plots of $C_{r . c o l l a r}$ plotted against wind tunnel velocity for same treatment conditions per subject

Figure 4.16: Scatter and mean plots of $C_{\text {chest }}$ plotted against wind tunnel velocity for same treatment conditions per subject

Figure 4.17: Scatter and mean plots of $C_{\text {l.lapel }}$ plotted against wind tunnel velocity for same treatment conditions per subject

Figure 4.18: Scatter and mean plots of $C_{\text {r.lapel }}$ plotted against wind tunnel velocity for same treatment conditions per subject

Figure 4.20 Four subjects' $\mathrm{C}_{\text {location }}$ average versus velocity for standing \& normal breathing treatments 68

Figure 4.21. Four subjects' $\mathrm{C}_{\text {location }}$ average versus velocity for sitting \& normal breathing treatments 68

Figure 4.22 Four subjects' $C_{\text {location }}$ average versus velocity for standing \& tube breathing treatments

Figure 4.23 Four subjects' $\mathrm{C}_{\text {location }}$ average versus velocity for sitting \& tube breathing treatments.... 69

Figure 4.24: Scatter and mean plots of $C_{\text {adj.nose }}$ plotted against wind tunnel velocity for same treatment conditions per subject 
Figure 4.25: Scatter and mean plots of $C_{\text {adj.nose }}$ plotted against wind tunnel velocity for same treatment conditions per subject

Figure 4.26: Scatter and mean plots of $\mathrm{C}_{\text {forehead }}$ plotted against wind tunnel velocity for same treatment conditions per subject 74

Figure 4.27: Scatter and mean plots of $C_{\text {forehead }}$ plotted against wind tunnel velocity for same treatment conditions per subject 75

Figure 4.28: Scatter and mean plots of $C_{\text {neck }}$ plotted against wind tunnel velocity for same treatment conditions per subject 76

Figure 4.29: Scatter and mean plots of $\mathrm{C}_{\text {neck }}$ plotted against wind tunnel velocity for same treatment conditions per subject 77

Figure 4.30: Scatter and mean plots of $C_{\text {r.collar }}$ plotted against wind tunnel velocity for same treatment conditions per subject 78

Figure 4.31: Scatter and mean plots of $C_{r . c o l l a r}$ plotted against wind tunnel velocity for same treatment conditions per subject 79

Figure 4.32: Scatter and mean plots of $\mathrm{C}_{\text {chest }}$ plotted against wind tunnel velocity for same treatment conditions per subject

Figure 4.33: Scatter and mean plots of $C_{\text {chest }}$ plotted against wind tunnel velocity for same treatment conditions per subject 81

Figure 4.34: Scatter and mean plots of $\mathrm{C}_{\text {l.lapel }}$ plotted against wind tunnel velocity for same treatment conditions per subject 82

Figure 4.35: Scatter and mean plots of $\mathrm{C}_{\text {l.lapel }}$ plotted against wind tunnel velocity for same treatment conditions per subject 83

Figure 4.36: Mean plots of all subjects for $\mathrm{C}_{\text {location }}$ ratio to $\mathrm{C}_{\text {mouth }}$ plotted against wind tunnel velocity for standing \& normal breathing treatment conditions 87 
Figure 4.37: Mean plots of all subjects for $C_{\text {location }}$ ratio to $C_{\text {mouth }}$ plotted against wind tunnel velocity for standing \& tube breathing treatment conditions.

Figure 4.38: Mean plots of all subjects for $\mathrm{C}_{\text {location }}$ ratio to $\mathrm{C}_{\text {mouth }}$ plotted against wind tunnel velocity for sitting \& tube breathing treatment conditions

Figure 4.39: Mean plots of all subjects for $C_{\text {location }}$ ratio to $C_{\text {mouth }}$ plotted against wind tunnel velocity for standing \& normal breathing treatment conditions. 88

Figure 4.40: Scatter and mean plots of $C_{\text {location }}$ ratio to $C_{\text {mouth }}$ plotted against wind tunnel velocity for sitting treatment conditions 89

Figure 4.41: Scatter and mean plots of $\mathrm{C}_{\text {location }} / \mathrm{C}_{\text {mouth }}$ plotted against wind tunnel velocity for standing treatment condition 89

Figure 4.42: Mean plots of all subjects for $\mathrm{C}_{\text {location }}$ ratio to $\mathrm{C}_{\text {mouth }}$ plotted against wind tunnel velocity for standing \& normal breathing treatment conditions. 91

Figure 4.43: Mean plots of all subjects for $C_{\text {location }}$ ratio to $C_{\text {mouth }}$ plotted against wind tunnel velocity for standing \& tube breathing treatment conditions. 91

Figure 4.44: Mean plots of all subjects for $\mathrm{C}_{\text {location }}$ ratio to $\mathrm{C}_{\text {mouth }}$ plotted against wind tunnel velocity for sitting \& tube breathing treatment conditions 92

Figure 4.45: Mean plots of all subjects for $C_{\text {location }}$ ratio to $C_{\text {mouth }}$ plotted against wind tunnel velocity for standing \& normal breathing treatment conditions. 92

Figure 4.46: Scatter and mean plots of $C_{\text {location }}$ ratio to $C_{\text {mouth }}$ plotted against wind tunnel velocity for sitting treatment conditions 93

Figure 4.47 : Scatter and mean plots of $C_{\text {location }}$ ratio to $C_{\text {mouth }}$ plotted against wind tunnel velocity for standing treatment condition

Figure 5.1: Wake zones downstream of subject at air flow velocity of $20 \mathrm{fpm}$ (taken from Li, 2005) 106 Figure 5.2: Wake zones downstream of subject at air flow velocity of $50 \mathrm{fpm}$ (taken from Li, 2005. 106 


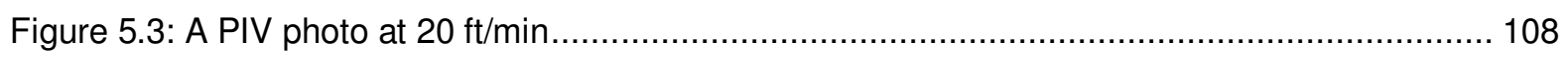

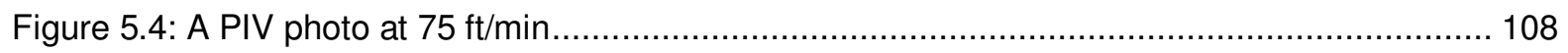

Figure 5.5: Four subjects' $C_{\text {location }}$ average versus velocity for standing \& normal breathing

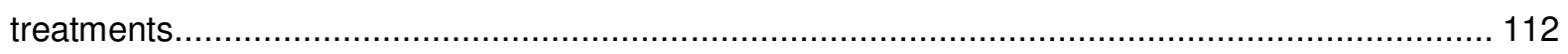

Figure 5.6: Four subjects' $C_{\text {location }}$ average versus velocity for sitting \& normal breathing

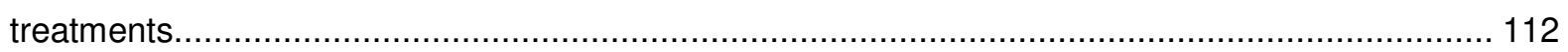

Figure 5.7: Four subjects' $\mathrm{C}_{\text {location }}$ average versus velocity for standing \& tube breathing

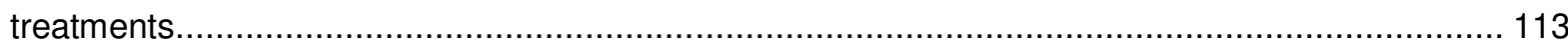

Figure 5.8: Four subjects' $C_{\text {location }}$ average versus velocity for sitting \& tube breathing treatments .. 113 Figure 5 9: Manikin seated locations concentration Vs velocity (taken from El Nahas, 2005)......... 121

Figure 5 10: Human subject seated locations concentration Vs velocity .................................. 121

Figure 5 11: Manikin standing locations concentration Vs velocity (taken from El Nahas, 2005) ..... 122

Figure 5 12: Human subject standing locations concentration Vs velocity ............................... 122

Figure 5.13: Change in rank during seated condition .......................................................... 123

Figure 5.14: Change in rank during standing condition ................................................. 123 


\section{LIST OF TABLES}

Table 3.1: Levels for independent variables and their binary coding.

Table 3.2: Description of surrogate sites

Table 4.1: Test conditions (two replications)

Table 4.2: Average of concentrations (ppm) for all subjects for each treatment condition

Table 4.3: Standard deviation (S) and Coefficient of Variation (CV) for all subjects for each treatment condition

Table 4.4: Descriptive statistics for subject's average $C_{\text {mouth }}$ for each posture across all velocities and breathing conditions

Table 4.5: Descriptive statistics summary computed for $\mathrm{C}_{\text {mouth }}$ for each subject, and both replications for breathing conditions and across all velocities

Table 4.6: Averaged effect of posture for all subjects on $\mathrm{C}_{\text {mouth }}$

Table 4.7: Comparing concentration for both breathing conditions of each velocity and for each posture 50

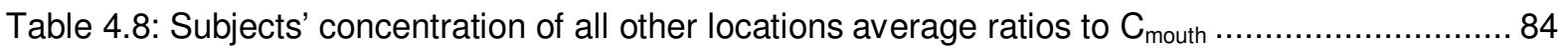

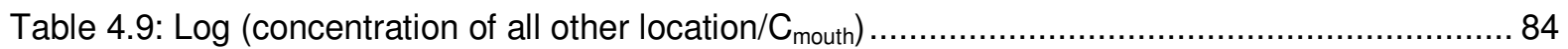

Table 4.10: Statistics summary for ratios of concentration of other location to $C_{\text {mouth }} \ldots \ldots \ldots \ldots \ldots \ldots \ldots . . . . . . . . . . .85$

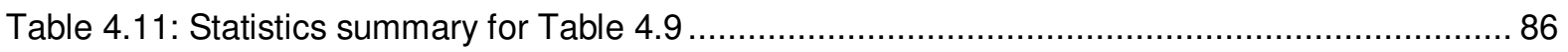

Table 5.1: Randomized factorial design of experiments 98 
Table 5.2: P-values from ANOVA's for concentrations at each location including sitting and standing ..... 101

Table 5.3: P-values from ANOVA's for individual concentrations for normal breathing, only 102

Table 5.4: P-values from ANOVA for individual concentrations in sitting conditions ..................... 103

Table 5.5: P-values from ANOVA's for individual concentrations in standing conditions 103

Table 5.6: Regression coefficients for standing and sitting condition: 105

Table 5.7: Statistics summary for other locations ratios to $C_{\text {mouth }}$ 115

Table 5.8: Mean values of $\mathrm{C}_{\text {location }} / \mathrm{C}_{\text {mouth }}$ averaged over all subjects and velocities for normal breathing

Table 5.9: Statistics summary for sampling locations for each posture condition and across all velocities and for normal breathing conditions:

Table 5.10: P-values from ANOVA for Log $\left(\mathrm{C}_{\text {location }} / \mathrm{C}_{\text {mouth }}\right)$ in sitting and standing Conditions......... 119

Table 5.11: Correction factor (i.e., $\mathrm{C}_{\text {mouth }} / \mathrm{C}_{\text {location }}$ ) for every sampled location 120 


\section{CHAPTER 1: INTRODUCTION}

\subsection{Background, \& Problem Statement}

Industrial hygienists use air sampling as a tool in evaluating worker exposures to airborne contaminants. The air samples are intended to be correlated to the inhaled amounts of the contaminants. Based on the measured concentrations, priorities for controls are set and specific engineering and management strategies are developed. Hence, it is important that each sample faithfully represent the true exposures to the worker. There is basis for concern that sampled values may poorly match inhaled concentrations under some conditions where exposures may be high.

The particular concern here is the practice of placing sampling probe inlets on the chest and collars of sampled workers. As will be discussed, there is insufficient proof that concentrations at those locations faithfully match inhaled concentrations.

Practitioners avoid sampling at the mouth or nose, presumably because it could be uncomfortable for the worker or infeasible for the industrial hygienist. Locations that are more convenient are needed.

The practice of sampling on the chest and collars is based on the concept of the so-called "breathing Zone" (BZ) of the worker, which is a region within which it is assumed that concentrations measured at any location will match inhaled concentrations. Occupational Safety and Health Administration (OSHA), the primary agency responsible for regulation of occupational health and safety of the United States defines this BZ to be: "A hemisphere forward of the shoulders within a radius of approximately 6-9 inches in front of the mouth" (OSHA, 2003) (see (Figure 1.1.) 


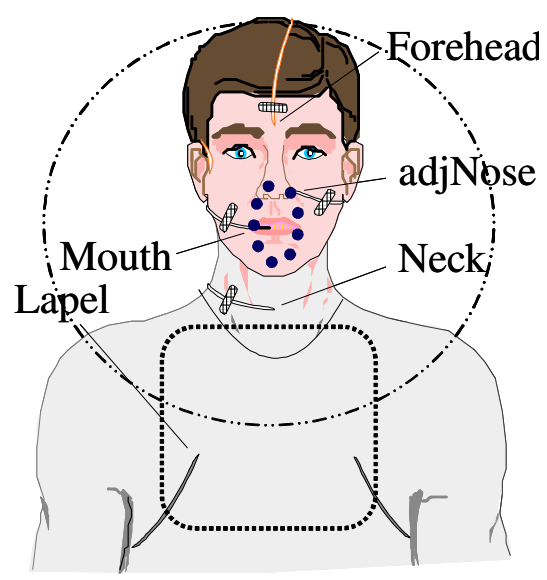

Figure 1.1: Sampling BZ

However, industrial hygienists typically speak of "lapel-sampling", suggesting that sampling is often done on the chest at roughly mid-sternum heights. When sampling with impingers and aerosol sampling, the apparatus is large enough that it is difficult to place the probes as high as 9" below the mouth.

This study investigates the correspondence between potential surrogate sites with concentration at the mouth. The surrogate sampling locations used for the study are all either currently used in practice or could be used. Currently used positions are the left and right collar and the left and right lapels and between the left and right lapels ("centerchest") and between the collars (i.e., the base of neck). Sometimes, sampling inlets are actually well below the collars and lapels, hence the selection of the center chest location. The forehead has been proposed as a sampling location by Cohen et al. (1982). The mouth location in this study is assumed to represent true "inhaled" concentrations. The adjacent nose position would be expected to be nearly the same as the mouth but somewhat more convenient for sampling. Sampler positions in front of the ear and on top of the shoulder were studied and rejected by Guffey et al. (2001) as they found 
concentrations there to be both erratic and substantially $(\sim 70 \%)$ lower than samples collected at the mouth.

Human exposures can be simulated using manikins or with computation fluid dynamics (CFD), but the results of simulations and manikin ultimately should be validated with results from the real life experiments. This study determines the concentrations at the mouth and the surrogate sites for set of treatment conditions. The results allow comparison of surrogate site concentrations to the mouth for a diverse range of conditions. It also allows comparison of human results to manikin results in previous studies (El Nahas, 2005) and to CFD simulations (Li et al., 2005).

In determining whether samples taken at a given location will have concentrations equal to inhaled concentrations, the main idea is to compare concentrations taken on human subjects at that location to samples simultaneously sampled near the mouths of the subjects. As will be discussed, testing human subjects can be inconvenient and costly. Manikins are more convenient subjects than humans are because humans must be treated with elaborate care to avoid harmful exposures and cannot be tested for long periods due to fatigue.

\subsection{Practical Need for the Proposed Research}

The study explores the representativeness of sampling on the face, neck, and chest when the source is near the worker and airflow is from the back. A previous study (El Nahas, 2005) established for a manikin that wind tunnel velocity, posture, and breathing were important. For that reason, this study compares concentrations taken for the same conditions as El Nahas. El Nahas found substantial errors for all surrogate sampling 
locations and very large errors for some conditions for sampling at the lapels and center chest. Since these locations are commonly used in practice, it is crucial to either verify or rebut the manikin findings.

Since manikins are much more convenient to use than human subjects are and are therefore commonly used in exposure assessment studies, it is important to determine if El Nahas' manikin study produced results similar to what would be found with human subjects under the same conditions.

\subsection{PROBLEM STATEMENT}

The impetus for this study was concerns about the use of lapel and chest locations as surrogates for inhaled concentrations. It is possible that sampling results could be strongly biased by using these surrogates, with the bias varying for different conditions. Specifically, this study investigates:

1. The effects of posture, velocity, and breathing on $\mathrm{C}_{\text {mouth }}$.

2. Whether samples taken at alternative sites (forehead, neck, chest, lapel, or adjacent to the nose) adequately represent inhaled exposures (i.e., $\mathrm{C}_{\text {mouth }}$ ).

3. The effects of posture, velocity, and breathing on deviations at other locations from $\mathrm{C}_{\text {mouth. }}$

In addition, the results from the human subjects are compared to those found by El Nahas for similar conditions for an anthropometric, heated, breathing manikin (2005). 


\subsection{Research Objectives}

The study determines the concentrations at the mouth and at surrogate locations under a diverse range of conditions. The research objectives are to:

1 Determine the effects of sitting/standing, breathing/not breathing, and cross draft velocity on concentrations at the mouth $\mathrm{C}_{\text {mouth }}$ and at each surrogate location for each human subject.

2 Determine conditions for which a given surrogate location reliably matches $\mathrm{C}_{\text {mouth}}$.

3 Determine which, if any, surrogate location is generally most reliable.

4 Verify the validity of using an anthropometric manikin subject as a surrogate for human subjects by comparing concentrations at the mouth and each surrogate location.

Given that, the following conditions were fixed for all tests:

- Exposures were tested in a large wind tunnel with controlled, relatively uniform flows

- All tests were collected inside the same wind tunnel.

- Air flowed from the back of the subjects with the tracer gas source located in front of the human subjects' waist level between the subjects' hands.

- Tasks performed by the subjects were the same. 


\section{Chapter 2: LITERATURE REVIEW}

\subsection{Introduction}

Personal sampling has been adopted as the most acceptable way (NIOSH, 1973) and (OSHA, 1985) to evaluate human exposures to airborne contaminants. Personal sampling is an attempt to measure the concentration of contaminants in the air inhaled by workers. Because of the inconvenience of sampling at the mouth, sampling at other locations has been accepted as equivalent to sampling inhaled air. The lack of specificity in selecting the exact location to place the sampling inlet carries the implicit assumption that concentrations vary little within some "breathing zone" region. The boundary of that region has been defined by the National Institute for Occupational Safety and Health (NIOSH) as encompassing varying distances up to one meter (three feet) from the nose and mouth (NIOSH, 1973). The Occupational Safety and Health Administration (OSHA) considered the breathing zone to be a hemisphere forward of the shoulder with a radius of approximately 6-9 inches (CFR, 1985). Sampling at the collar or lapel is a common practice (NIOSH, 1973).

It is a fact that, no published proof in literature confirmed that concentrations at the chest, collars, or lapels are representative of inhaled concentration. As will be discussed, there is evidence in the literature that demonstrates significant differences between concentrations at the mouth and at the chest. What is lacking are studies that: 1) delineate how important factors (e.g., cross-draft velocity and subject posture) affect concentrations at the mouth and the relationship between the concentrations at other 
locations to the mouth, and 2) determines whether there are any locations on the face and upper chest that could be used as surrogates for the mouth with acceptable errors.

\subsection{Human Studies}

Significant concentration differences have been reported when the sampler is placed in different locations within the supposedly uniform "breathing zone" (Malek, 1993; Chatterjee, 1969). Cohen et al. (1982) measured exposure to styrene and found that the concentration measured at the nose for an individual was about $76 \%$ of that measured at the chest.

Cohen et al. (1982) measured workers exposures to styrene vapor in a reinforced

plastic industry. They found that the concentration measured at the nose for an individual was about $76 \%$ of the level measured at the chest. Cohen et al. (1982) showed that there was significant variation of air concentrations within the workers breathing zone. The concentration measured at the nose for an individual was $76 \%$ of that measured at the chest.

In a field study, conducted by Martinelli et al. (1983), aerosol concentrations were measured simultaneously at the nose, lapel, and forehead. They found considerable variability in concentrations at different sampling locations. However, the concentration at the lapel was higher than at the nose and forehead. They speculated that the discrepancies were due to re-suspension of dust from clothing, the job performed, and individual work practice differences. 
Van Der Val et al. (1984) in a field experiment for painters showed that, the right lapel concentrations on a right-handed painter were over $50 \%$ greater than their corresponding left lapel concentrations.

Malek et al. measured concentration variations in a boat manufacturing plant where the average air velocity in the workers breathing zone was $60-80 \mathrm{ft} / \mathrm{min}$. The study concluded that there was no correlation between the left lapel and the right lapel concentrations and strongly suggested that the ideal location to sample was the chest because the chest concentration was higher than that of the nose.

However, Chatterjee et al. (1969) investigated the lead concentrations in a lead acid electric accumulator (battery) factory by attaching two filter heads to the upper chest of the worker, one 5 inches below the other. The mean concentration obtained in the upper position was $22 \%$ less than the lower one.

In a study where beryllium was sampled in a workplace, Donaldson and Stringer (1980) observed that lapel samplers for beryllium gave results that are different from a composite of breathing zone and general area samples.

\subsection{Manikin Studies}

Manikins were often used in studies. However, as will be discussed later, the results of studies using unheated, non-breathing manikins are often questionable utility.

\subsubsection{Manikins: Unheated and Non-breathing}

Kim and Flynn (1991a) found that "chest" concentrations were approximately three times nose concentrations when the source was within the torso wake zone for 
unheated, non-breathing manikin. However, they were not measuring chest concentrations on the mannequin, but rather at seven points on a plane in front of the mannequin. In a smoke visualization study where vortex size was estimated, Kim and Flynn (1991b) found that the wake zone profile downstream of a manikin was not uniform. The wake zone was a much shorter distance downstream at the neck than at the hips. Furthermore, different airflow patterns prevailed in the head region than the chest region. Above the chest, a downwash over the top of the head was dominant, while for the chest to elbow region a combination of downwash and vortex shedding was important. Above the hip level, the net airflow was directed upwards, while below the hip it was directed downwards.

Studies investigated the effects of cross draft velocities on airflow patterns around a worker (Fletcher and Johnson, 1996; Kim and Flynn, 1992; Kulmala et al., 1996; Welling et al., 2001; Heist et al., 2003). They found that recirculation length downstream of the manikin (wake zone) depended on cross draft velocities and can be estimated using the manikin $1 / 2$ dimensions. Therefore, velocity is important and in this research, it was studied at different levels that are currently found in industrial environment.

Kim et al. in a study of airflow patterns around a worker in a uniform free stream showed that the airflow around the worker can be affected by activity level and surface irregularities (e.g. hair, hat, and clothing). Kim et al. in another study showed that the reductions in the breathing zone of $30-50 \%$ were observed with other distributional factors such as the presence of a flat plate downstream of the worker. The worker's motion and the distance between the source and the body significantly affected results. 
Flynn and Ljungqvist (1995) studied wake effects on worker exposure and ventilation design using smoke visualization. They indicated the importance of flow visualization using smoke to detect and correct problems. Moreover, they pointed out that work practices are as important as ventilation design in controlling exposures. When sampling location and the source are in the wake zone, circulation patterns with the wake transports contaminant throughout its volume. If the source is in the hands and air is flowing from the back, then the face, lapel area, and hands were all within the wake zone. For flow from the side or front, none of these locations is in the wake. Thus, one would expect dramatically higher contaminant transport to the face and chest when the flow is from the back, as has been verified in other smoke visualization studies (Kim and Flynn, 1991a; 1991b; Guffey et al., 2001) that used a manikin holding a source in its hands.

Kim et al. (2000) in another study showed that the reductions in the breathing zone of 30-50\% were observed with other distributional factors such as the presence of a flat plate downstream of the worker. The worker's motion and the distance between the source and the body significantly affected results.

Welling et al. (2000) found that arm movement had the same effect as a fan causing variations in velocity and concentration in the breathing zone. The presence of a table and arm movement at the source level increased the concentration slightly.

Welling et al. (2000) studied the dispersion of acetone from a low and moderate low "impulse" source in a uniform air stream flow. Concentrations were measured at nine sampling locations (including nose level) within the breathing zone of a human subject and unheated manikin. The effects of orientation and velocity of airflow, convection due to the human body, arm movement of a human being, and the type of 
source on the concentration gradients were studied. They tested the effects of facing, side, and back orientations to a cross draft of $0.3 \mathrm{~m} / \mathrm{s}(59.1 \mathrm{fpm})$. They found that concentrations were profoundly higher for the back orientation. They also tested the effects of arm movements and body heat for the back to flow orientation at 0.1 (19.7 fpm), $0.3(59.1 \mathrm{fpm})$, and $0.5 \mathrm{~m} / \mathrm{s}(98.4 \mathrm{fpm})$. They found that concentrations at nose were higher for the human subject than the unheated manikin and were higher for arm movement than for stationary human. However, neither of these results was statistically significant.

Limited research had been conducted on the effect of movement (Ljungqvist, 1979; Guffey, 2001, Welling, 2000) on breathing zone concentrations of a manikin or human. It was concluded that movement tended to disperse contaminant more erratically and towards the mouth level. However, other study authors found no effect of movement on breathing zone concentrations.

Limited research has been conducted to determine the effect of posture on sampling location in the breathing zone of manikin. Brohus (1997) found posture is important and had substantial effects on breathing zone concentrations and should be considered as part of the activities performed in work environments.

Rodes et al. suggested the importance of locating the personal monitor as near as practical to the "breathing zone". Based on studies considering the use of a manikin holding a source in its hands (Guffey, et al. 2001; Kim and Flynn, 1992; George et al., 1990; Welling et al., 2001) found dissimilar results when the source located within wake zone than outside the wake zone. 
Guffey et al. (2001) used a manikin to study the effect of manikin orientation (back, side to, and facing), cross draft velocity (10, 22, 47, and 80) and movement of manikin torso on three sampling locations within the breathing zone. The tracer gas used was undiluted $\mathrm{SF}_{6}$ at $0.1 \mathrm{1} / \mathrm{min}$. It was found that concentrations at the chest were 2.9 times the concentrations at the nose, with the ratio decreasing as wind tunnel velocity increased. They concluded that the ear was not a location to sample as there was a high variability in the ear concentrations as compared to the nose. In addition, concentrations at all sample locations were 100-200 times higher for the back-to-flow orientation than for the side and facing flow orientations. Although, the manikin used in their study was anthropometrically scaled, it did not breathe nor was it heated. In addition, the $\mathrm{SF}_{6}$ released was not neutrally buoyant, which could have had substantial effects on the results.

\subsubsection{Manikin versus Human Subjects}

Rodes et al. suggested that a realistic mannequin be used for studies that relate flow and concentration studies. Johnson et al. studied the air movement around the worker in a low speed flow field and suggested that a mannequin selected for sampling studies should be heated, rounded, and breathing, and should resemble a human subject with clothes as much as possible.

Fletcher and Johnson (1988) compared nose and lapel concentrations for a human subject and a manikin in industrial environment. Sampling at the nose, left lapel, and right lapel, they found slight differences between samples at the lapel and the nose for a human subject seated at a table with a neutrally buoyant source on the table. The manikin showed lower breathing zone concentration values than a human subject under 
the same conditions. When a denser than air source was substituted, they found that concentrations varied with sampling location with the concentration at the nose the lowest. Although Fletcher and Johnson used an anthropometric manikin, their manikin did not breathe nor was it heated. In addition, the experimental conditions were not defined clearly.

\section{$\underline{\text { 2.3.3 Heated Manikin }}$}

Only Fletcher and Johnson (1996) and Heist (2003) had manikins heated to simulate humans. They compared heated and non-heated manikins and concluded that heating changed the airflow patterns around the manikin and has substantial effect at low velocity ranges. Therefore, simulating body heat is important when the manikin is used as surrogate to human.

El Nahas (2005) had the most realistic manikin and the most complete study. Ethanol concentrations were measured on an anthropometrically correct, heated, breathing manikin holding a source in its hands at waist height while both sitting and standing in a wind tunnel with its back to the cross draft. Sampling probes were placed at the manikin's mouth, nose, forehead, neck, both collars, center chest and both lapels. Test conditions included five levels of cross-draft velocities $(11.3,27.2,47.5,81.5$ and $103.5 \mathrm{ft} / \mathrm{min}$ ), two levels of body heat (unheated/heated), and two levels of posture (sitting/standing).

Wind tunnel velocity, heating, and posture each had a statistically significant effect for all sampling locations. For the unheated manikin, concentrations for all sampling locations declined monotonically with wind tunnel velocity. However, for the 
heated conditions, concentrations varied with an inverted-V relationship with wind tunnel velocity.

For heated conditions, concentrations at the mouth were always higher for standing than sitting. Concentrations measured at the chest and shoulder levels were higher than mouth concentrations for the standing posture and were lower than mouth concentrations for sitting. Concentrations measured at the forehead location were always lower than concentrations measured at the mouth for both sitting and standing.

Based on the results of this study, center chest, left and right lapels, neck, left and right collars, and forehead locations were unreliable surrogates for actual inhalation exposure. Surprisingly, adjacent to the nose also was not always a reliable surrogate, either. The lapels and collars were generally very poor surrogates for mouth concentrations. The dramatic effects of heating and postures suggest that manikins used to represent humans in exposure studies should always be heated and always tested in both sitting and standing postures.

\subsection{Computational Fluid Dynamics Studies (CFD)}

Simulations using CFD may be of great value because they can investigate conditions that are difficult to produce experimentally. However, it is important to first validate the CFD model against experimentally determined results.

Welling et al. (2001) characterized the reverse flow zone created in front of a human being in a uniform flow using both experimental data and numerical simulation. Experiments were carried out by moving a point source of acetone vapor in front of the 
human subject and measuring the contaminant concentration at nose level in front of the subject. They found that the length of the reverse flow region was 0.9-1.4 $\mathrm{m}(2.95-4.59$ $\mathrm{ft})$ with free stream velocities between 0.1 and $0.5 \mathrm{~m} / \mathrm{s}(19.7-98.4 \mathrm{fpm})$ for a stationary human being. With the person moving its arms, the length of reverse flow fell between 0.5-1.2 $\mathrm{m}(1.64--3.94 \mathrm{ft})$ for the same velocities. In addition, numerical simulations were carried out to predict the length of reverse flow using the k- $\varepsilon$ turbulence model. Compared to experimental data, they found that the extent of the reverse flow region was predicted fairly well using numerical modeling.

Kulmala et al. in a study of the effects of contaminant source location in the near wake region showed that the breathing zone concentration decreases rapidly as the distance of the contaminant source from the body increases.

Li et al.. (2005) found that rounded body shape (closest approximation to human body) resulted in much lower concentration levels than over simplified bodies.

Flynn et al. developed mathematical models to estimate the worker exposure. They concluded that there could be a difference in the exposures between workers as a function of workers size, generation rate, and the air velocity. The workers location with respect to the source of pollutant was thought to be critical.

\subsection{Typical Cross-draft Velocities}

The wind speeds experienced by people in indoor environments are important when investigating personal exposures. For example, Baldwin and Maynard (1998) reported that wind speeds in homes and offices are usually between 0.05 to $0.1 \mathrm{~m} / \mathrm{s}(9.84$ 
-19.7 fpm). However, when industrial work environments were considered, the averaged wind speeds increased to $0.3 \mathrm{~m} / \mathrm{s}(95.1 \mathrm{fpm})$. They also reported that average values of wind speed distributions were approximately $0.05 \mathrm{~m} / \mathrm{s}(9.84 \mathrm{fpm})$ higher than measurements from static anemometers. 


\section{CHAPTER 3: RESEARCH DESIGN, METHODS, APPARATUS AND PROCEDURES}

\subsection{Research Design and Methods}

\subsubsection{Introduction}

This research investigates the effect of breathing, posture, cross draft velocity on human subjects while performing a simple task while standing or sitting in the WVU Exposure Assessment Wind Tunnel. The goal of the study is to determine if surrogate locations fairly represent concentrations at the mouth and how study conditions affect the correlation between them.

\subsubsection{Experimental Design}

The dependent variables are the concentrations measured at each probe location (see Table 3.1). The independent variables for this study were chosen based on results from previous studies with manikins (El Nahas, 2005). The experimental design was a full factorial with each subject tested twice for each condition (Table 3.1). The order of tests for each subject was selected at random, including replicates. Each subject testing required 10 days, which were spread out over 4 months. Hence, the test days for all four subjects were intermixed within the 4-month period. 
Preliminary data were collected on 10 human subjects. However, due to lack of time, no subject completed all study conditions. The results could not be analyzed with confidence but did suggest that wind tunnel velocity (V), posture, and breathing were likely to be important.

Table 3.1: Levels for independent variables and their binary coding

\begin{tabular}{|l|l|l|}
\hline Condition & Levels \\
\hline $\begin{array}{l}\text { Cross Draft Velocity } \\
\text { (fpm) }\end{array}$ & $11.3,27,48,82,105$ \\
\hline Human Subjects & 4 human subjects: A, B, C, D \\
\hline Posture Sitting & Standing $=0$ & Sitting $=1$ \\
\hline Breathing & No breathing $=0$ & Breathing = 1 \\
\hline
\end{tabular}

The following conditions were the same for all tests:

- Exposures tested in a large wind tunnel with relatively controlled uniform flows

- Air flowed from the back of the human subjects with the tracer gas source located in front of the human subjects' waist level.

- Tasks conditionally performed by the subjects were with their both hands moving according to pre-designed setup for both left and right side arm motion controlled on a pace maker ticktometer. 


\subsection{Apparatus}

The apparatus for the study consisted of a wind tunnel and its related apparatus, apparatus used to measure environmental conditions, sampling locations, the sampling system, the tracer gas release system, the tracer gas concentrations measurement system, and the human subjects.

\subsubsection{Wind Tunnel}

The wind tunnel is $50 \mathrm{ft}$ long with a "working section" of $32 \mathrm{ft}$ length. It is $12 \mathrm{ft}$ wide and $9 \mathrm{ft}$ height. The exhaust plenum is $7 \mathrm{ft}$ long. A N.Y. Blower fan (model QASR76R) exhausts air from the plenum at a rate controlled by a variable frequency drive. The wind tunnel upstream and downstream ends are fitted with HEPA filters to improve the uniformity of the airflows and minimize flow turbulence in the working section. Repeated rounds of constant temperature anemometry (CTA) measurements taken at 6" intervals vertically and 12" intervals horizontally found a coefficient of variation of $10 \%$ for velocity along the axis of the wind tunnel. The turbulent intensity ranged up to $15-20 \%$ near the ceiling and was $3-5 \%$ in the middle section where the subject stood. The wind tunnel fan was controlled by a variable frequency drive allowing a range of wind tunnel velocities of 10 to $155 \mathrm{ft} / \mathrm{min}$. Air exhausted back into the room was within $10^{\circ} \mathrm{F}$ of $72^{\circ} \mathrm{F}$ almost every day.

Activated charcoal filter panels are installed just upstream of the downstream HEPA filters. The nearly $300 \mathrm{lbs}$ of activated charcoal ensures the removal of ethanol before the air is exhausted into the room to return the wind tunnel inlet. 
To reduce thermal gradient effects between of the floor and ceiling surfaces, the floor of the building was insulated with a 0.75 " layer of styrene foam sheet, topped with 1" plywood sheet, and then covered with linoleum floor covering.

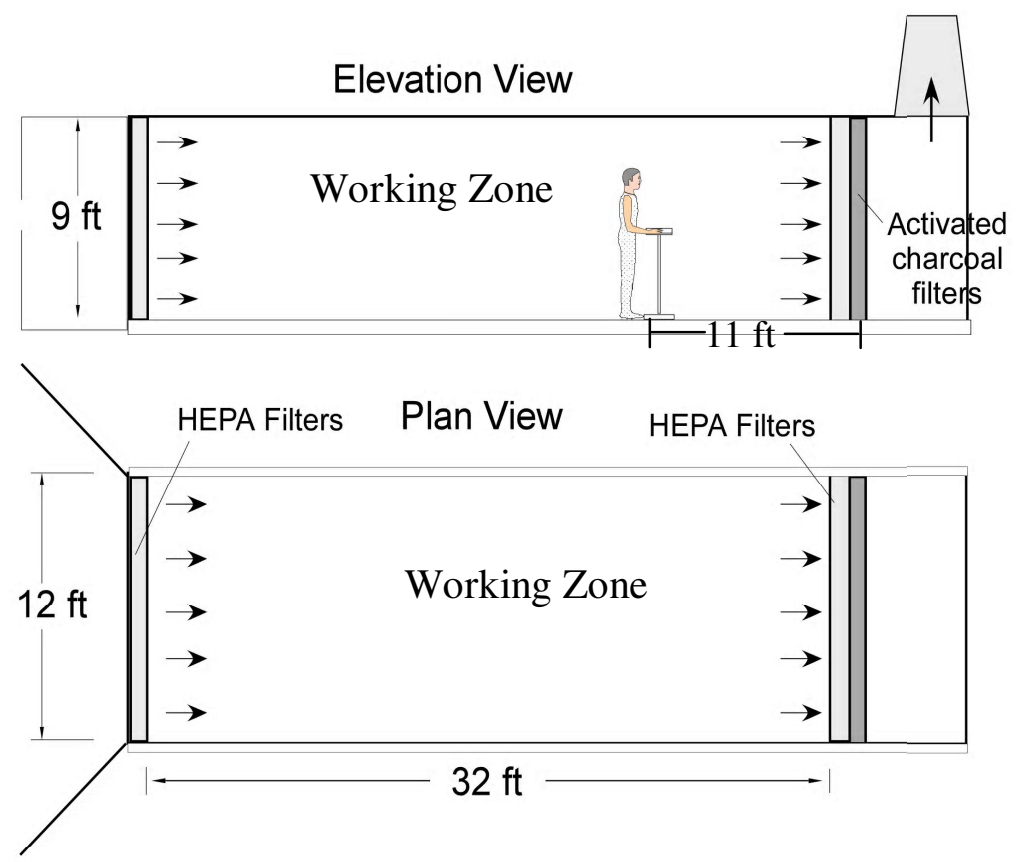

Figure 3.1 Wind tunnel

During test runs, human subjects were standing or sitting at a marked location nearly $4 \mathrm{ft}$ from each wall and 9 to $11 \mathrm{ft}$ from the downstream HEPA filters (Figure 3.1). In the Sitting posture, the subjects sat in a chair at a desk (see Figure 3.2). In the standing posture, subjects stood at a waist height workspace. In both cases, the source for the tracer gas was placed on the work surface in front of the subject during the experiment within a relaxed working distance. The cross-section of the desk, worktable, and subject blocked less than $20 \%$ of the wind tunnel cross-section. 
Variable controlling frequency panel located outside the wind tunnel wall controls the wind tunnel fan driving speed. The velocity of the airflow ranges from 10 to 155 $\mathrm{ft} / \mathrm{min}$.

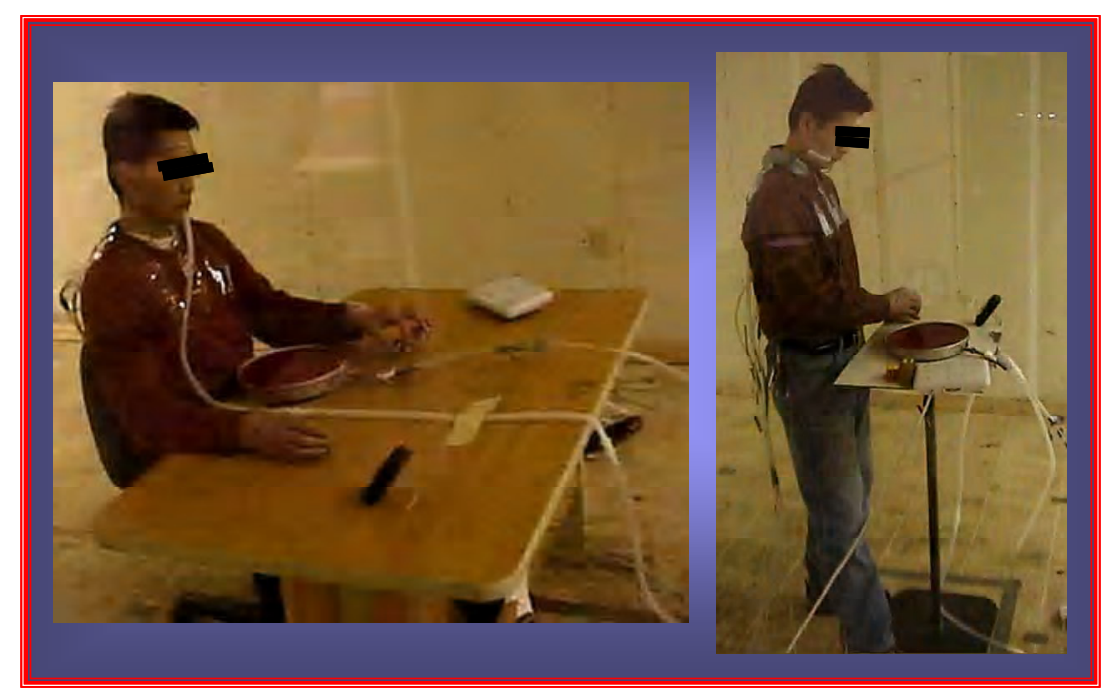

Figure 3.2: Posture for human subject

\subsubsection{Temperature, Humidity and Barometric Measurements}

All surface temperatures in the tunnel where measured pre and post experimental runs by an infrared thermometer (Oakton, model number EW-35629). Temperature differences between these surfaces were within $92.8^{\circ} \mathrm{F}$ on each day of testing. Using the same instrument, the human skin temperatures of the subjects were measured at the forehead location at the beginning of the test runs that day. Temperatures varied from one day to another as well as from on subject to another on same day. Subject's body surface temperatures ranged from $69.8^{\circ} \mathrm{F}$ to $79.3^{\circ} \mathrm{F}, 9.5^{\circ} \mathrm{F}$ range on a given day.

A standard laboratory dry bulb thermometer was used to measure wind tunnel air temperature before and after each experimental run. Temperature differences between 
the wind tunnel walls surfaces and the air flowing through the working section of the wind tunnel were always within $6^{\circ} \mathrm{F}$ during winter and summer.

Humidity inside and outside the wind tunnel were determined using a standard psychrometer. The barometric pressure was measured with a standard laboratory mercury barometer mounted outside the wind tunnel.

\subsubsection{System for Generation and Dispersion of Tracer Gas Mixture}

Ethanol liquid was evaporated in a mixing chamber and used as a tracer (i.e., exposure) gas. Liquid droplets were injected to a mixing chamber from a gas-tight syringe with a tracer gas pump, Cole-Parmer syringe pump, model EW-74900-10, regulating the liquid dispensing rate. The liquid ethanol droplets dripped onto a resistor element inside the mixing chamber. The electric resistor

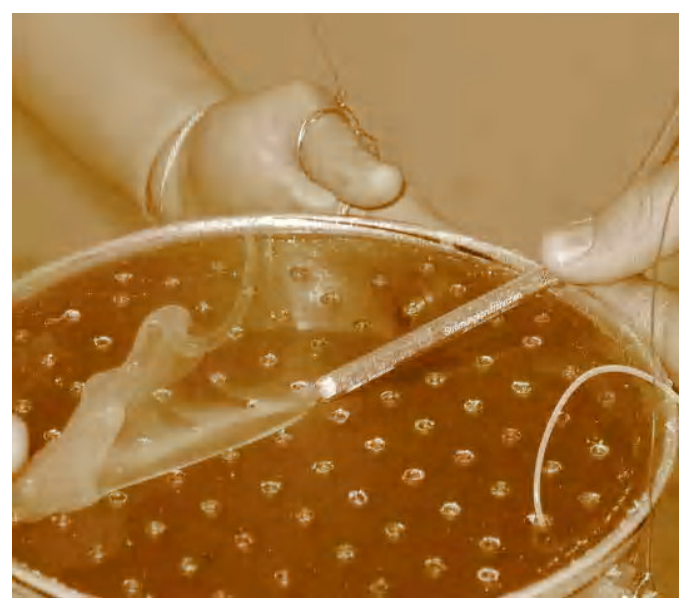

Figure 3.3 Tracer gas source tested by smoke generator was energized by 10 watts of power from regulated DC power source. The resistor was wrapped with a thin silver foil film to improve the evaporation process, which was observed to be nearly instantaneous.

Ultra pure nitrogen flowed from a compressed cylinder that was regulated to flow with a pressure of $0.7 \mathrm{PSI}$ in the nitrogen feeding system for flow rate of $1 \mathrm{lpm}$ as measured by a mass flow meter, Massflow model GFM171 flow range 0-1000 ml/min.

The nitrogen after being mixed with the evaporated ethanol was carried out through a Teflon line of 0.25 diameter that ran into the wind tunnel to a 9" diameter pie- 
pan of 1" deep made of aluminum that served as the contaminant source. The Teflon line was attached to a custom-made connector fitted in the side of this pie-pan and was forced to pass through a custom-made acrylic cover that was tightly glued to the top of the piepan and drilled with 99 1/8" diameter hole. The drilled holes were spread uniformly across the cover. The exit velocity through the $1 / 8$ " hole was less than $1 \mathrm{ft} / \mathrm{min}$. A smoke source was used to check visually on the holes velocity pattern and whether it could affect the flows in the wake zone in front of the subject or not. It was noticed that the smoke generated by a smoke generator was not affected by the flow coming out of the holes i.e. the source flow is of a very small exiting velocity that will not affect the dispersion pattern of ethanol on the wind tunnel (Figure 3.3 ).

The ethanol tracer gas was always set to a rate of $0.071 \mathrm{lpm}$ when mixed with 1 lpm of $\mathrm{N}_{2}$; this produced a source concentration of 30,000 ppm. If $\mathrm{N}_{2}$ was replaced with air, that concentration would be equal to $80 \%$ of the lower explosive limit (LEL) for ethanol.

\subsubsection{Sampling Locations}

Ten sampling locations on the face, neck, and torso were selected for simultaneous sampling (see Figure 3.4 and Table 3.2). 


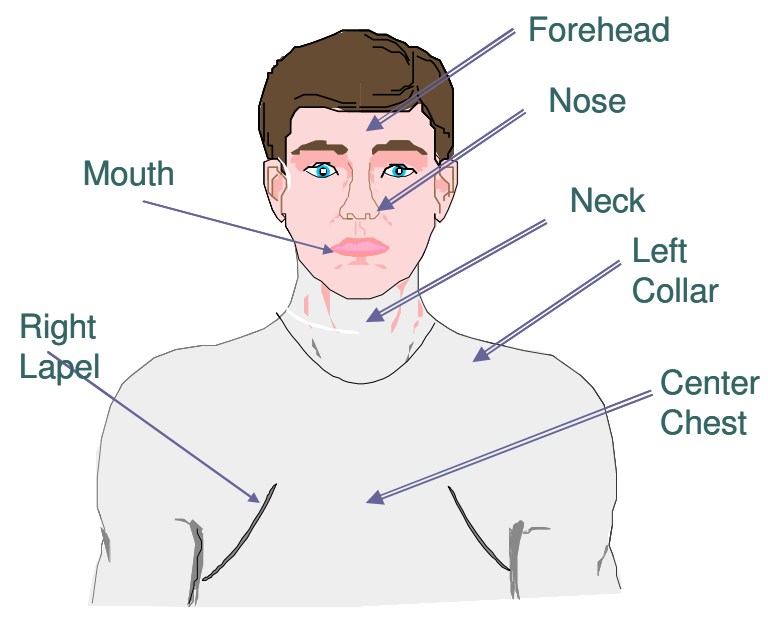

Figure 3.4: Sampling locations

The mouth location was assumed to represent the true inhaled concentration for the subjects. Two probes were set at the corner of the mouth location within $1 \mathrm{~mm}$ to provide duplicate sampling, allowing estimation of precision for sampling/analysis.

Table 3.2: Description of surrogate sites

\begin{tabular}{|l|l|c|}
\hline Label & \multicolumn{1}{|c|}{ Anatomical Name Location } & $\begin{array}{c}\text { Currently used by } \\
\text { Industrial Hygienists }\end{array}$ \\
\hline Forehead & On the orbital midline 0.79" above the brow ridge & No \\
\hline Nose & $0.2^{\text {" ' laterally from nasal orifice }}$ & No \\
\hline Mouth & At the mouth 1.18" from the right of the lip & No \\
\hline Neck & Sternoclavicular region & Often \\
\hline Right Collar & Right mid-clavicle & Often \\
\hline Left Collar & Left mid-clavicle & Often \\
\hline Right lapel & $4^{\text {th }}$ intercostal space on the right mid-clavicular line & Often \\
\hline Center Chest & Mid point of left and right lapel & Often \\
\hline Left lapel & $4^{\text {th }}$ intercostal space on the left mid-clavicular line & \\
\hline
\end{tabular}

\subsubsection{Gas and Vapor Sampling System}

The $1 / 8$ " internal diameter polypropylene sampling probes were taped to the designated sampling locations on the human body using duct tape. For facial locations, a hypo-allergic adhering tape was used to avoid skin allergic reactions. Every probe was 
connected to a 1/16" diameter $4 \mathrm{ft}$ long Teflon tube which ran over the shoulders to the back of the subject. Each Teflon tube was connected to a 1/4" Tygon tube with an approximate length of $11 \mathrm{ft}$ that terminated outside the wind tunnel at a SKC (low-flow) sampling pump.

From the pump, the air was pushed out through the sampling pump outlet joint to a 3 L Teflon sampling bag (Jensen- Teflon 3L capacity). Each pump was calibrated to a flow rate of $0.15 \mathrm{Lpm}$ using a digital calibrating Dry Cal (DCL5K). All pumps were hooked directly to electric outlets to ensure continuation of sampling in case the charged batteries failed to operate the pumps.

Periodically, leak and adsorption tests in sampling lines were conducted. If a leak was discovered, the line was re-connected and tested again. Similarly, bags were placed underwater to look for leaks.

Losses of ethanol vapor to the plastic tubing and bags were reduced to about $5 \%$ by using Teflon lines and bags and by following the pre-treating procedures described later.

\subsubsection{Gas and Vapor Analysis}

All sampled ethanol air mixtures collected in the Teflon bags were analyzed using a Photovac Voyager gas chromatograph (GC) equipped with a photo-ionized detector (PID). Calibration for the GC was done before, during, and after analyses every sampling day.

The calibration regression lines showed an R-sq of $97 \%$ or higher. 


\subsection{Procedures}

Procedures for the study are listed below.

\subsubsection{Procedures for Operating the Tracer Gas Release System}

This system consistent of several components that needed to be prepared for and setup prior to operation to generate the aimed concentration of the tracer gas used (ethanol)

\subsubsection{Procedures for ethanol liquid preparation for usage in tracer gas pump:}

1. Ethanol dark glass (4 L) container is opened in a laboratory hood.

2. A graduated scaled $(15 \mathrm{ml})$ pipit was used to pump ethanol out of the glass container and then used to fill out completely the tracer gas pump syringe $(10 \mathrm{ml})$

3. For every new run, the syringe remaining amount of ethanol was disposed safely and a fresh new ethanol liquid from the container is used. No old used ethanol's remaining from any run was ever used for sampling the next run.

4. After each time being used the ethanol container was always tide fitted, sealed than placed for storage in the dark ventilated compartment of the lab hood.

\subsubsection{Procedures for setting and controlling the nitrogen gas release system}

1. Compressed ultra pure nitrogen cylinder regulated by a 2-stage regulator was turned on. 
2. Nitrogen was controlled by the regulator is set to flow with a pressure of 0.7 PSI into the feeding pipe Teflon line.

3. Just after the regulator the flow rate was measured by a mass flow meter plugged on the nitrogen pressurized feeding line.

4. The Nitrogen supplying line flow was controlled by a calibrated rotameter that was fitted to the feeding line after the mass flow meter. The rotameter knob was adjusted until the mass flow meter read a nitrogen flow rate of 1 $1 \mathrm{pm}$.

\subsubsection{Procedures for setting electric heating element (evaporation device) system}

1. The aluminum foil wrapped resistor was usually started before any sampling session by at least 30 minutes for stabilization purposes

2. Its electric DC power supply was permanently set and checked at the beginning of the runs to be 6 Volts and 1.5 Amperes

\subsubsection{Procedures for setting tracer gas pump system}

1. Ethanol Tracer gas pump rate was set on $0.071 \mathrm{ml} / \mathrm{min}$; and set to operate after the nitrogen gas being released in the system for at least 5 minutes to avoid any explosion risk.

2. Ethanol syringe containing the ethanol liquid was fitted into its position and the system was secured for operation. The ethanol dropping line fitter 
was mated with the ethanol inlet of the mixing chamber and both were secured.

3. Dripping Teflon line is usually check for any entrained air bubble to be removed to ensure proper mixed amount of ethanol with the nitrogen.

4. At the beginning of each session, to ensure evaporation rate steadiness, the count of ethanol drops actually dripped on the foil paper were checked in a set time interval. The dripping rate was uniform and was checked periodically for consistency.

\subsubsection{Sampling procedures for checking the concentration levels of tracer gas generated}

1. Samples from the source pie-pan were collected by a special Hamilton (100 ml) sampling syringe.

2. The syringe was connected to a long Teflon tube adapter that is run into the inlet opening of the source pie-pan. The tube ions allowed running in the source tube for a length of almost $2 \mathrm{ft}$.

3. While ethanol tracer gas system is operating normally the syringe plunger is pulled out sampling with a constant withdrawing rate till it is filled up with around $50 \mathrm{ml}$

4. Collected samples was injected with a known volume to a clean purged bag and than using a calibrating pump a known volume of clean air is added to this bag. 
5. The bag is then tapped for mixing its content uniformly for few minutes than it is deflated ( for treatment procedure)

6. Again, same steps are repeated with same procedure with same volume used and the bag is then analyzed by the GC.

7. Later the concentration can be detected and the original concentration can be calculated reversely the expected level of concentration was usually ranging from $50-60 \mathrm{ppm}$.

\subsubsection{Procedures for Sampling System}

\subsubsection{Procedures for sampling lines preparation for sampling}

At each run, the following procedures were followed to prepare the sampling lines for sampling:

1. Teflon sampling lines were checked for being fitted tidily to the correct labeled sampling pumps outside the wind tunnel from one side and fitted to the desired sampling probe to sample at the a specific sampling location on the human subject body.

2. Sampling lines are purged with the existing wind tunnel air prior to sampling for about 5 minutes. This air is dumped without being collected until stabilization for the system is reached.

3. To account for the adsorption of ethanol on the sampling lines internal walls, the sampling lines are treatment with the wind tunnel pulled air for a period of 7 minutes 
4. then sampling could start for 15 minutes

\subsection{Leak detection procedure for sampling line}

Leaks in the sampling lines were measured by following the set procedures:

1. Attaching bags filled with known concentrations of ethanol gases to a sampling probe

2. Hook up the sampling pump on the down stream of the sampling line and allow it to sample for 7 minutes dumping this 7 minutes sample to an empty bag

3. Keep pump sampling while you purge the sampling bag

4. Then hook the sampling bag again and sample for 15 minutes. This was done without flushing with clean air

5. Finally the sampling bag and the bag containing the known mixture sampled from are both analyzed and their concentrations where compared together if the collected concentration level was less than the prepared concentration level by $90 \%$ the line is marked for being leaking and needs to be checked for leaks.

\subsubsection{Procedures for sampling lines preparation for sampling}

All Teflon sampling bags were prepared for sampling prior to each running condition.

1. Bags were filled up and deflated completely three times using clean air supplied by the pressurized laboratory airlines (previously checked and 
analyzed for its chemical mixture and interference with ethanol analysis and proved to be free of ethanol traces).

2. The 3-liter capacity bag was filled up to $90 \%$ of its capacity (visually judged) then it was left for a minute to settle then air was vacuumed out by the laboratory vacuum line.

3. Labels identifying sampling wind tunnel velocity, run code condition, sampling location collected from and date and time of the run were adhered randomly to each bag.

4. A set of 10 bags after being labeled were set together in an open labeled container waiting to be used for its specified run condition marked on the container and were subjected to outside working environment of the wind tunnel to acquire the same environmental physical conditions.

5. At the run the needed marked container containing the bags dedicated for this run were picked up. Its bags were hooked up to the exhaust port of the sampling pumps. Bag labels and pump labels were checked to be matching with same-labeled sampling location.

6. The 10 locations were sampled simultaneously for a total of 27 minutes for each condition.

7. Before sampling for a set condition the lines were left running without hooking the bags for 5 minute to allow for the stabilization of all environmental conditions in wind tunnel and in sampling system. 
8. Then sampling bags were hooked up for a treatment session of 7 minutes duration. Bags were purged with the same concentrations as that of the set exposure.

9. Then bags were hooked up again to the pumps in the treatment session and they were regularly sampled for 15 minutes.

10. Bags were then collected after their valves were firmly locked and were set to be analyzed within 2 hours. The concentration of ethanol and air mixture in each bag was analyzed using Voyager gas chromatograph with PID.

\subsection{Leak detection procedure for sampling bags}

1. Bags were set to be tested for leaks every 12 runs ( 3 sessions)

2. The bag is to be filled up with air till its $90 \%$ of its capacity

3. The bag valve is tightly locked

4. A large deep transparent plastic container is filled up with water

5. The bag is dipped completely and slowly in the water and its surface is visually checked for any air bubbles to be rolling or generated from its surface

6. Bag valve is also checked for leaks by pressing on it in different direction to check if there is any leaks that can happen when applying a pressure or moving the valve 
7. Any bag when checked and proved to be leaking is discarded and replaced with a new one.

\subsubsection{Low flow pumps set procedures for operation:}

1. Low flow sampling pumps were calibrated before being used for sampling.

2. Calibrated low flow pumps were labeled with the same name of sampling line that was hooked up from its inlet probe for sampling.

3. They were set to a sampling rate of $0.15 \mathrm{ml} / \mathrm{min}$ and actual calibration rate was marked on each pump label.

4. Pumps were operated before sampling by at least 20 minutes to purge the sampling lines and the pumps completely from any traces of old ethanol.

5. Later when sampling procedures started, sampling bags were labeled with the same sampling location and hooked up to the exhaust of the pump for sampling.

6. Pumps were continuously left running from the start of the running sessions until the end of the last run of the sampling session.

\subsection{Leak detection procedure for sampling pumps}

Pumps were tested for leaks following their operating manual procedures

(Appendix A) and any pump proved to fail the testing standards it was discarded and sent for the manufacturer for maintenance. 


\subsubsection{Adjustment of Fan Speed}

1. The wind tunnel cross draft velocity was set according to the desired run speed levels.

2. Before run sampling, from the control panel fan was set to the desired run speed by adjusting the fan predetermined equivalent RPM value.

3. Prior to each run the wind tunnel speed was left to run idling for 5 minutes for stabilization of the airflow inside the wind tunnel and dampness of any temporarily turbulence effects.

\subsubsection{Procedures for Analyzing Ethanol Sampling Bags}

1. A prepared recoding $\log$ sheet was printed with the date and time, run number, and coded condition were all printed clearly on it

2. A clean Teflon bag ready for sampling was open and filled up with clean air. Then the collected air sample was hooked up to the GC inlet sampling port for analysis.

3. The $\mathrm{GC}$ results for the peak height $(\mathrm{mV})$, integrated peak area (mVS), and retention time (sec) were recorded in the log-recording sheet. Any comments or errors were also recorded in the sheet.

4. Randomly a sampled bag was picked up from the other remaining sampling bags and hooked up to the GC inlet sampling port. 
5. Before sampling analysis starts, all information on the bag label is recorded in a recoding the log recording sheet. Special observations, if any, were noted in the results.

6. The next bag was selected at random until all bags were analyzed.

\subsubsection{Procedures for GC Calibration}

1. The GC was calibrated each day it was to be used after analyzing samples.

2. Records of the minimum and the maximum result values of the GC intergraded area (mVS) on the day of the experiment. These records were compared to a known ppm.

3. "Known ppm" range was noted for the maximum and minimum values.

4. Fresh ethanol liquid $(15 \mathrm{ml})$ was used and pipetted from the storing container to a gas tide glass vial adapted with a rubber septum (130 $\mathrm{ml})$

5. Before calibration by 15 minutes the ethanol vial is placed in a container filled to $1 / 2$ the vial height with water.

7. The water temperature was recorded after 15 minutes from the instant the ethanol vial is placed in it. The temperature was measured with a calibrated mercury thermometer. 
8. Temperature was used to compute the desired headspace volume needed to achieve a desired calibration concentration.

9. The concentration range in step 3 was then divided into 2 or more values.

10. 2.4 liters of clean, ambient air was injected in a Teflon sampling bag after opening its valve, by using a manual air calibration syringe.

11. The volumes of the ethanol vapor "head space" associated to the desired concentration values set in step 8 are calculated. These volumes were derived from an Excel sheet that was set for this purpose. The input of temperature in step 6 and the volume of the air to be prepared in the sampling calibrating bags were set to be 2.4 L by default are the main important input to the spread sheet

12. The exact amount of ethanol vapor (saturated headspace) was drawn from the septa of the glass vial. The vapor in the syringe was injected into the Teflon sampling calibrating bags each with its desired volume. The bags' valves were then locked.

13. The Teflon sampling bags were then gently tapped for few minutes to ensure good mixing and the uniformity of the concentration all over the bag content.

14. The bags were then kept in the exhaust hood for 5 minutes.

15. Bags were then opened and connected to the GC to be analyzed. 
16. A peak voltage $(\mathrm{mV})$ and the integrated area were recorded for each calibration-sampling bag analyzed.

17. A graph was then plotted between the known concentration (ppm) of the bag and the its corresponding obtained record of integrated peak area (mVS) on a MS Excel spreadsheet and a calibration curve was generated.

18. Later the linear regression equation was generated for the curve and was used to compute sampling bag concentrations (ppm) for that day. 


\section{CHAPTER 4: RESULTS OF STUDY}

For every test in this study,

the subject used his hands to move children's play blocks from one side of a source to the other and back again.

The source was on a table or a stand (see Figure 4.1) and the subject was: 1) either sitting or standing, and, 2)
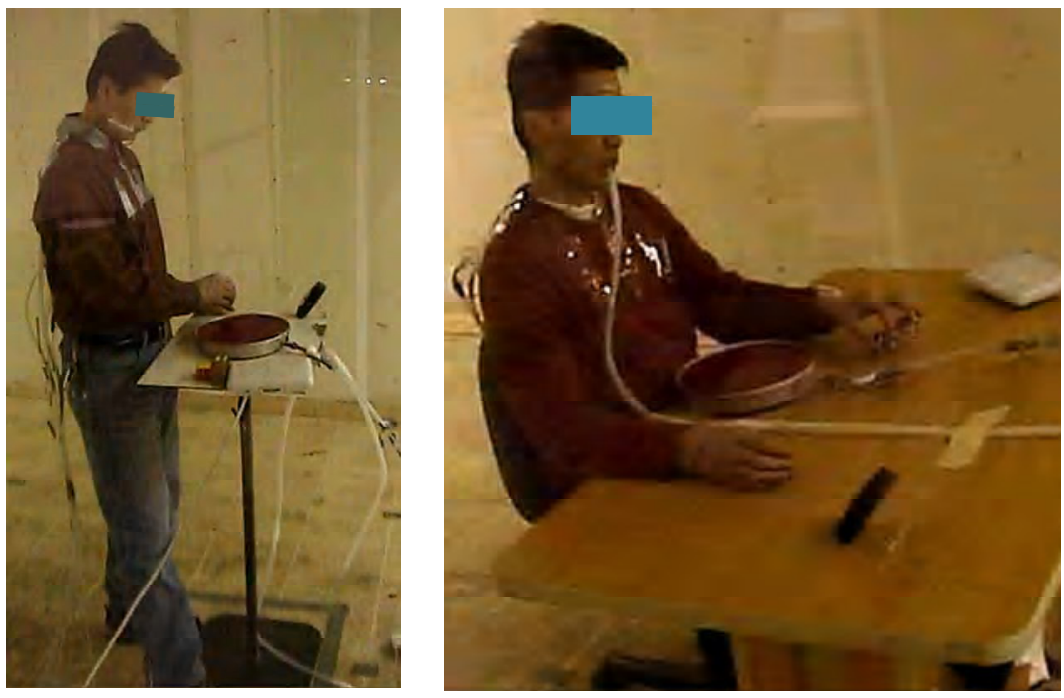

Figure 4.1: Breathing \& posture treatments

either exhaling through a tube in his mouth or not.

This study was a factorial design with each condition tested twice in random order (see

Table 4.1). All experiments were conducted on a group of four human subjects

Table 4.1: Test conditions (two replications)

\begin{tabular}{|l|l|}
\hline CONDITION & LEVELS \\
\hline Cross Draft velocity (fpm) & $11.3,27.2,47.5,81.5,103.5 \mathrm{ft} / \mathrm{min}$ \\
\hline Subjects & 4 Subjects (A,B,C \& D) \\
\hline Tube Breathing & Exhaling normally, Exhaling through tube \\
\hline Posture & Standing, Sitting \\
\hline
\end{tabular}


The four broad goals of this study were to use statistical analyses of the experimental results to:

1. Determine the importance of environmental (i.e., cross-draft velocity) and subject factors (i.e., breathing and posture) to concentrations at the mouth $\left(\mathrm{C}_{\text {mouth }}\right)$,

2. Determine the importance of the same factors to the concentrations at each of the other sampling locations,

3. Determine which sampling locations have concentrations most consistent with measurements taken at the mouth $\left(\mathrm{C}_{\text {mouth }}\right)$ for all of the combinations of subject postures and cross-draft velocities,

4. Determine the degree that each of the factors affects the ratio of the concentrations at each location to the mouth.

5. Compare the results from the human subjects to the results found by El Nahas (2005) for similar conditions for an anthropometric, heated, breathing manikin. 
Table 4.2: Average of concentrations (ppm) for all subjects for each treatment condition

\begin{tabular}{|c|c|c|c|c|c|c|c|c|c|c|c|}
\hline \multicolumn{3}{|c|}{ Treatment Condition } & \multicolumn{9}{|c|}{ Location Mean Concentration (ppm) } \\
\hline 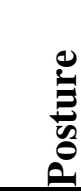 & صِّ. & V fpm & $\underbrace{\bar{u}}$ & E & نَّ & نَّ & 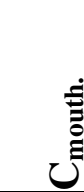 & نั. & త্ & ن⿳亠二口犬 & U⿺辶ّ \\
\hline \multirow{10}{*}{ 量 } & \multirow{5}{*}{$\stackrel{\Xi}{\Xi}$} & 11.3 & 24.7 & 17.6 & 15.3 & 18 & 16.1 & 15.5 & 14.3 & 10.2 & 13.4 \\
\hline & & 27.2 & 28.2 & 20.8 & 18.2 & 19.1 & 16.8 & 16.6 & 15.2 & 10.6 & 12.8 \\
\hline & & 47.5 & 50.3 & 42.8 & 40.7 & 37.5 & 38 & 34.5 & 29.9 & 31 & 31.7 \\
\hline & & 81.5 & 55.6 & 39.5 & 36.7 & 36.6 & 32.8 & 31.1 & 33.5 & 30.7 & 25.2 \\
\hline & & 103.5 & 55.9 & 43.9 & 43.2 & 41.5 & 34.1 & 30 & 32.6 & 35.2 & 24.2 \\
\hline & \multirow{5}{*}{ 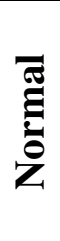 } & 11.3 & 13.8 & 12.9 & 12.1 & 11.7 & 12.7 & 12.5 & 10.7 & 10.2 & 11.9 \\
\hline & & 27.2 & 24.6 & 18.5 & 17.1 & 18.1 & 15.5 & 15.6 & 15.4 & 11.3 & 14 \\
\hline & & 47.5 & 34.6 & 31.4 & 28.7 & 29 & 28.6 & 26.6 & 24.1 & 19.9 & 24.8 \\
\hline & & 81.5 & 27.3 & 22.8 & 23.2 & 23.4 & 23.2 & 21 & 24.6 & 18.9 & 18.4 \\
\hline & & 103.5 & 31.8 & 28.2 & 27.4 & 26.9 & 23.5 & 20.1 & 25 & 24.5 & 16.7 \\
\hline \multirow{10}{*}{ : } & \multirow{5}{*}{$\frac{\Xi}{\Xi}$} & 11.3 & 17 & 12.6 & 10.8 & 11.5 & 10.8 & 9.9 & 15 & 12.3 & 8.8 \\
\hline & & 27.2 & 21.3 & 15.6 & 14.4 & 13.9 & 13.2 & 12.1 & 18.7 & 20.6 & 10.7 \\
\hline & & 47.5 & 35 & 24.6 & 22.7 & 22.3 & 19.6 & 19.4 & 30.1 & 30.5 & 17.3 \\
\hline & & 81.5 & 15.4 & 11.9 & 11.2 & 11.1 & 9.2 & 8.1 & 14.9 & 16.5 & 6.9 \\
\hline & & 103.5 & 14.3 & 10.3 & 10.1 & 10.1 & 8.6 & 7.8 & 13.9 & 14.7 & 6.6 \\
\hline & \multirow{5}{*}{ 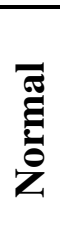 } & 11.3 & 13.5 & 11 & 9.1 & 9.6 & 8.8 & 8.3 & 12.7 & 11.7 & 7.8 \\
\hline & & 27.2 & 17.8 & 12.7 & 11.2 & 11.7 & 10.6 & 10.1 & 16.7 & 14.8 & 9.3 \\
\hline & & 47.5 & 29.9 & 24.7 & 21.6 & 22.5 & 19.8 & 17.8 & 29.3 & 27.7 & 15 \\
\hline & & 81.5 & 18.5 & 12.7 & 11.8 & 12.1 & 9.8 & 8.9 & 16.6 & 17.6 & 7.6 \\
\hline & & 103.5 & 13 & 12.8 & 13.5 & 9.2 & 8.8 & 9.4 & 7.7 & 6.4 & 5.9 \\
\hline
\end{tabular}


Table 4.3: Standard deviation (S) and Coefficient of Variation (CV) for all subjects for each treatment condition

\begin{tabular}{|c|c|c|c|c|c|c|c|c|c|c|c|}
\hline \multicolumn{3}{|c|}{$\begin{array}{c}\text { TREATMENT } \\
\text { CONDITION LEVELS }\end{array}$} & \multicolumn{9}{|c|}{ Location $\mathrm{S}$ and $\mathrm{CV}$} \\
\hline 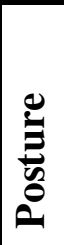 & 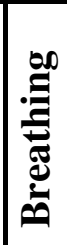 & V fpm & 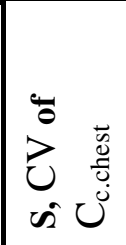 & 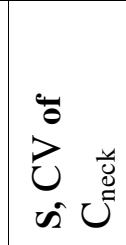 & 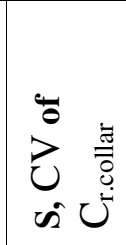 & 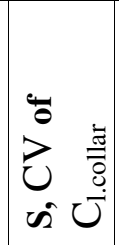 & 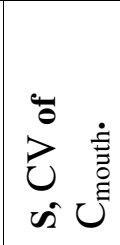 & 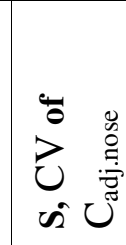 & 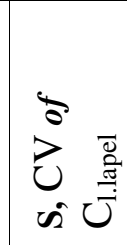 & 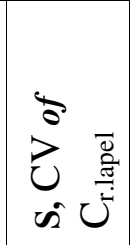 & 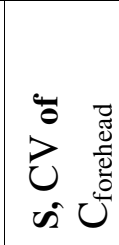 \\
\hline \multirow{10}{*}{ 禹 } & \multirow{5}{*}{$\frac{0}{\Xi}$} & 11.3 & $18.5,0.8$ & $15.6,0.9$ & $12.4,0.8$ & $0.5,0.5$ & $11.1,0.7$ & $9.8,0.6$ & $\overline{11.8,0.8}$ & $7.7,0.8$ & $8.1,0.6$ \\
\hline & & 27.2 & $23.6,0.8$ & $13.2,0.6$ & $12,0.7$ & $0.3,0.2$ & $8.7,0.5$ & $8.5,0.5$ & $13.9,0.9$ & $10.5,1$ & $6.4,0.5$ \\
\hline & & 47.5 & $35.8,0.7$ & $19.4,0.5$ & $19.2,0.5$ & $0.3,0.3$ & $15.1,0.4$ & $12.6,0.4$ & $25.4,0.9$ & $22.5,0.7$ & $10.9,0.3$ \\
\hline & & 81.5 & $37.3,0.7$ & $15.8,0.4$ & $14.1,0.4$ & $0.2,0.2$ & $10.5,0.3$ & $10.1,0.3$ & $19.3,0.6$ & $17.8,0.6$ & $7.3,0.3$ \\
\hline & & 103.5 & $40.2,0.7$ & $25.7,0.6$ & $22.7,0.5$ & $0.3,0.3$ & $10.7,0.3$ & $9.1,0.3$ & $23.4,0.7$ & $24.8,0.7$ & $6.1,0.3$ \\
\hline & \multirow{5}{*}{ 苞 } & $\mathbf{1 1 . 3}$ & $7.3,0.5$ & $6.2,0.5$ & $5.9,0.5$ & $0.2,0.3$ & $5.6,0.4$ & $5.6,0.4$ & $4.4,0.4$ & $6.2,0.6$ & $4.4,0.4$ \\
\hline & & 27.2 & $27.1,1.1$ & $13.1,0.7$ & $10.3,0.6$ & $0.3,0.3$ & $7.8,0.5$ & $7.2,0.5$ & $15.2,1$ & $6.8,0.6$ & $4.7,0.3$ \\
\hline & & 47.5 & $25.3,0.7$ & $19.8,0.6$ & $17.1,0.6$ & $0.3,0.3$ & $15,0.5$ & $13.7,0.5$ & $20.2,0.8$ & $313.1,0.7$ & $11.7,0.5$ \\
\hline & & 81.5 & $14.9,0.6$ & $11.6,0.5$ & $8.9,0.4$ & $0.3,0.3$ & $6.2,0.3$ & $4.2,0.2$ & $15.7,0.6$ & $511.1,0.6$ & $2.2,0.1$ \\
\hline & & 103.5 & $13.4,0.4$ & $12.2,0.4$ & $12,0.4$ & $0.1,0.1$ & $8,0.3$ & $5.5,0.3$ & $9.9,0.4$ & $8.7,0.4$ & $4.4,0.3$ \\
\hline \multirow{10}{*}{ 泀 } & \multirow{5}{*}{$\frac{0}{Z}$} & 11.3 & $7.8,0.5$ & $4.7,0.4$ & $5.2,0.5$ & $0.1,0.1$ & $5.2,0.5$ & $4.7,0.5$ & $6.7,0.5$ & $6.8,0.6$ & $4.3,0.5$ \\
\hline & & 27.2 & $4.8,0.2$ & $4,0.3$ & $4.7,0.3$ & $0.1,0.1$ & $4,0.3$ & $3.5,0.3$ & $4.3,0.2$ & $4.3,0.2$ & $3.5,0.3$ \\
\hline & & 47.5 & $11.6,0.3$ & $6.8,0.3$ & $6.2,0.3$ & $0.1,0.1$ & $6.1,0.3$ & $6.4,0.3$ & $10,0.3$ & $7.8,0.3$ & $5.4,0.3$ \\
\hline & & 81.5 & $4.2,0.3$ & $2.2,0.2$ & $2.7,0.2$ & $0.1,0.1$ & $2,0.2$ & $1.5,0.2$ & $3.6,0.2$ & $4.7,0.3$ & $1.3,0.2$ \\
\hline & & 103.5 & $3,0.2$ & $2.5,0.3$ & $3,0.3$ & $0.2,0.1$ & $2.7,0.3$ & $2.7,0.4$ & $3.2,0.2$ & $1.9,0.1$ & $2.8,0.4$ \\
\hline & \multirow{5}{*}{ 苞 } & 11.3 & $3.7,0.3$ & $4.7,0.4$ & $3.4,0.4$ & $0.1,0.1$ & $3.7,0.4$ & $3.6,0.4$ & $4,0.3$ & $3.5,0.3$ & $3.5,0.4$ \\
\hline & & 27.2 & $5.9,0.3$ & $3.8,0.3$ & $3,0.3$ & $0.1,0.1$ & $3.2,0.3$ & $3.1,0.3$ & $7.7,0.5$ & $3.7,0.3$ & $2.5,0.3$ \\
\hline & & 47.5 & $9.2,0.3$ & $7.9,0.3$ & $5.6,0.3$ & $0.3,0.2$ & $7.5,0.4$ & $6.5,0.4$ & $10,0.3$ & $6.7,0.2$ & $5.4,0.4$ \\
\hline & & 81.5 & $5,0.3$ & $3.8,0.3$ & $3.9,0.3$ & $0.2,0.2$ & $3.3,0.3$ & $2.9,0.3$ & $4.5,0.3$ & $4.1,0.2$ & $2.6,0.3$ \\
\hline & & 103.5 & $3.3,0.3$ & $1.8,0.2$ & $1.7,0.2$ & $0.2,0.2$ & $1.5,0.2$ & $2.5,0.4$ & $3.6,0.3$ & $3.9,0.3$ & $1.1,0.2$ \\
\hline
\end{tabular}

\subsection{Effects of Independent Variables on Concentration at Mouth Location $\left(\mathbf{C}_{\text {mouth }}\right)$}

In this study, $\mathrm{C}_{\text {mouth }}$ is assumed to represent inhaled concentrations, so the effects

of the independent variables (Breathing, Posture, Velocity, and Subject) on $\mathrm{C}_{\text {mouth }}$ are of great interest.

Table 4.2 lists the results for every treatment condition averaged over all four subjects and both replications. Examination of the values in the table show that values of $\mathrm{C}_{\text {mouth }}$ varied substantially with Velocity and Posture. For example, the values of $\mathrm{C}_{\text {mouth }}$ 
at $\mathrm{V}=47.5 \mathrm{fpm}$ were generally at least double the values at $\mathrm{V}=11.3 \mathrm{fpm}$. Likewise, values for Sitting were generally roughly double corresponding values for Standing. In contrast, the differences between mean values for Normal versus Tube-Breathing were moderate for Sitting and negligible for Standing.

As shown on Table 4.3, the standard deviations computed for each condition over both replications and all four subjects were not uniform, varying over a range of 1.5 to 15 ppm. The coefficients of variability ranged over the narrower range of $20 \%$ to $70 \%$. Sitting with tube exhalation showed the highest variability with a coefficient of variation $(\mathrm{CV})$ of $(70 \%)$. In the sitting posture, the ranges in standard deviations for different subjects were higher than for standing. As can be seen in Table 4.5 Subject $C$ had the worst CV (70\%) in standing condition and Subject A had the worst CV (50\%) in seated condition. Finally, Subject D had the same CV value for both posture conditions. Values of $\mathrm{CV}$ varied between Breathing and non-breathing. 


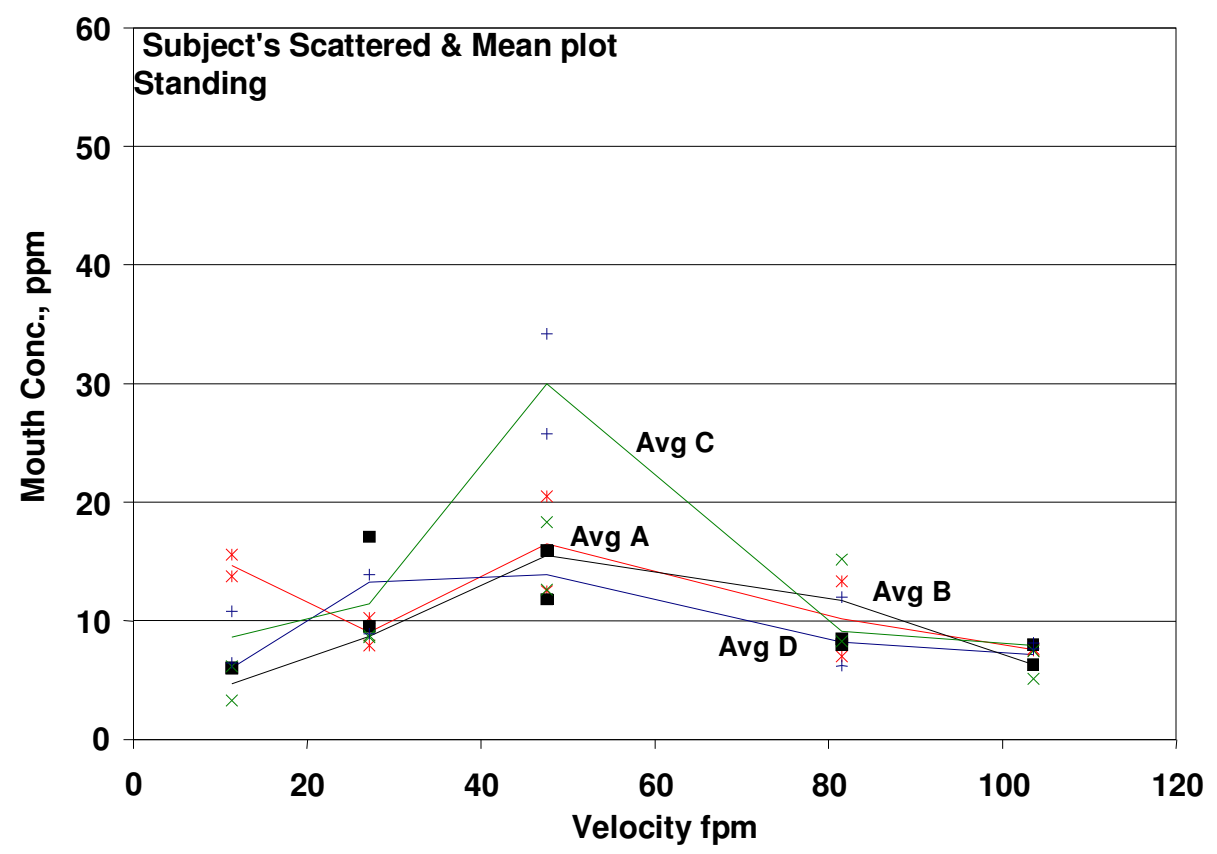

Figure 4.2: Scatter and mean plot of $C_{\text {mouth }}$ vs. velocity for subjects standing

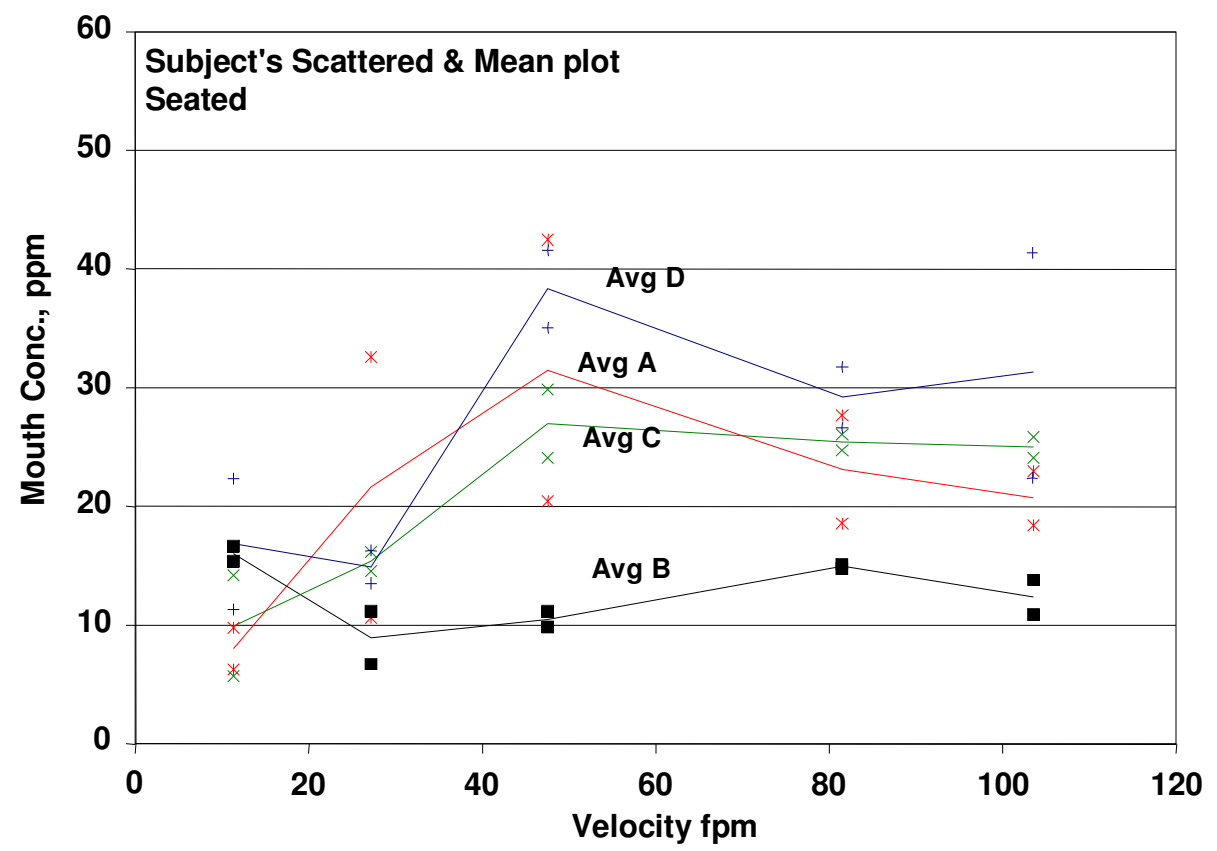

Figure 4.3: Scatter and mean plot of $C_{\text {mouth }}$ vs. velocity for subjects sitting 


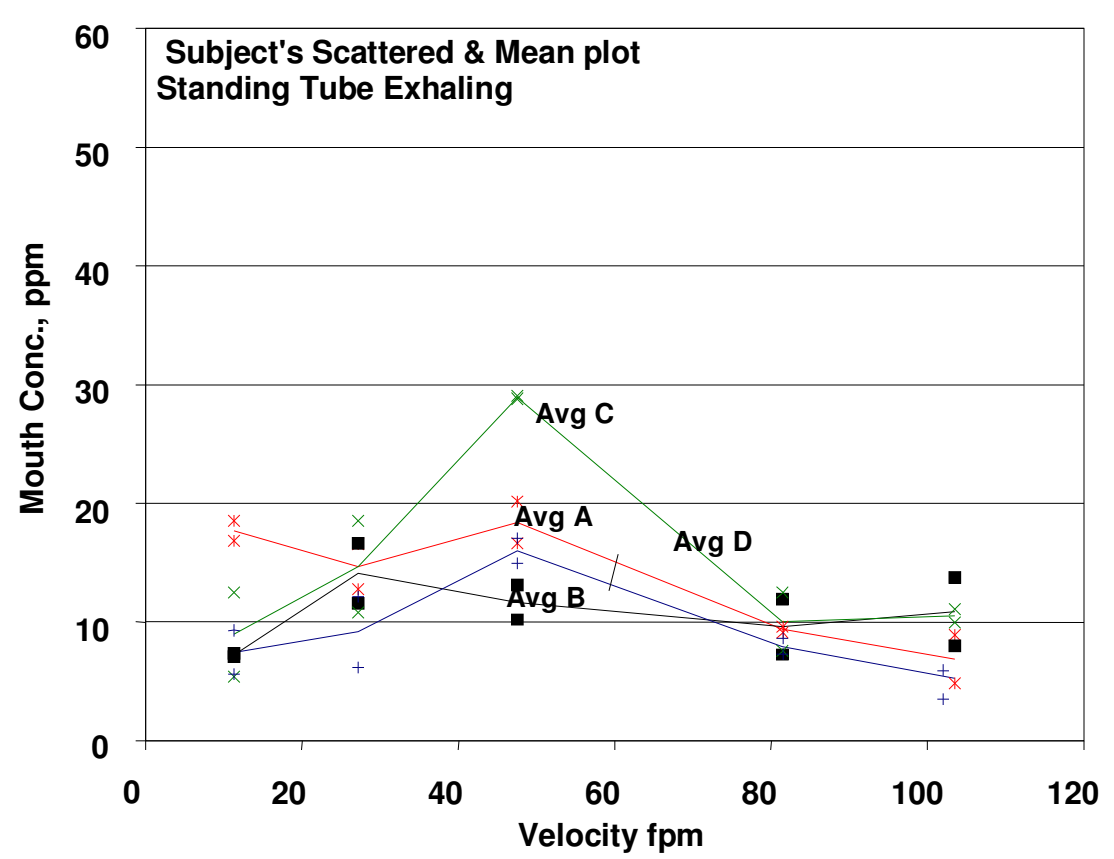

Figure 4.4: Scatter and mean plot of $C_{\text {mouth }}$ vs. velocity for subjects standing and exhaling through a tube

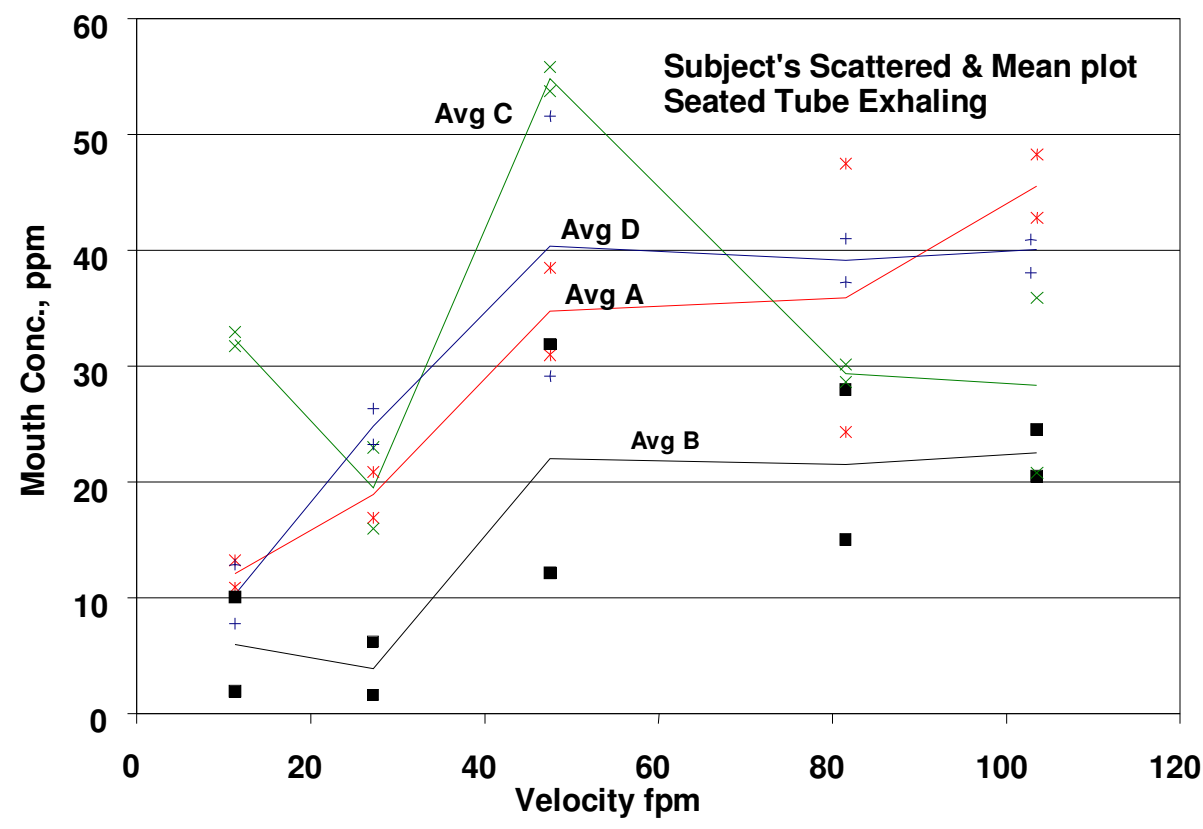

Figure 4.5: Scatter and mean plot of $C_{\text {mouth }}$ vs. velocity for subjects sitting and exhaling through a tube 


\section{$\underline{\text { 4.1.1 Velocity }}$}

As shown in Figure 4.2 and Table $4.5, \mathrm{C}_{\text {mouth }}$ changed as the cross draft velocity changed in a similar manner for all conditions. Concentrations rose to a peak at $47.5 \mathrm{fpm}$ for all except two conditions: 1) Subject B with seated posture when breathing normally, and 2) Subject B when standing and breathing through a tube, concentrations. For the Standing Posture (see Figure 4.2 and Figure 4.3), concentrations formed an inverted V with Velocity that was roughly symmetrical. For the seated posture (see Figure 4.4 and Figure 4.5), with the exception of Subject B, concentrations fell modestly to a plateau for both velocities greater than $47.5 \mathrm{fpm}$.

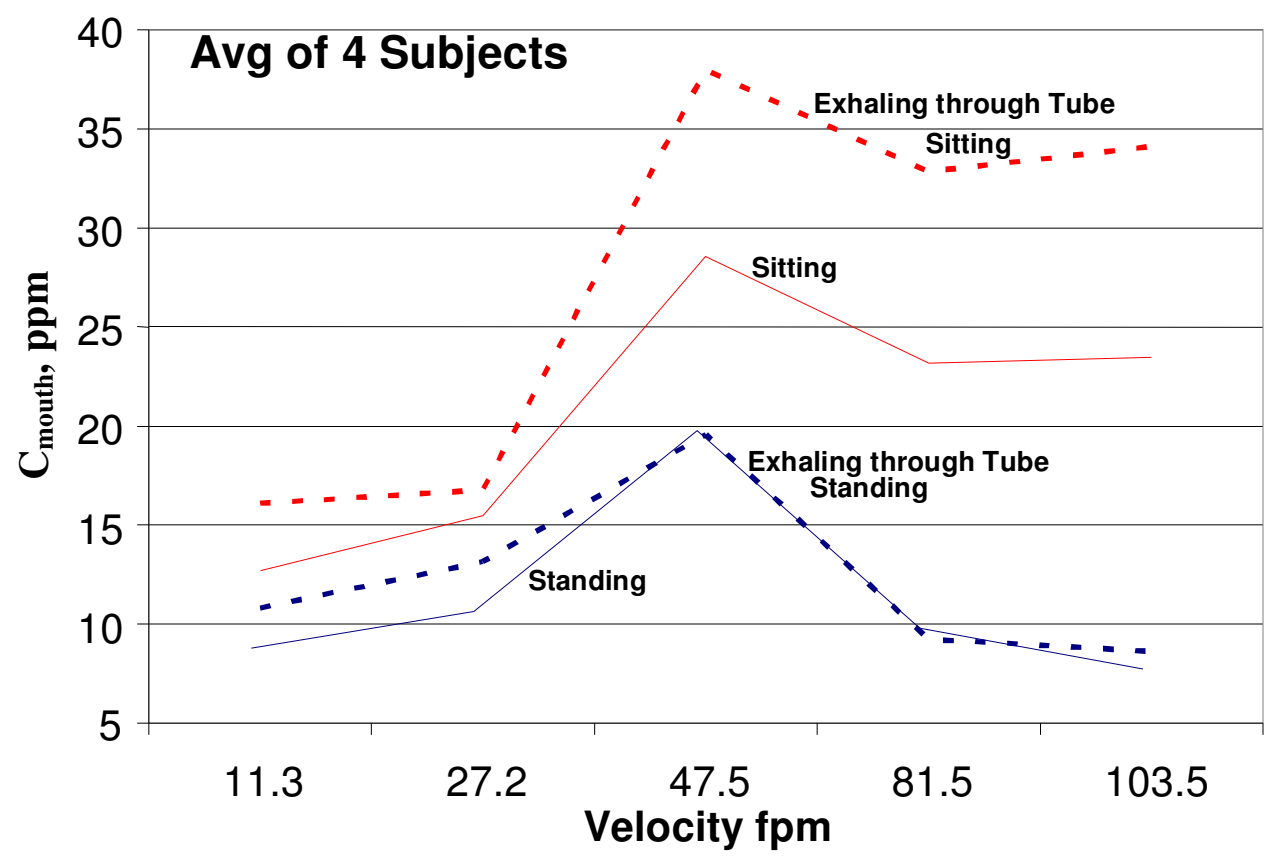

Figure 4.6 Mouth average concentration for the four subjects

When averaged over all four subjects and both replications, the patterns became

more pronounced. As shown in Figure 4.6, the inverted $\mathrm{V}$ shape of $\mathrm{C}_{\text {mouth }}$ with velocity occurred for both normal breathing and for exhaling through a tube. For the sitting 
posture, the higher velocities show the plateau of $\mathrm{C}_{\text {mouth }}$ while for the standing posture $\mathrm{C}_{\text {mouth }}$ was roughly symmetrical about $\mathrm{V}=47.5 \mathrm{fpm}$ for both normal and tube breathing.

Table 4.4: Descriptive statistics for subject's average $C_{\text {mouth }}$ for each posture across all velocities and breathing conditions

\begin{tabular}{|c|c|c|c|c|c|c|}
\hline & Count & Mean & Median & Min & Max & Range \\
\hline Subject Standing & & & & & & \\
\hline A & 10 & 11.6 & 11.4 & 7.0 & 20.5 & 13.5 \\
\hline B & 10 & 9.4 & 8.4 & 3.3 & 18.3 & 15.1 \\
\hline C & 10 & 13.4 & 9.9 & 6.2 & 34.2 & 28.0 \\
\hline D & 10 & 9.7 & 8.3 & 6.0 & 17.1 & 11.1 \\
\hline \hline Subject Sitting & & & & & & \\
\hline A & 10 & 21.0 & 19.5 & 6.3 & 42.5 & 36.2 \\
\hline B & 10 & 12.6 & 12.5 & 6.7 & 16.7 & 9.9 \\
\hline C & 10 & 20.5 & 24.1 & 5.7 & 29.8 & 24.1 \\
\hline D & 10 & 26.1 & 24.5 & 11.3 & 41.6 & 30.3 \\
\hline
\end{tabular}

\subsubsection{Subject}

As shown on Figure 4.7 - Figure $4.10, \mathrm{C}_{\text {mouth }}$ appeared to vary among the four subjects. Concentrations for each subject averaged over all velocities are shown for both postures in Table 4.4. For the sitting posture, $\mathrm{C}_{\text {mouth }}$ varied substantially but with no consistently high or low subjects. Concentrations for each subject averaged over all velocities are shown for each subject for both postures in Table 4.4. The concentrations were lower and differed between subjects much less dramatically when subjects were standing than when sitting, with the exception of Subject $\mathrm{C}$ at $\mathrm{V}=47.5 \mathrm{fpm}$. That subject's results at that velocity were nearly twice as high as other subjects' (see Table 4.5 and Figure 4.7) but about the same as other subjects at other velocities.

Subjects A, C and D had nearly similar results for the sitting posture (see Table 4.5 and Figure 4.2 - Figure 4.5). In standing posture subject $C$ had the highest $C_{\text {mouth }}$ 
values and subject $\mathrm{B}$ had the lowest $\mathrm{C}_{\text {mouth }}$ values. Subject $\mathrm{B} \mathrm{C}_{\text {mouth }}$ concentration was

less than $1 / 2$ the values of any other subjects in sitting treatment conditions.

Table 4.5: Descriptive statistics summary computed for $\mathbf{C}_{\text {mouth }}$ for each subject, and both replications for breathing conditions and across all velocities

\begin{tabular}{|c|c|c|c|c|c|c|c|c|c|c|c|c|c|c|c|c|}
\hline \multirow{3}{*}{\begin{tabular}{|l|} 
Posture \\
Breathing \\
Subject \\
\end{tabular}} & \multicolumn{8}{|c|}{ Sitting } & \multicolumn{8}{|c|}{ Standing } \\
\hline & \multicolumn{4}{|c|}{ Tube } & \multicolumn{4}{|c|}{ Normal } & \multicolumn{4}{|c|}{ Tube } & \multicolumn{4}{|c|}{ Normal } \\
\hline & $\bar{A}$ & $\bar{B}$ & C & $\bar{D}$ & $\bar{A}$ & $\bar{B}$ & C & $\bar{D}$ & $\bar{A}$ & $\bar{B}$ & C & D & $\bar{A}$ & $\bar{B}$ & C & $\bar{D}$ \\
\hline Mean & 28.01 & 15.19 & 30.98 & 30.93 & 20.48 & 12.55 & 20.89 & 24.96 & 12.64 & 11.33 & 14.04 & 9.78 & 11.01 & 9.65 & 13.40 & 10.16 \\
\hline$S$ & 14.45 & 10.72 & 13.71 & 13.68 & 13.88 & 4.01 & 8.04 & 11.15 & \begin{tabular}{|l|}
4.92 \\
\end{tabular} & 3.76 & 8.09 & 4.18 & 4.21 & 4.34 & 9.28 & 4.63 \\
\hline $\mathrm{CV}$ & $52 \%$ & $71 \%$ & $44 \%$ & $44 \%$ & $68 \%$ & $32 \%$ & $38 \%$ & $45 \%$ & $39 \%$ & $33 \%$ & $58 \%$ & $43 \%$ & $38 \%$ & $45 \%$ & $69 \%$ & $46 \%$ \\
\hline
\end{tabular}

In Table 4.5 in the sitting posture, Subjects C and D had the two lowest average CV values (42\%, 44\% respectively), while Subject B had the highest CV value (71\%) at same condition. In the standing posture, B had the lowest CV value (20\%)

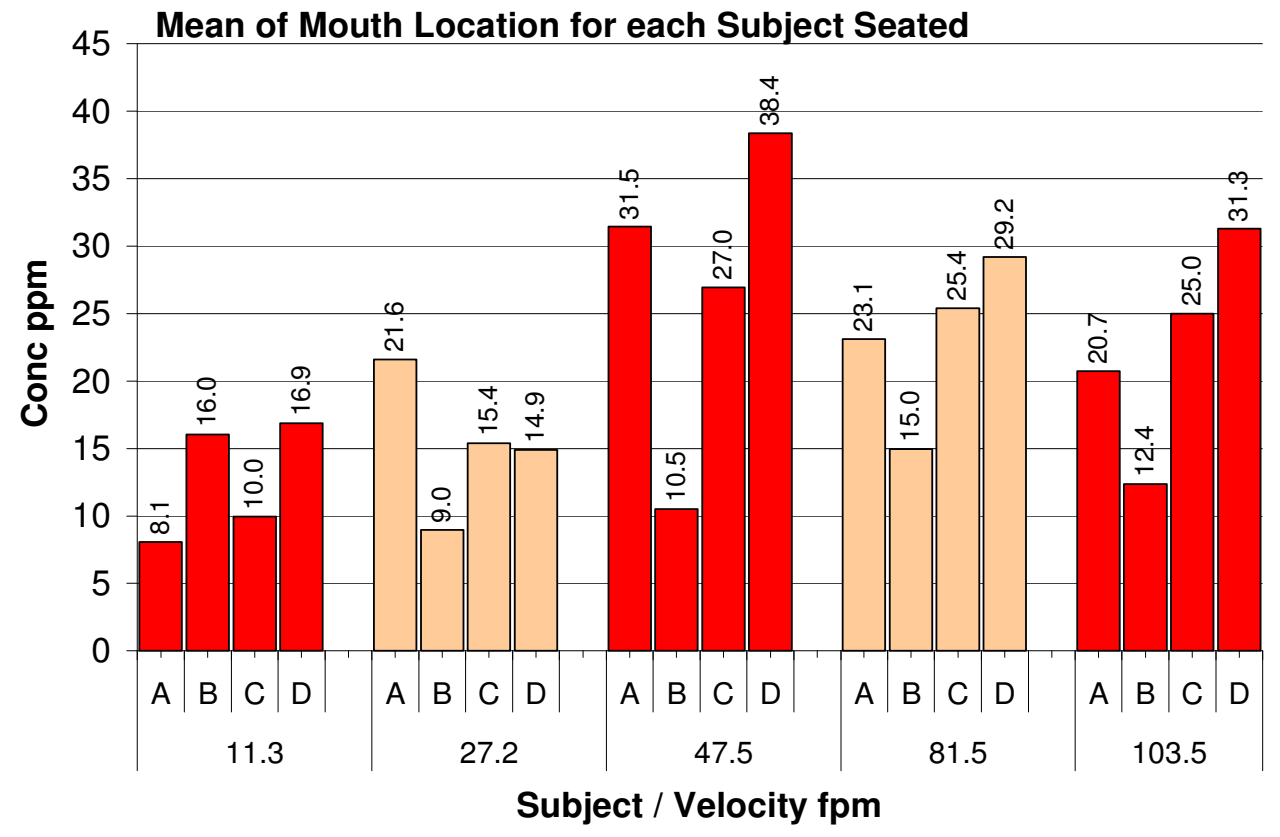

Figure 4.7 Barchart for subject's $C_{\text {mouth }}$ Vs velocity at seated posture 


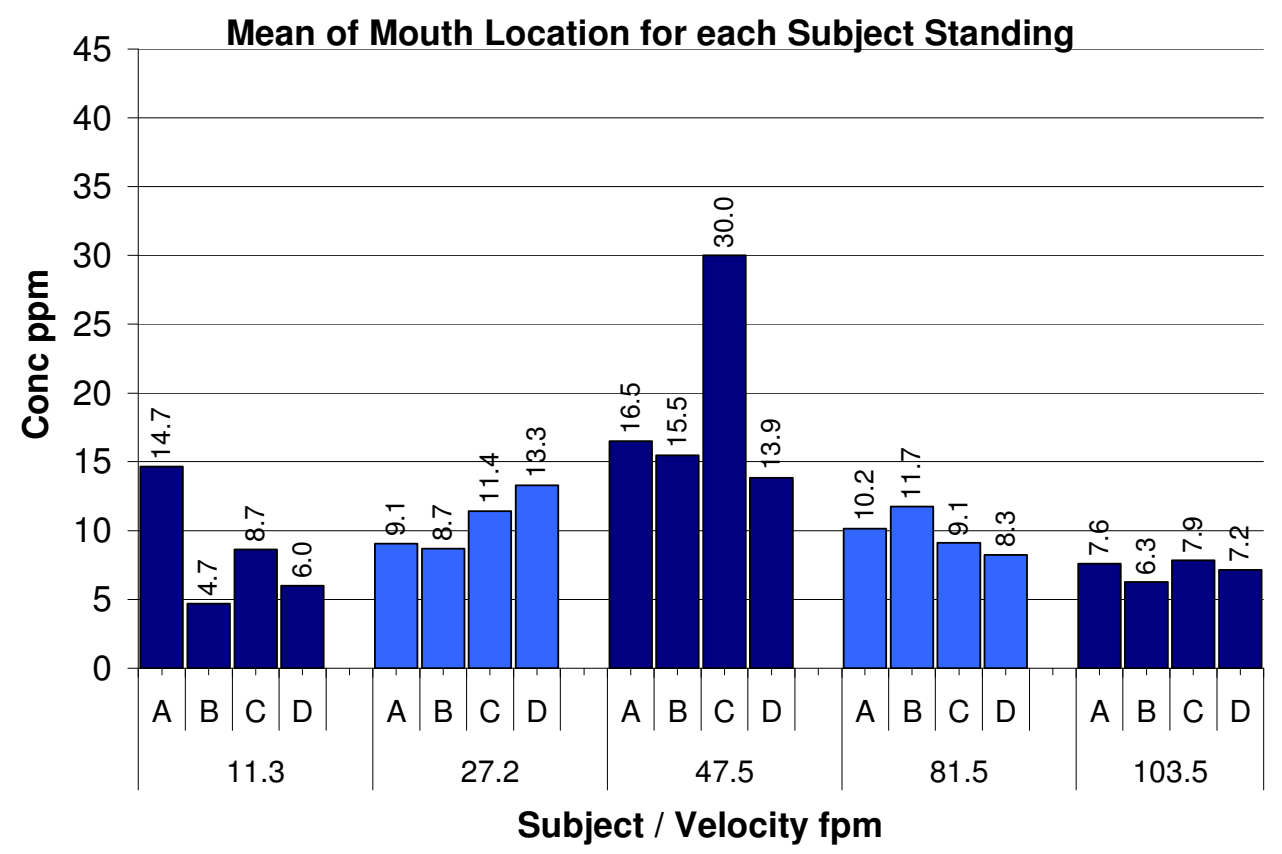

Figure 4.8 Barchart for subject's $C_{\text {mouth }}$ Vs velocity at standing posture

\subsubsection{Posture}

The effect of Posture on $\mathrm{C}_{\text {mouth }}$ values was striking. Seated values were roughly twice the corresponding values for standing postures (see Table 4.5 - Table 4.7), except for $\mathrm{B}$, which was only $30 \%$ higher.

Table 4.6: Averaged effect of posture for all subjects on $\mathbf{C}_{\text {mouth }}$

\begin{tabular}{|r|r|r|r|r|r|r|r|}
\hline Posture & Breathing & $\begin{array}{l}\text { lverage of } \\
\mathrm{C}_{\text {mouth }}\end{array}$ & $\begin{array}{l}\text { Std Dev of } \\
\mathrm{C}_{\text {mouth }}\end{array}$ & $\mathrm{CV}$ & \multicolumn{1}{l|}{$\begin{array}{l}\text { Min of } \\
\mathrm{C}_{\text {mouth }}\end{array}$} & \multicolumn{1}{l}{$\begin{array}{l}\text { Max of } \\
\mathrm{C}_{\text {mouth }}\end{array}$} & Range \\
\hline Sitting & Normal & 26.54 & 14.33 & 0.54 & 1.60 & 55.82 & 54.22 \\
\hline Sitting & Tube & 19.53 & 10.64 & 0.54 & 4.88 & 52.99 & 48.11 \\
\hline Standing & Normal & 12.03 & 5.58 & 0.46 & 4.82 & 29.07 & 24.25 \\
\hline Standing & Tube & 11.01 & 5.82 & 0.53 & 5.09 & 34.16 & 29.08 \\
\hline
\end{tabular}




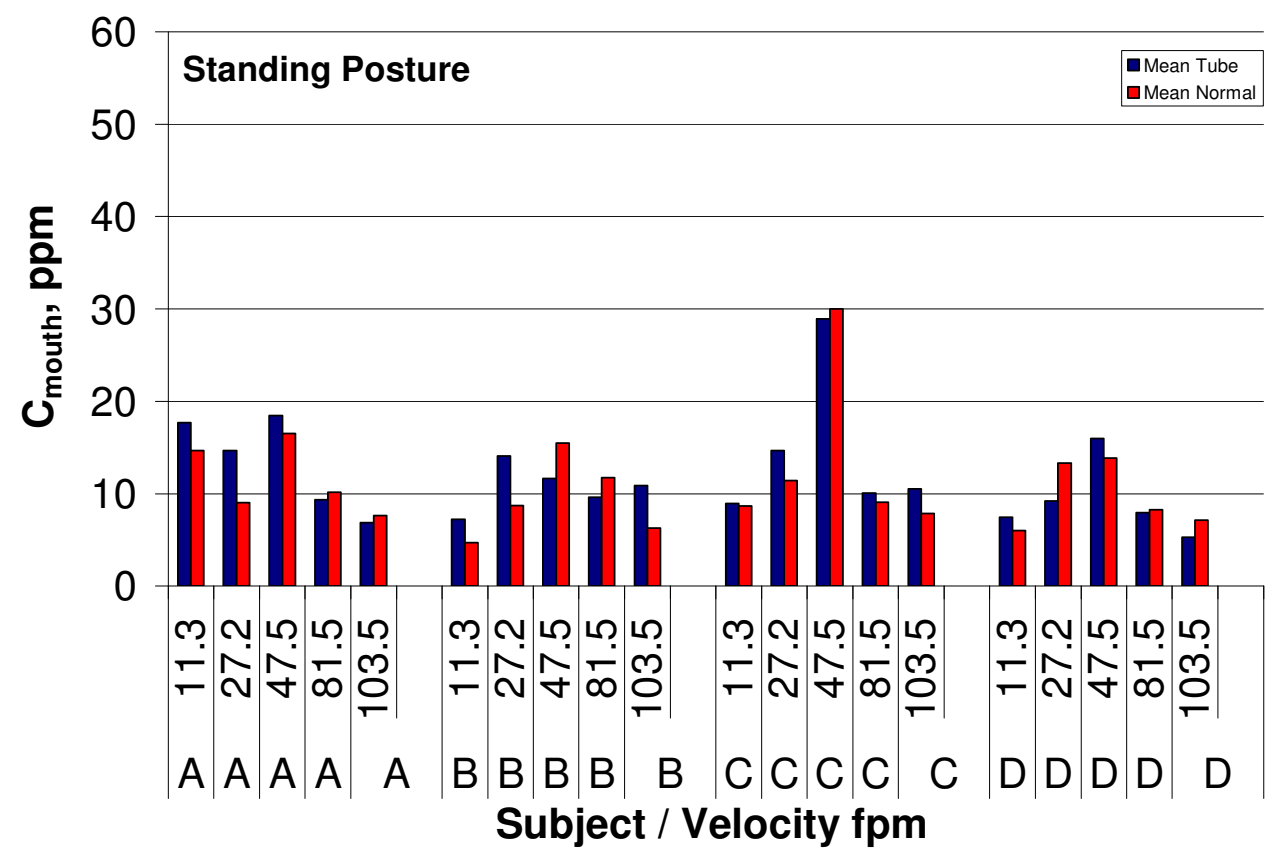

Figure 4.9: Barchart showing breathing treatment effects on each subject's $\mathbf{C}_{\text {mouth }}$ Vs velocity at standing posture treatment

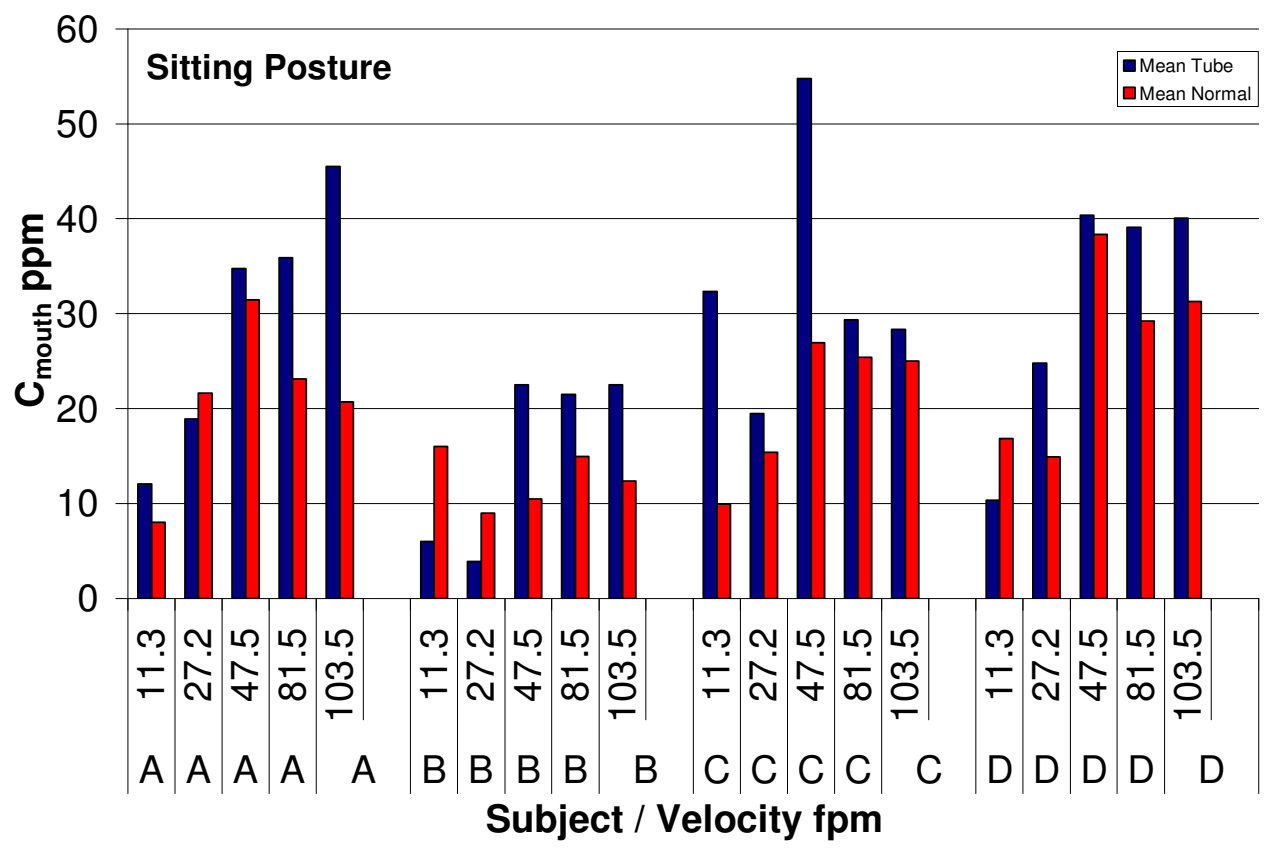

Figure 4.10: Barchart showing breathing treatment effects on subject's $C_{\text {mouth }}$ Vs velocity at sitting posture treatment (Note : A, B, C, and D are human subjects) 
Table 4.7: Comparing concentration for both breathing conditions of each velocity and for each posture

\begin{tabular}{|l|c|c|c|c|c|}
\hline \multirow{4}{*}{ Posture } & Velocity & $\begin{array}{c}\text { Normal } \\
\text { Breathing, } \\
\text { ppm }\end{array}$ & $\begin{array}{c}\text { Tube } \\
\text { Breathing, } \\
\text { ppm }\end{array}$ & $\begin{array}{c}\text { Difference, } \\
\text { ppm }\end{array}$ & \%Difference \\
\hline Standing & 11.30 & 8.78 & 10.81 & 2.03 & $23 \%$ \\
\cline { 2 - 6 } & 27.16 & 10.62 & 13.15 & 2.53 & $24 \%$ \\
\cline { 2 - 6 } & 47.55 & 19.75 & 19.55 & -0.19 & $-1 \%$ \\
\cline { 2 - 6 } & 81.50 & 9.81 & 9.24 & -0.57 & $-6 \%$ \\
\cline { 2 - 6 } & 103.54 & 7.72 & 8.61 & 0.89 & $12 \%$ \\
\hline \multirow{5}{*}{ Sitting } & 11.30 & 12.71 & 16.09 & 3.38 & $27 \%$ \\
\cline { 2 - 6 } & 27.16 & 15.50 & 16.77 & 1.27 & $8 \%$ \\
\cline { 2 - 6 } & 47.55 & 28.57 & 37.97 & 9.40 & $33 \%$ \\
\cline { 2 - 6 } & 81.50 & 23.17 & 32.83 & 9.67 & $42 \%$ \\
\cline { 2 - 6 } & 103.54 & 23.46 & 34.11 & 10.65 & $45 \%$ \\
\hline
\end{tabular}

\subsubsection{Breathing}

The effect of breathing through a tube was strongly affected by whether the subject was sitting or standing. Results were generally higher for tube breathing than normal breathing. For standing, results when breathing through a tube were $-1 \%$ to $23 \%$ higher, with high differences associated with the two lower velocities (see Table 4.7 and Figure 4.9). For sitting, results when breathing through a tube were $8 \%$ to $45 \%$ higher, with high differences associated with high velocities (see Table 4.7 and Figure 4.10).

As shown in Figure 4.6, for both normal and tube-exhalation, $\mathrm{C}_{\text {mouth }}$ varied in an inverted $\mathrm{V}$ relationship with velocity with peaks at $\mathrm{V}=47.5 \mathrm{fpm}$. 
Figure 4.11: Scatter and mean plots of $C_{\text {adj.nose }}$ plotted against wind tunnel velocity for same treatment conditions

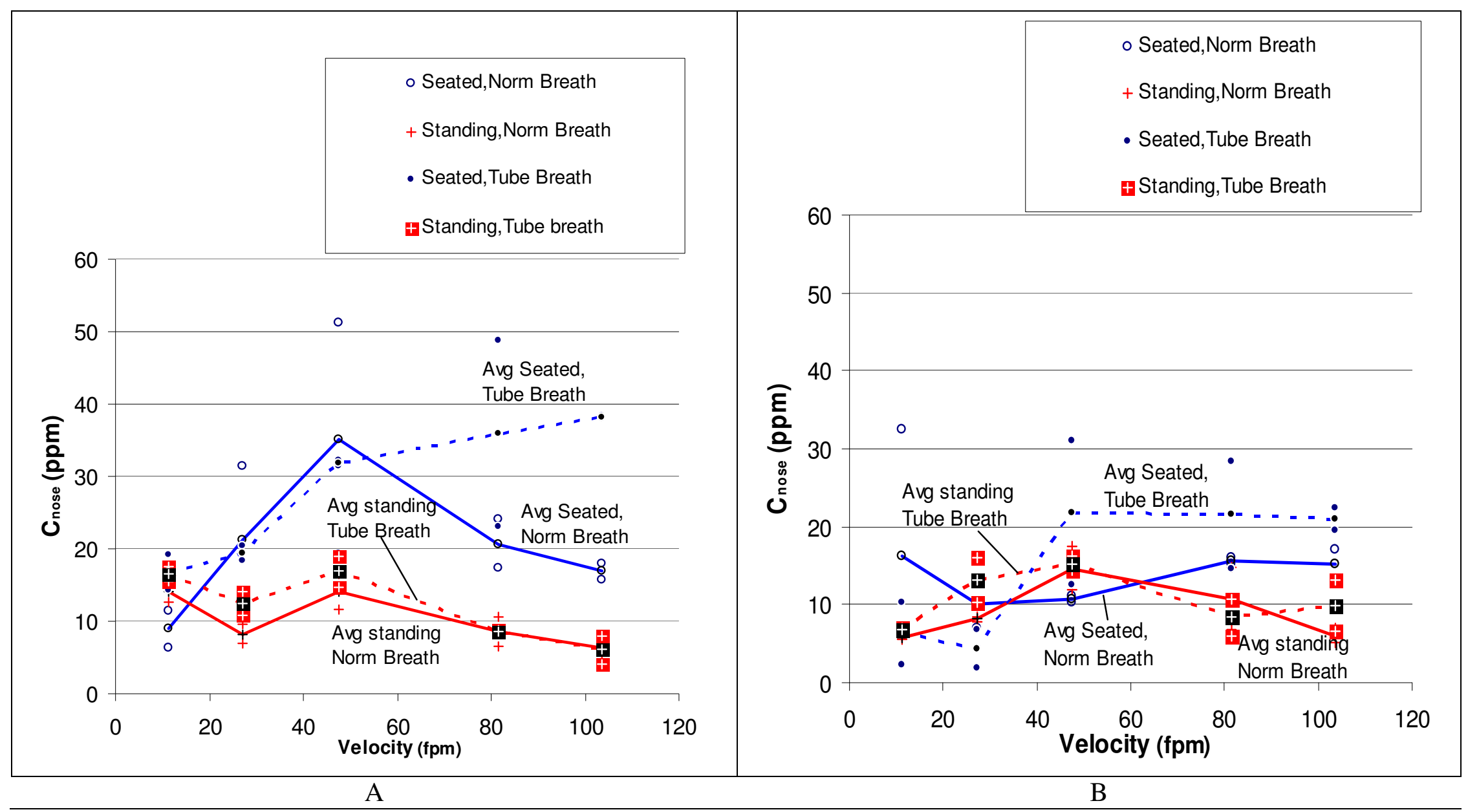




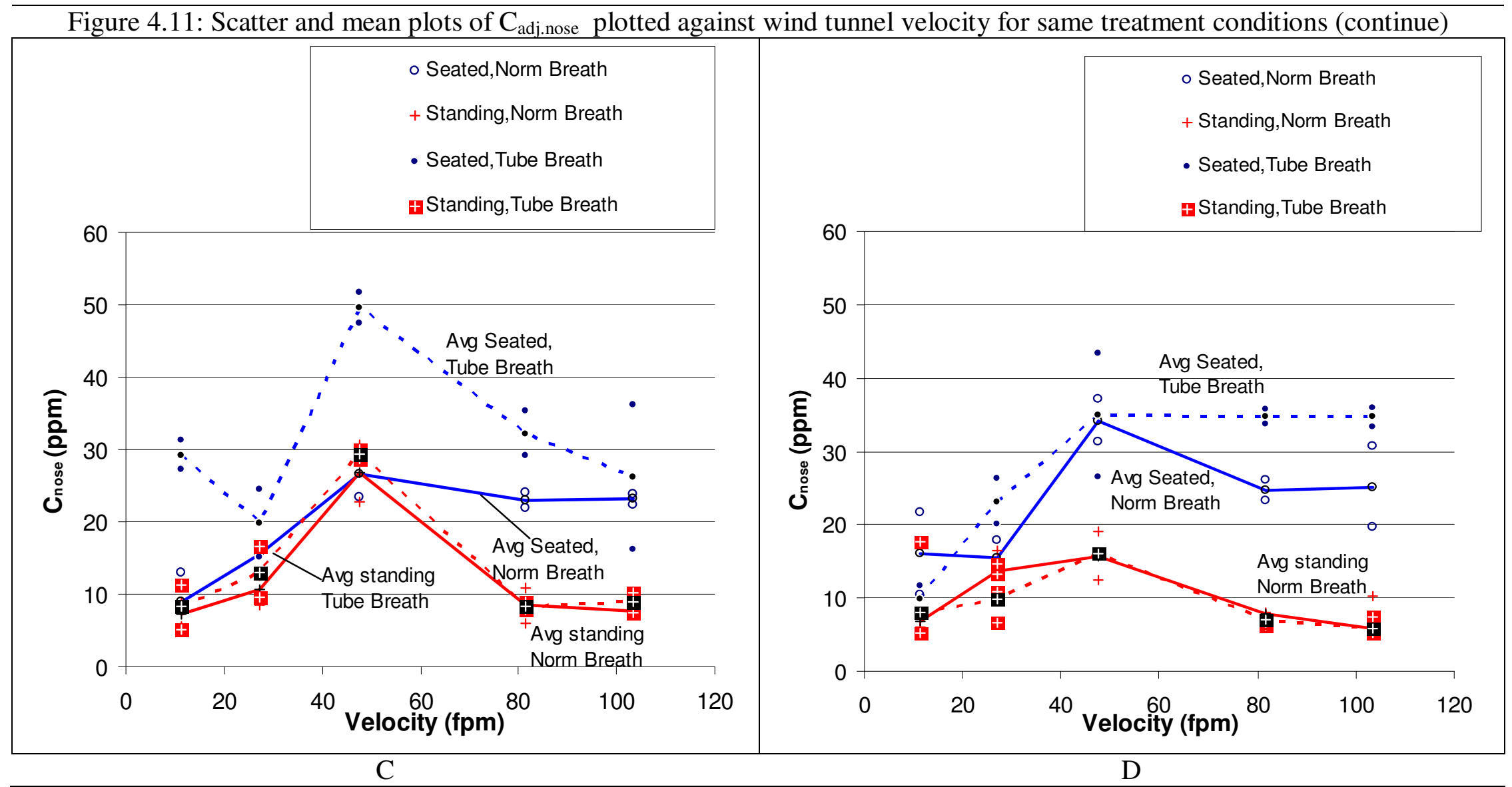


Figure 4.12: Scatter and mean plots of $\mathrm{C}_{\text {forehead }}$ plotted against wind tunnel velocity for same treatment conditions per subject

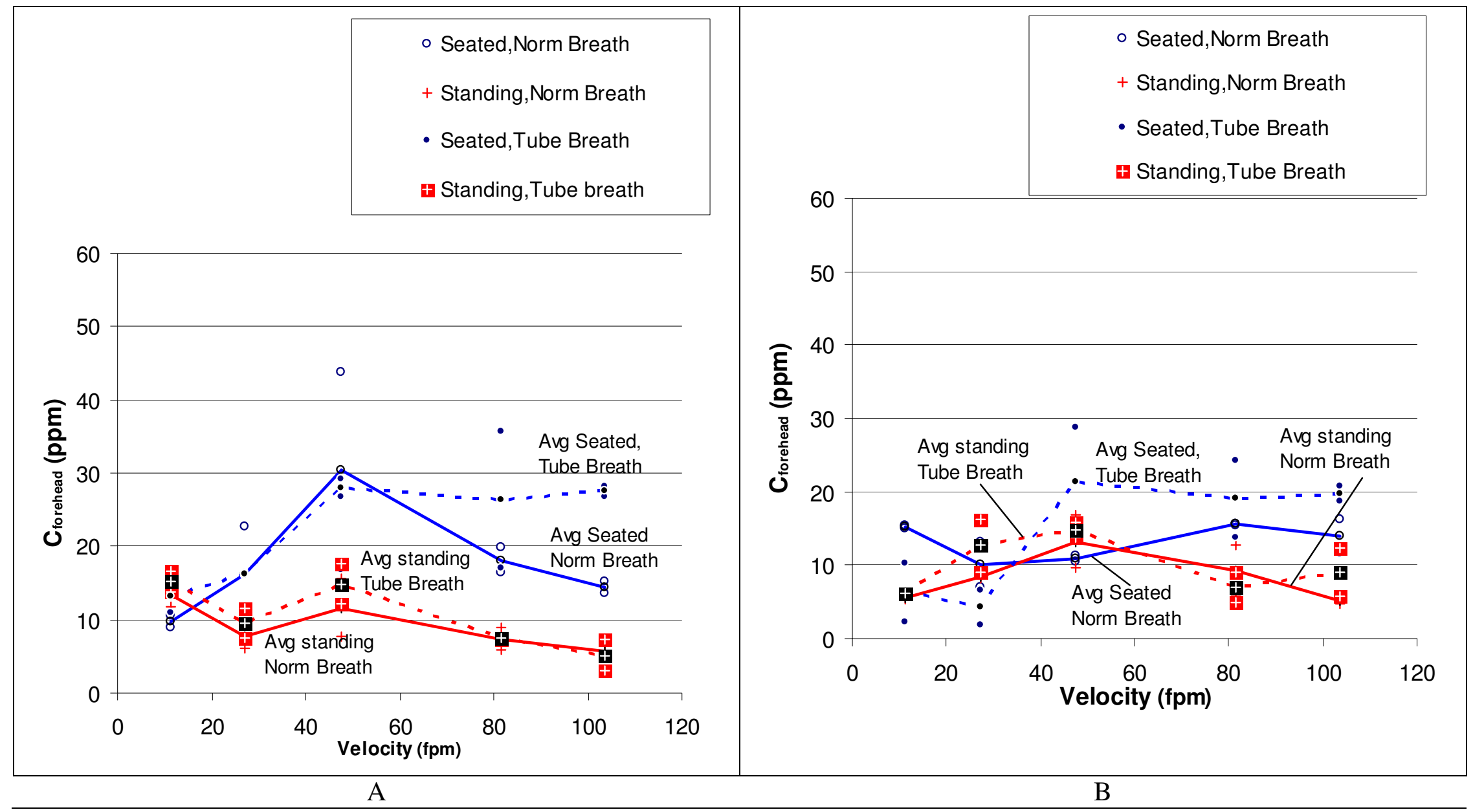


Figure 4.12: Scatter and mean plots of $\mathrm{C}_{\text {forehead }}$ plotted against wind tunnel velocity for same treatment conditions per subject (continue)

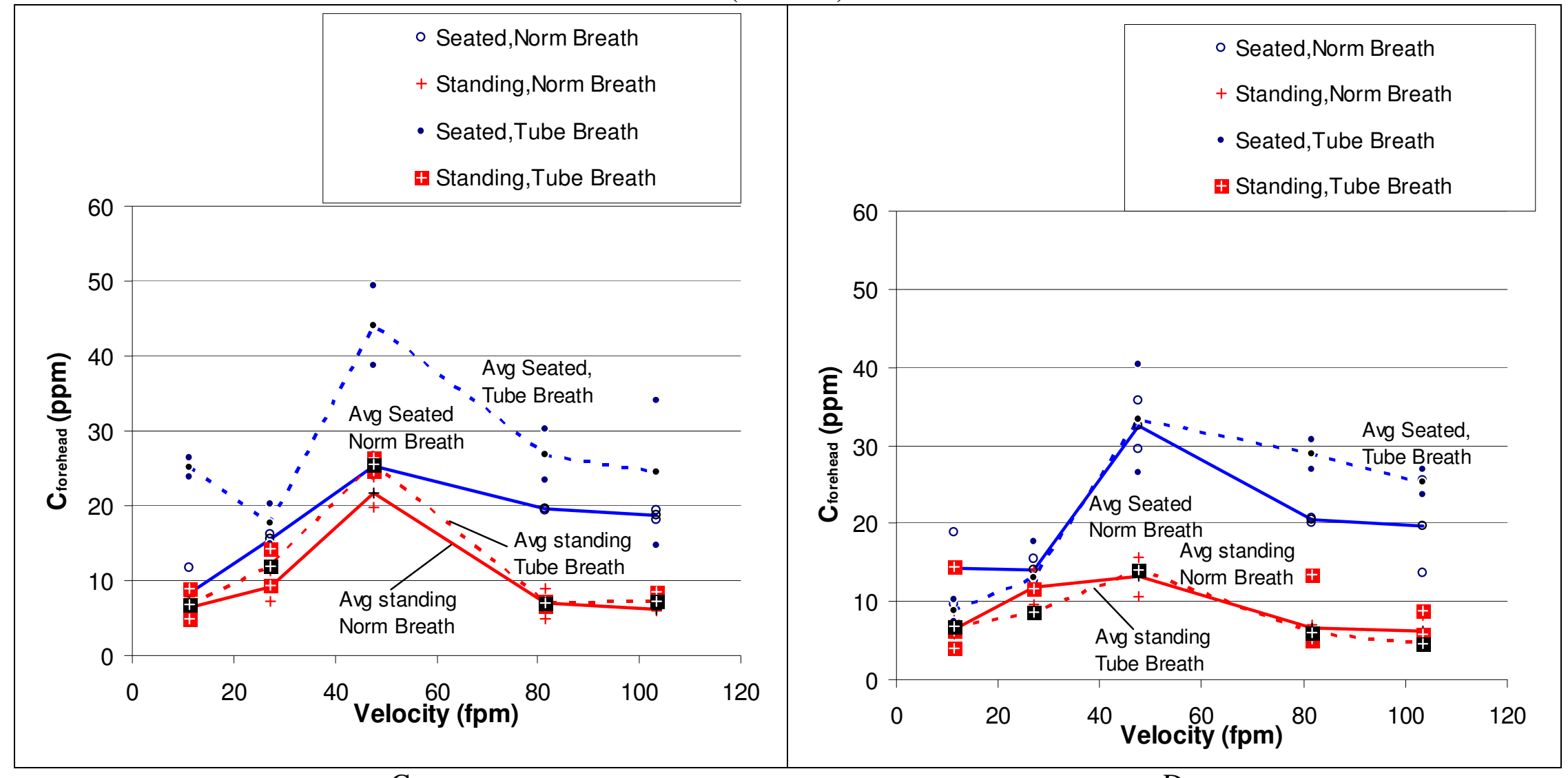

$\mathrm{C}$ 
Figure 4.13: Scatter and mean plots of $C_{\text {neck }}$ plotted against wind tunnel velocity for same treatment conditions per subject

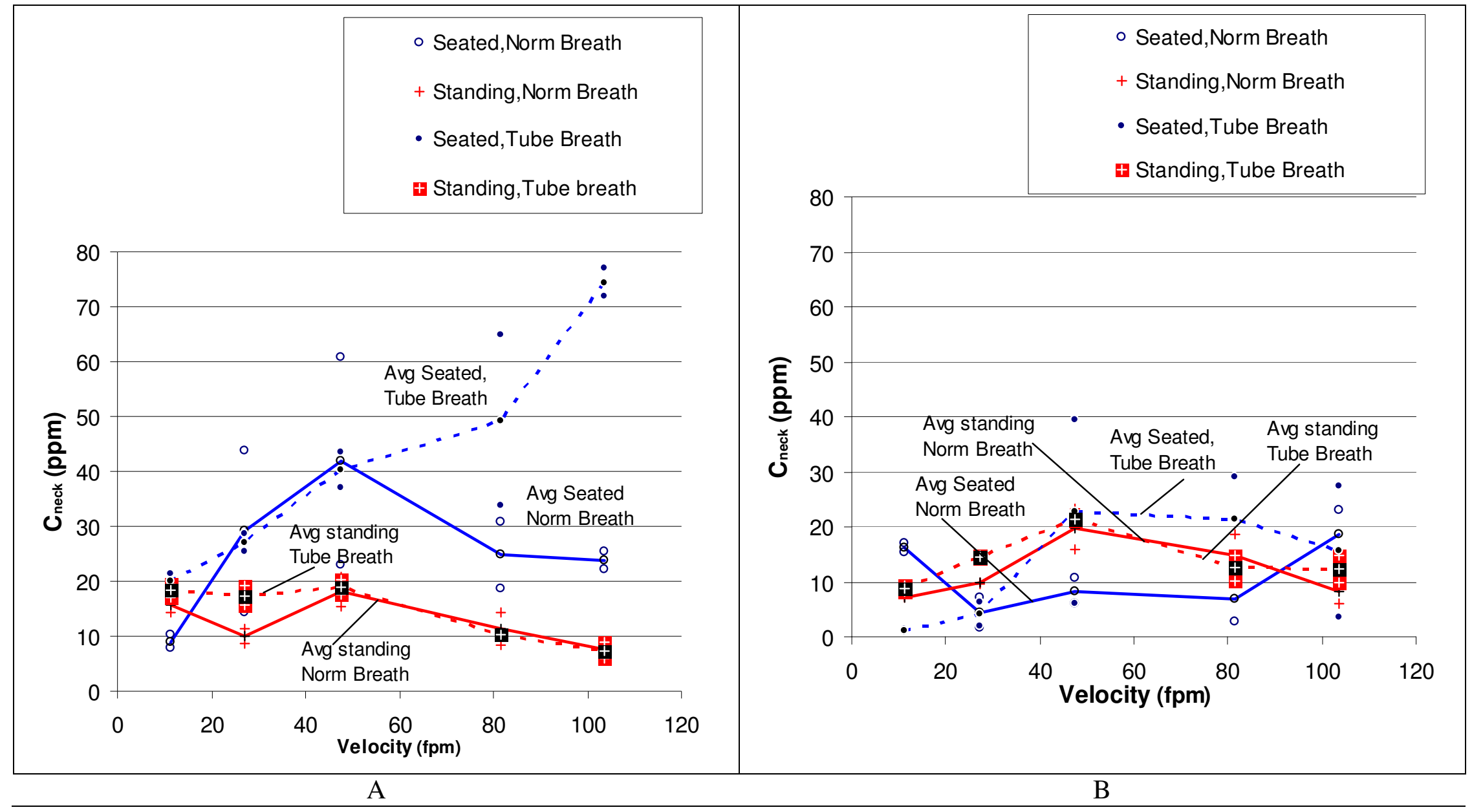


Figure 4.13: Scatter and mean plots of $\mathrm{C}_{\text {neck }}$ plotted against wind tunnel velocity for same treatment conditions per subject (continue)

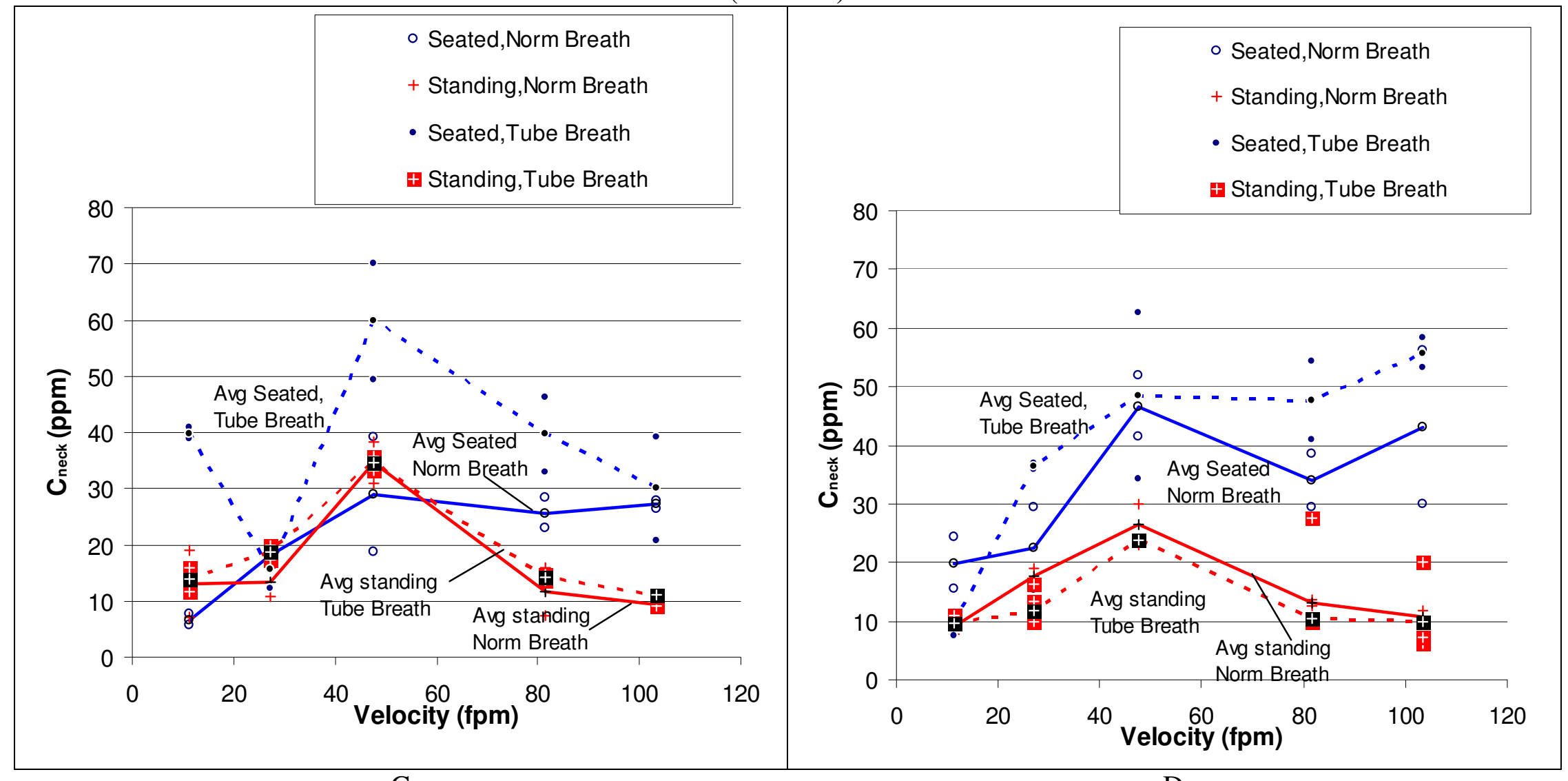

$\mathrm{C}$ 
Figure 4.14: Scatter and mean plots of $\mathrm{C}_{\text {l.collar }}$ plotted against wind tunnel velocity for same treatment conditions per subject

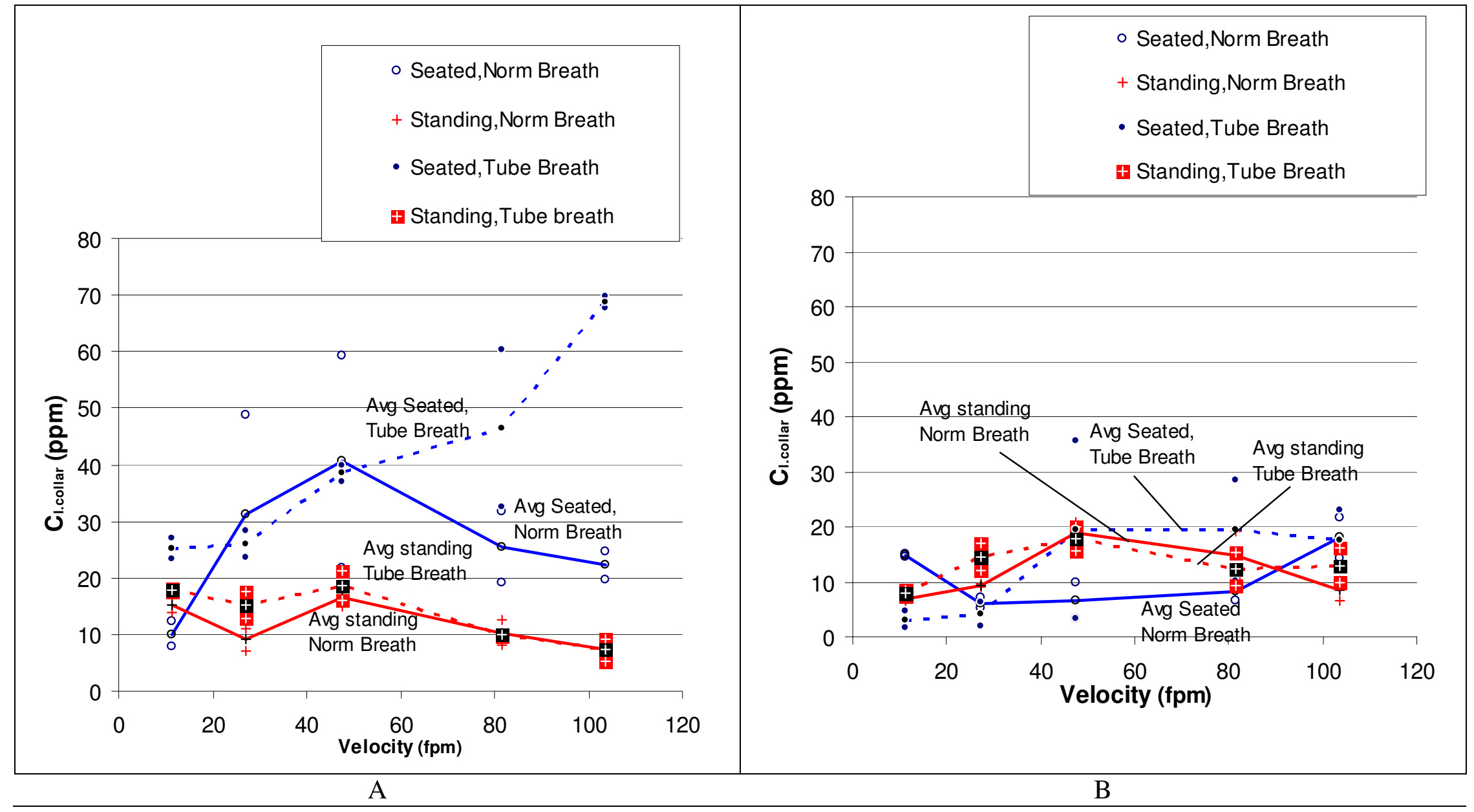


Figure 4.14: Scatter and mean plots of $\mathrm{C}_{\mathrm{l} \text {.collar }}$ plotted against wind tunnel velocity for same treatment conditions per subject (continue)

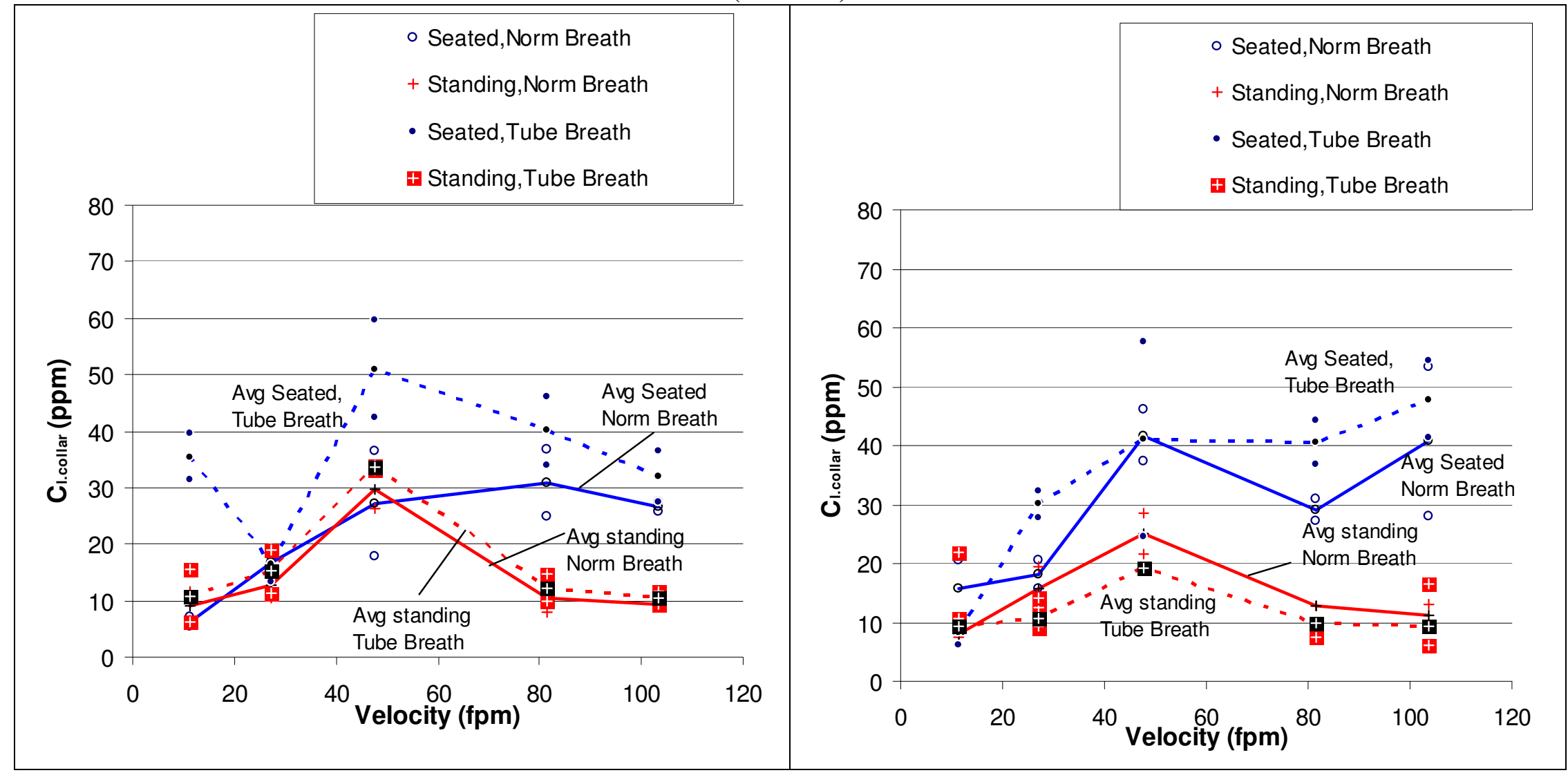

C 
Figure 4.15: Scatter and mean plots of $\mathrm{C}_{\mathrm{r} . \mathrm{collar}}$ plotted against wind tunnel velocity for same treatment conditions per subject

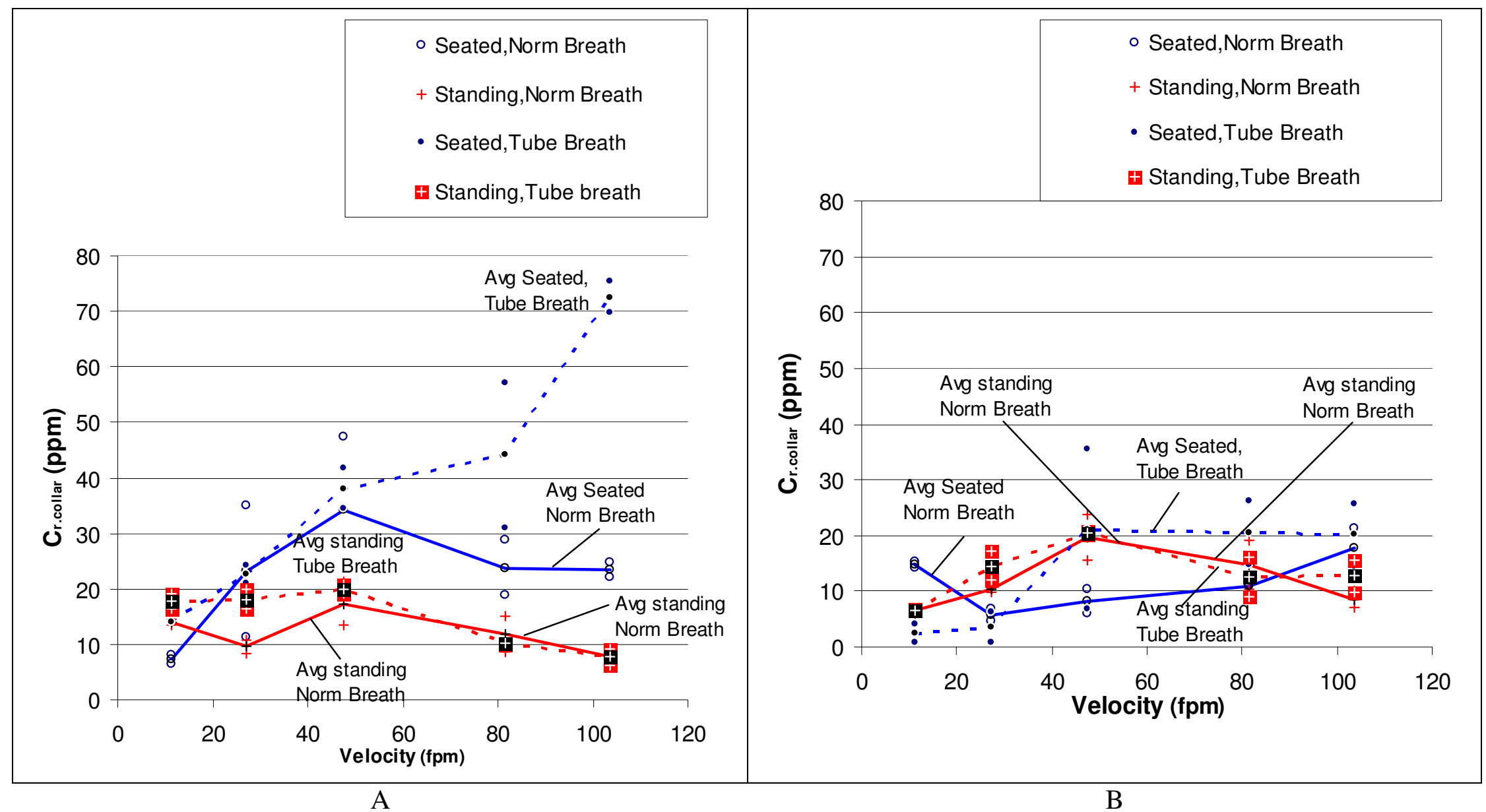


Figure 4.15: Scatter and mean plots of $\mathrm{C}_{\mathrm{r} \text {.collar }}$ plotted against wind tunnel velocity for same treatment conditions per subject

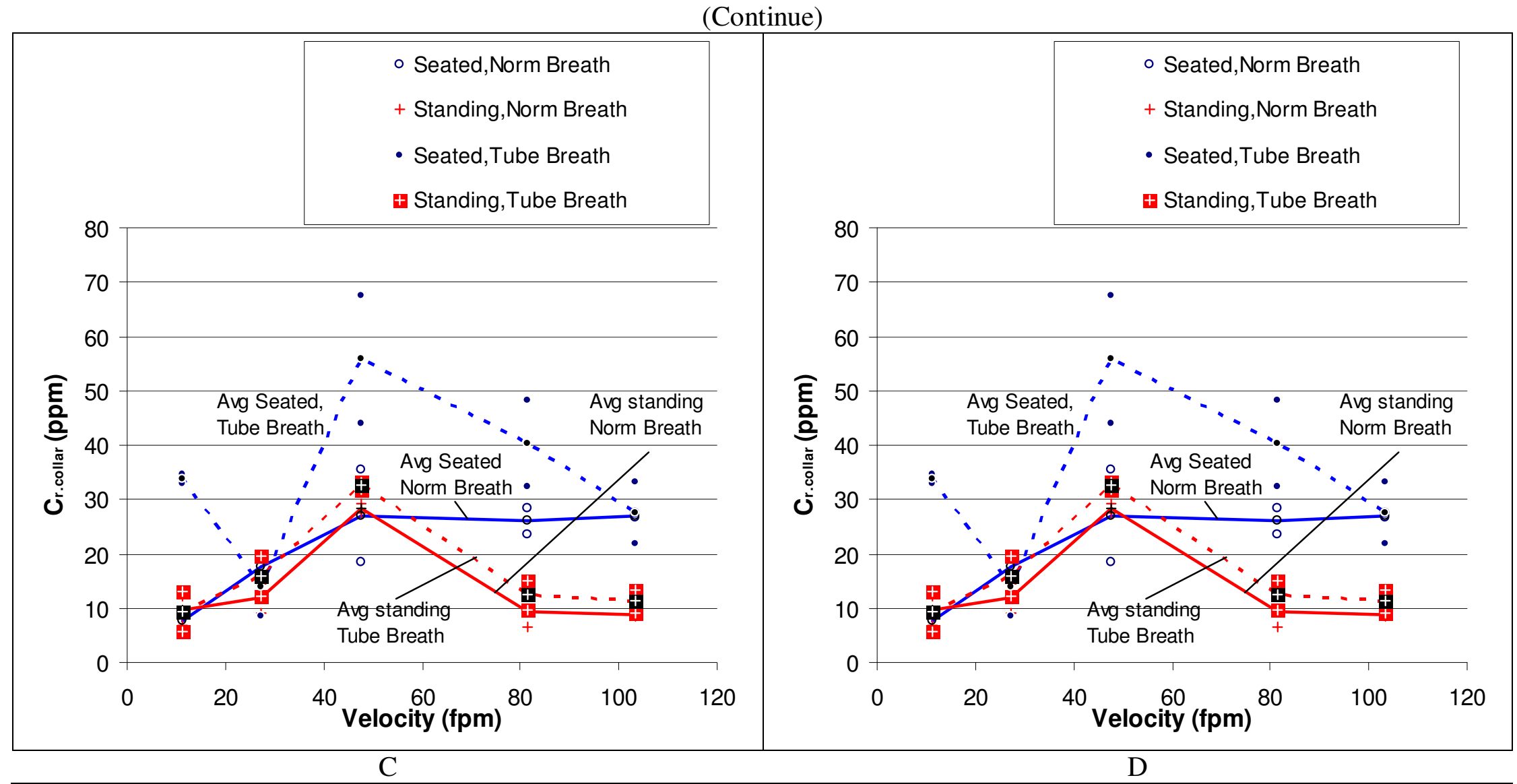


Figure 4.16: Scatter and mean plots of $\mathrm{C}_{\text {chest }}$ plotted against wind tunnel velocity for same treatment conditions per subject

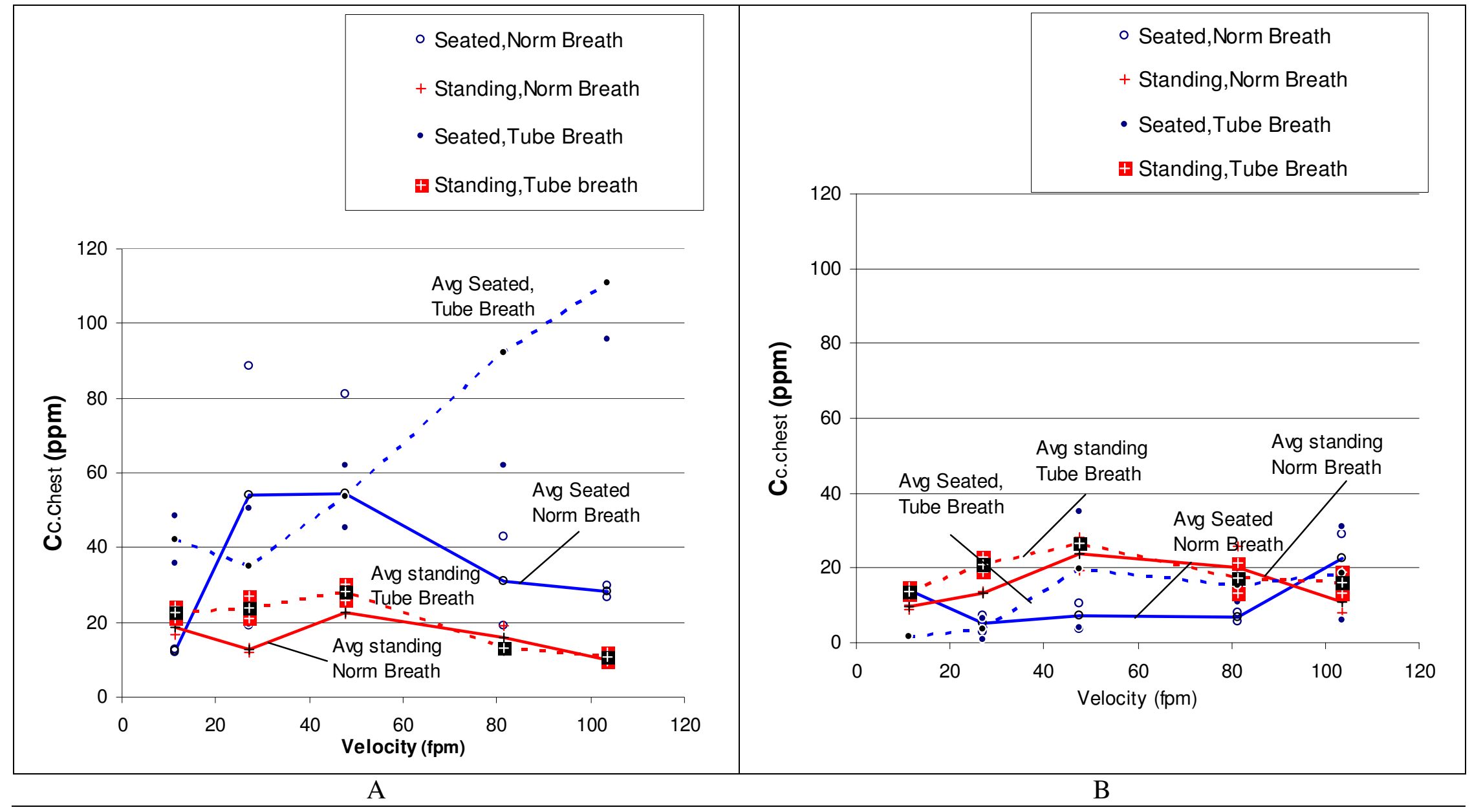


Figure 4.16: Scatter and mean plots of $\mathrm{C}_{\text {chest }}$ plotted against wind tunnel velocity for same treatment conditions per subject(continue)

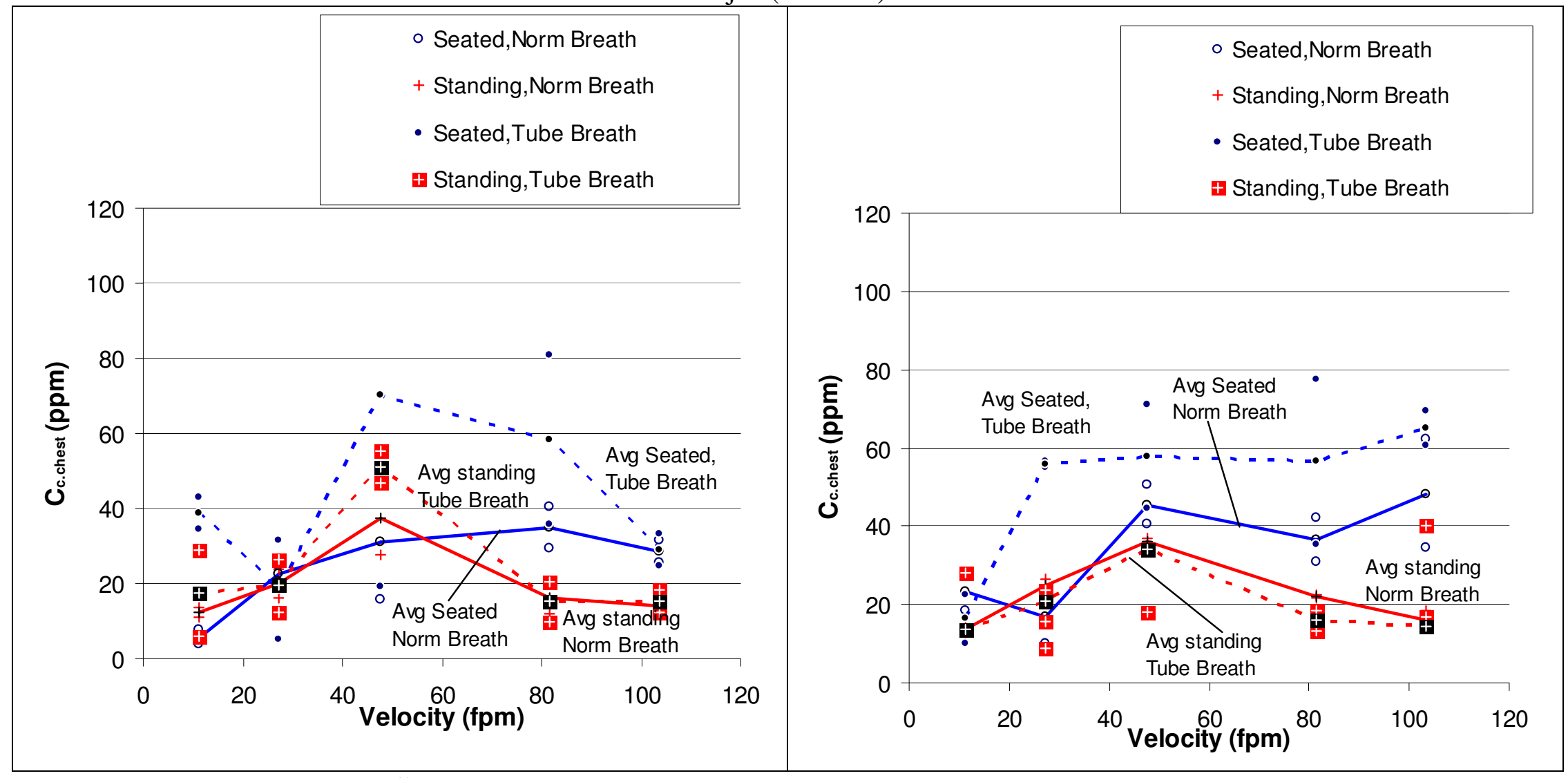

C 
Figure 4.17: Scatter and mean plots of $\mathrm{C}_{1.1 \text { lapel }}$ plotted against wind tunnel velocity for same treatment conditions per subject

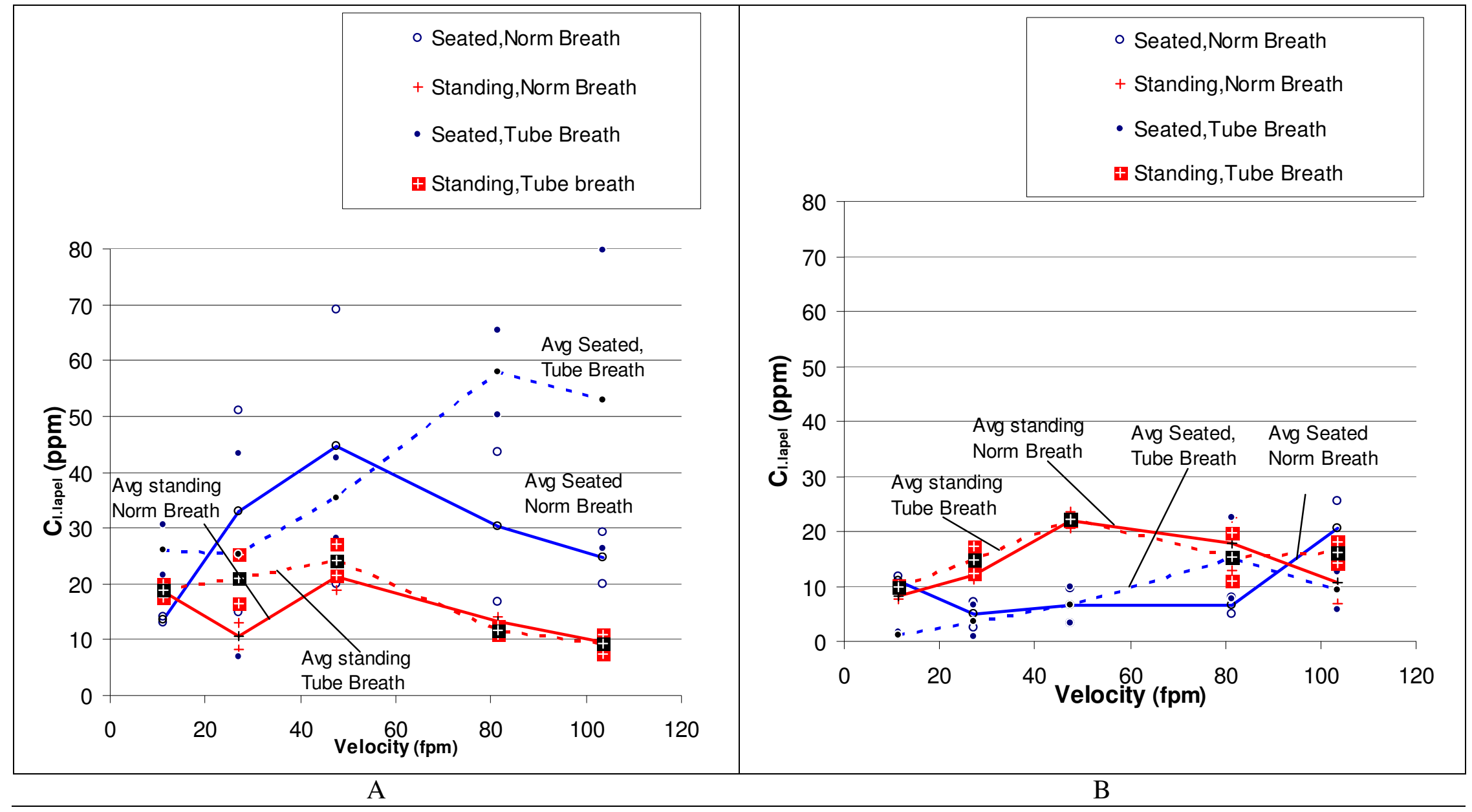




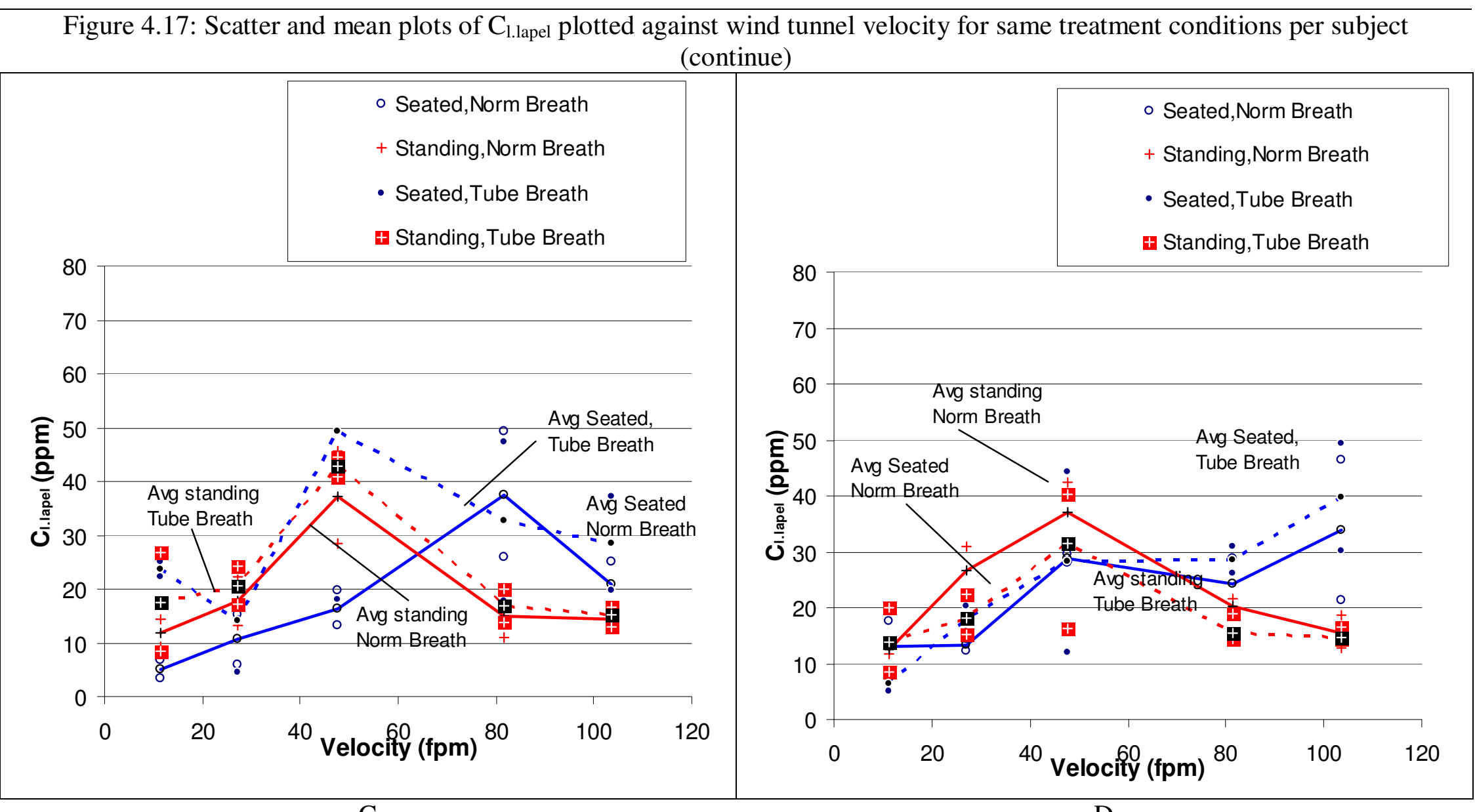

C 
Figure 4.18: Scatter and mean plots of $\mathrm{C}_{\mathrm{r} \text {.lapel }}$ plotted against wind tunnel velocity for same treatment conditions per subject

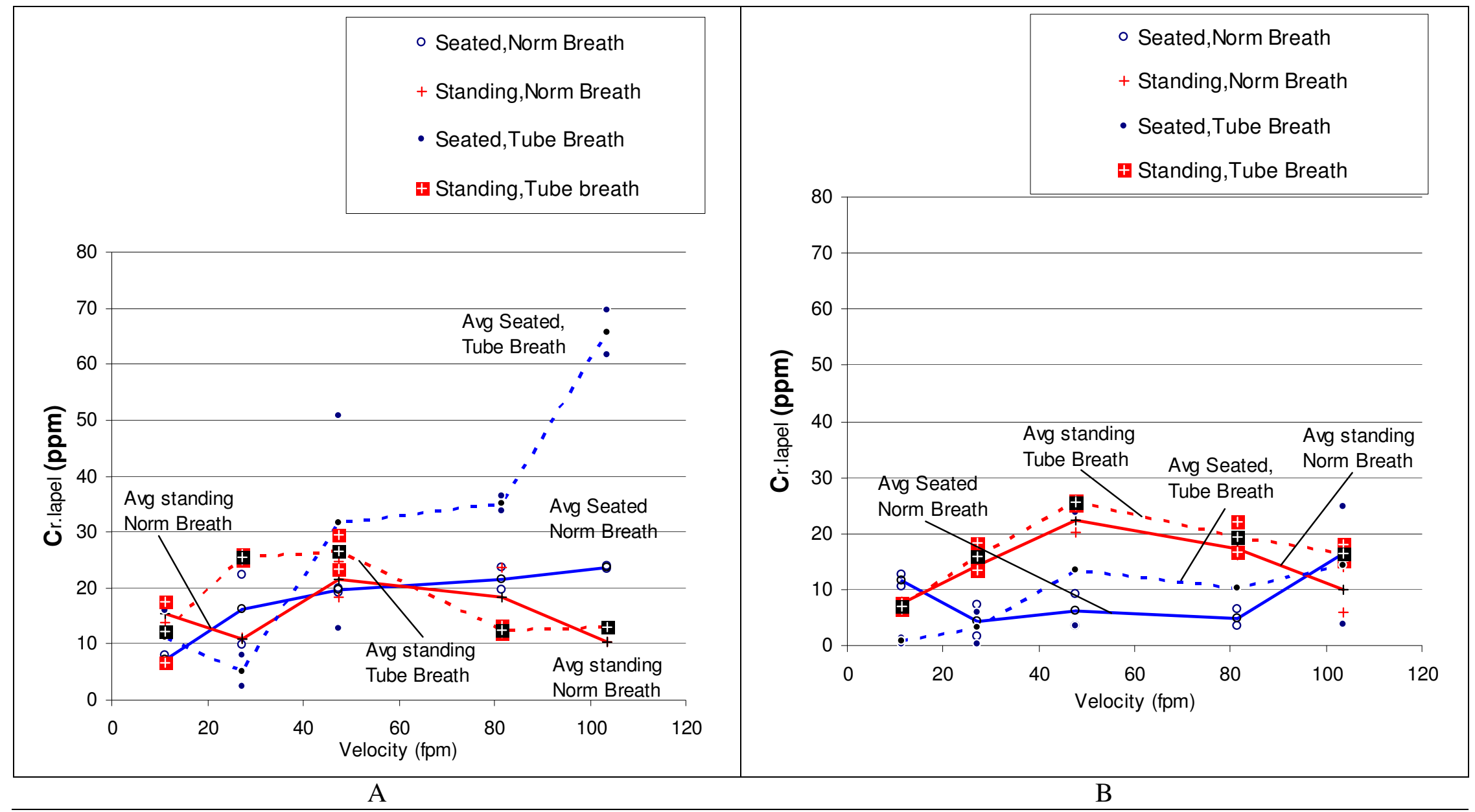




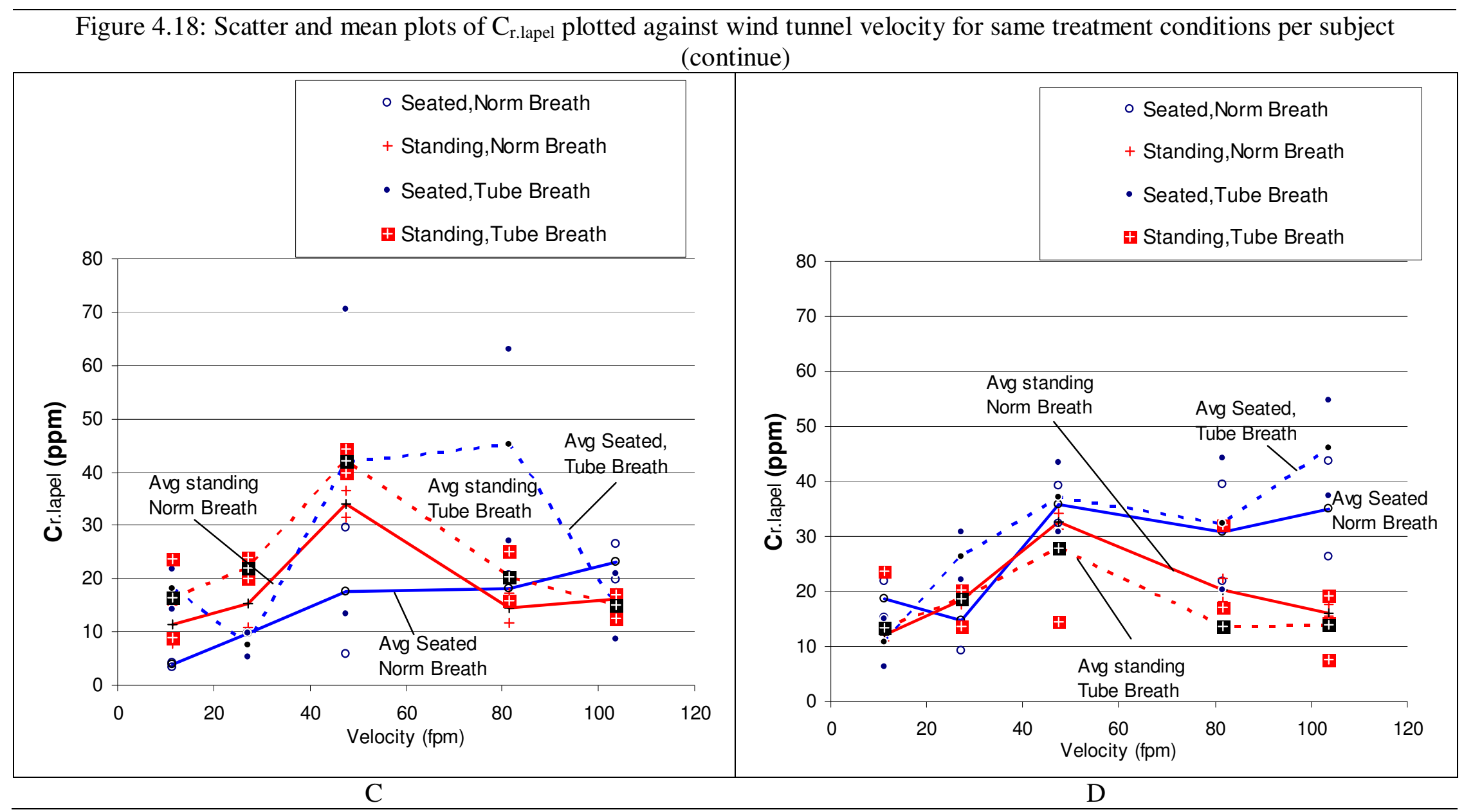




\title{
4.2 Effects of Independent Variables on other Sampling Locations Concentrations $\left(\mathbf{C}_{\text {location }}\right)$
}

\author{
As shown in Table 4.2, values of facial concentrations $\left(\mathrm{C}_{\text {mouth }}, \mathrm{C}_{\text {adj.nose }}\right.$ and \\ $\left.\mathrm{C}_{\text {forehead }}\right)$, neck Level concentrations $\left(\mathrm{C}_{\text {neck }}, \mathrm{C}_{\text {l.collar }}, \mathrm{C}_{\mathrm{r} . \mathrm{collar}}\right)$, and torso concentrations \\ $\left(\mathrm{C}_{\text {c.chest }}, \mathrm{C}_{\text {l.lapel }}, \mathrm{C}_{\text {r.lapel }}\right)$ varied with wind tunnel velocity, subject, posture and breathing. \\ See sampling locations in Figure 4.19. \\ As also shown in Table 4.2, concentrations measured at the forehead and adjacent \\ to the nose were generally about $10 \%$ lower than concentrations measured at the mouth. \\ Concentrations measured at the level of the shoulder were moderately higher (20-54\%) \\ than the mouth, and concentrations measured at the chest were dramatically higher than \\ the mouth. Concentrations at the left and right lapel were higher than the mouth when \\ standing and somewhat lower when sitting.
}

\subsubsection{Effect of Velocity}

As shown in Figure 4.11- Figure

4.18, the effect of velocity on the

concentrations at all other locations were substantially similar to $\mathrm{C}_{\text {mouth }}$. The peak concentration occurred at the same velocity, $\mathrm{V}=47.5 \mathrm{fpm}$. The concentrations at each location varied with velocity in an inverted V relationship (see Figure 4.20 -

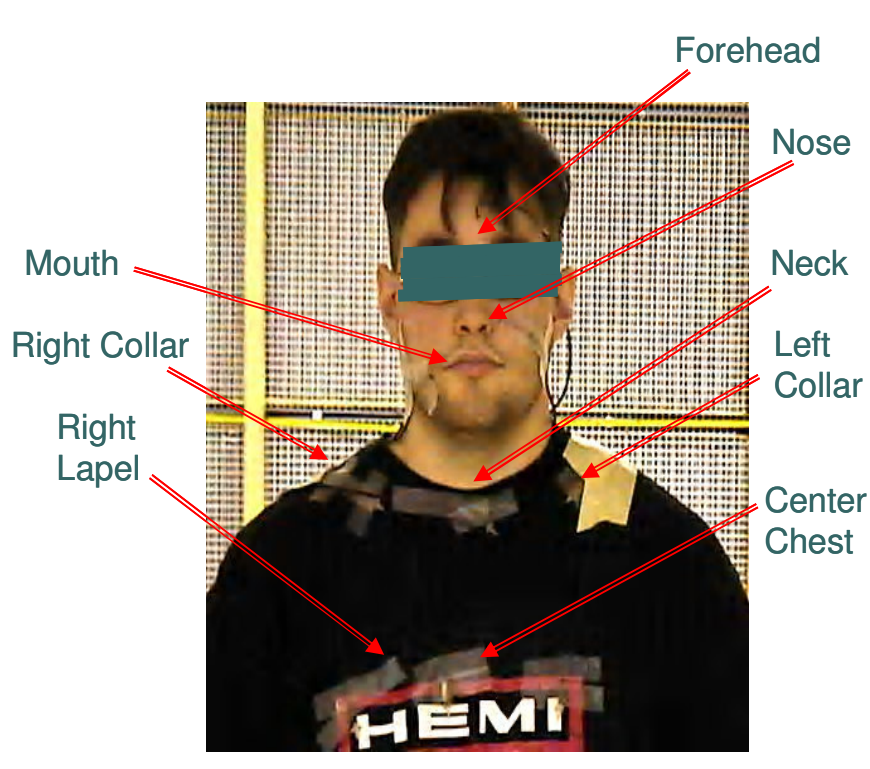

Figure 4.19 Sampling locations 
Figure 4.23) for both postures and breathing conditions as they did for $\mathrm{C}_{\text {mouth }}$.

As shown in Figure 4.20 - Figure 4.23, the concentrations at the higher and lower velocities were symmetrical for standing and were asymmetrical for sitting, just as they were for $\mathrm{C}_{\text {mouth }}$.

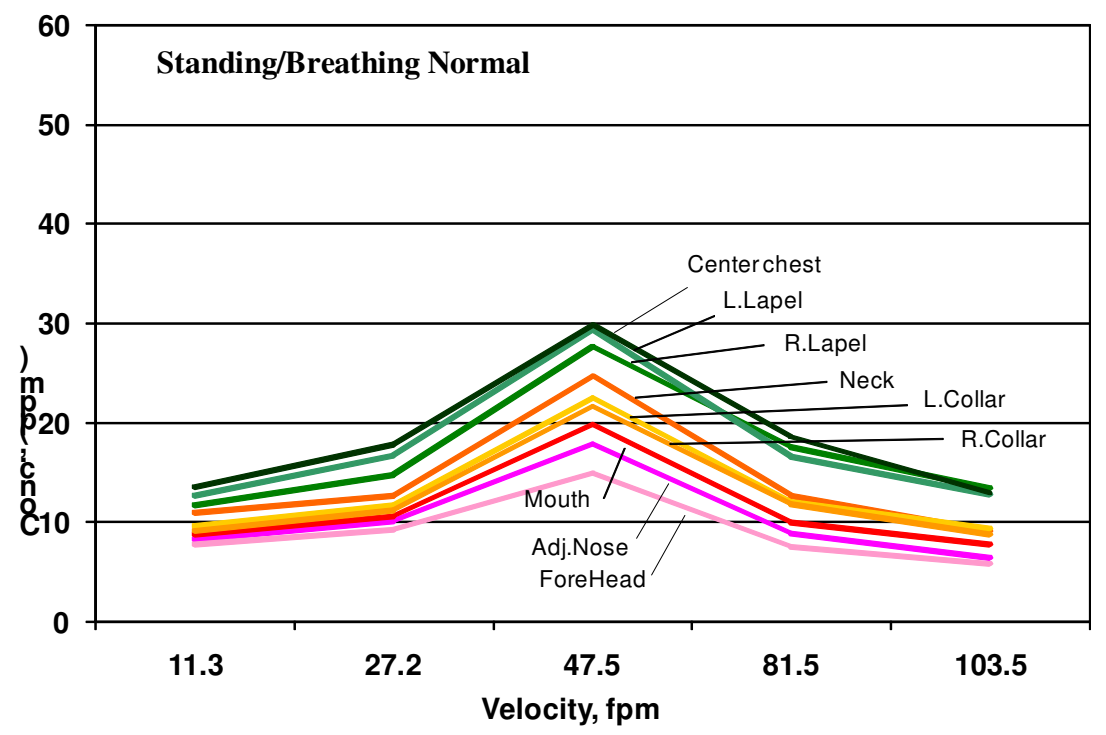

Figure 4.20 Four subjects' $C_{\text {location }}$ average versus velocity for standing \& normal breathing treatments

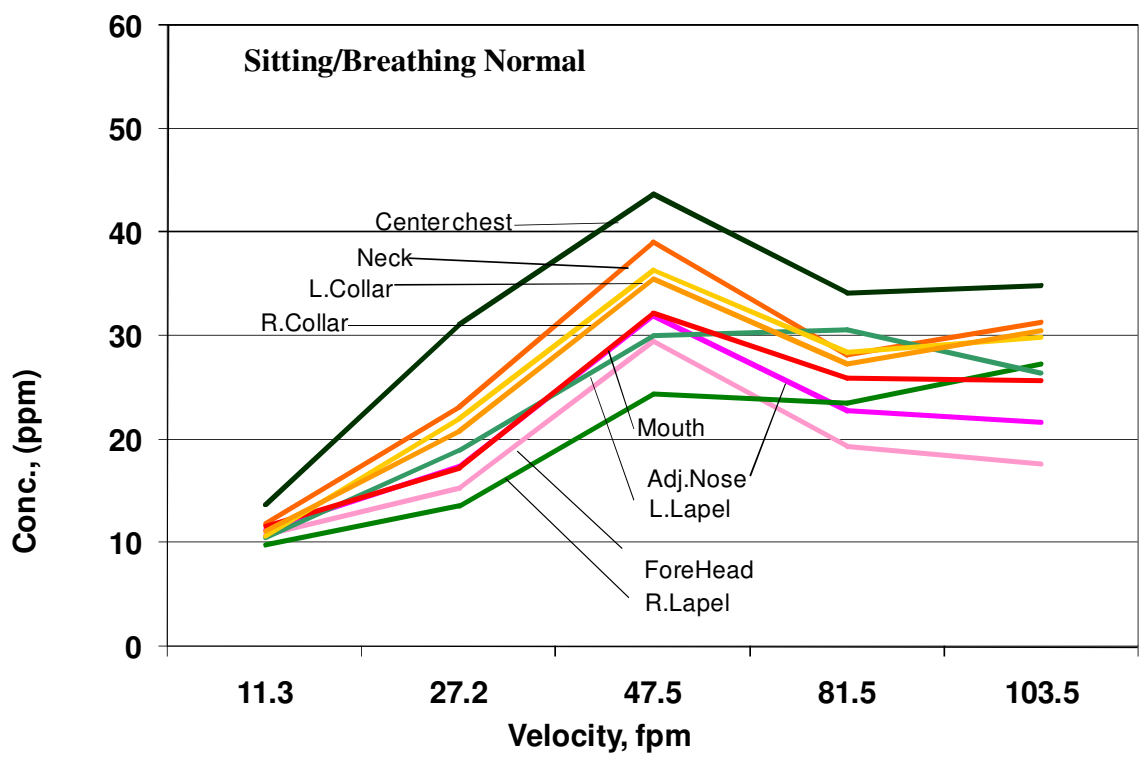

Figure 4.21. Four subjects' $C_{\text {location }}$ average versus velocity for sitting \& normal breathing treatments 


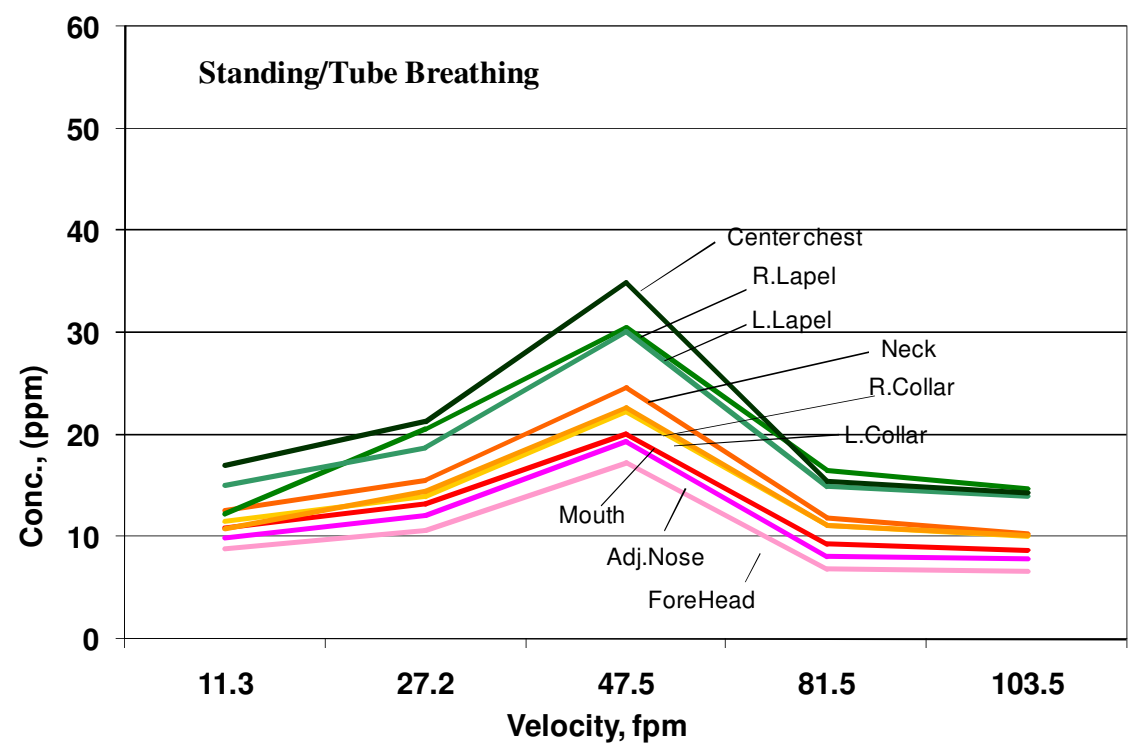

Figure 4.22 Four subjects' $C_{\text {location }}$ average versus velocity for standing $\&$ tube breathing treatments

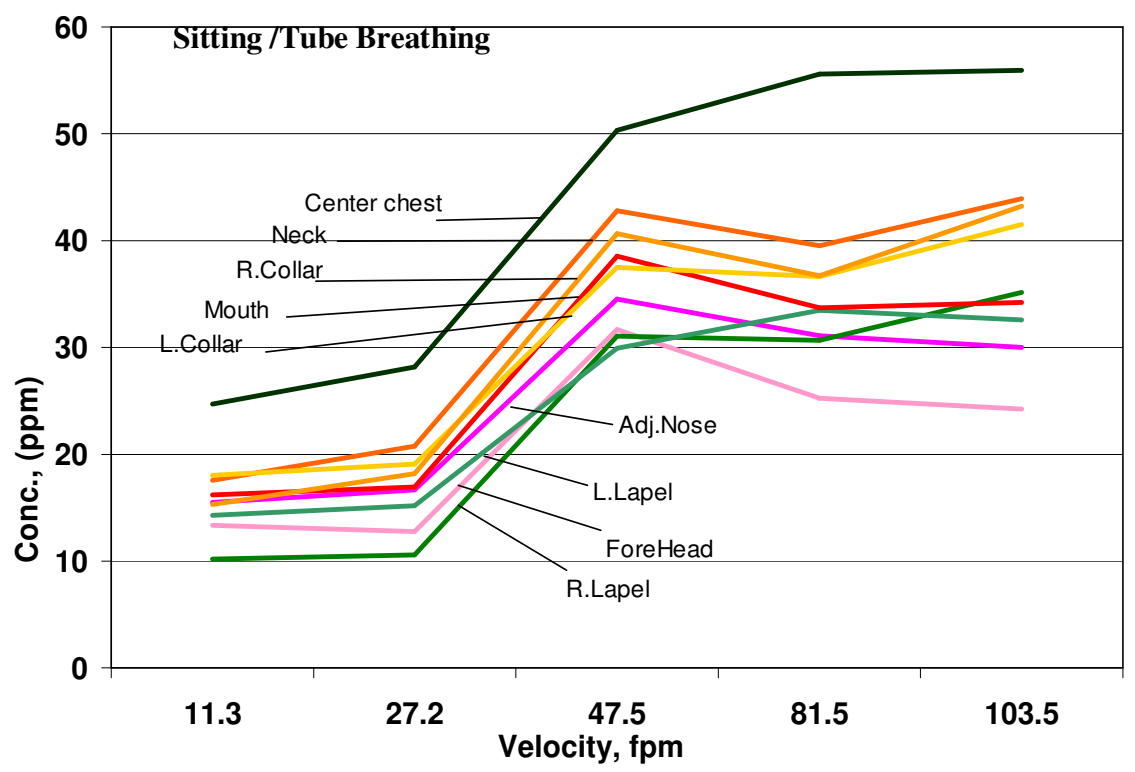

Figure 4.23 Four subjects' $C_{\text {location }}$ average versus velocity for sitting $\&$ tube breathing treatments

The very strong congruence between the concentrations at the mouth to all other locations for each combination of posture and breathing is clearly seen in Figure 4.20Figure 4.23. 


\subsubsection{Subjects}

The average concentrations for the subjects varied. Figure 4.11 - Figure 4.18 display the individual test results for subjects A, B, C, and D for all tested conditions. The results for three of the four subjects appeared to fall into very similar patterns for all conditions but with different magnitudes. Subject B appeared to be similar to the other three subjects for standing conditions but very dissimilar for the sitting conditions, perhaps because subject B was of the slimmest body of all other subjects and had a very apparent scoliosis. This difference for Subject B for sitting occurred for all locations, not just the mouth, and formed no apparent pattern.

Generally, concentrations inferred for sitting posture were almost double the standing posture results along all velocity ranges. As listed in Figure 4.16, Subject A was the highest at $110 \mathrm{ppm}$ and Subject B was the lowest at $5 \mathrm{ppm}$. Subject D was the highest overall but not for all conditions. However, the rank order varied with tested conditions. Concentration peaks varied from one subject to another and for posture treatment conditions.

\subsubsection{Posture}

As shown in Figure 4.21- Figure 4.23, the effects of posture on concentrations at the mouth and on other locations appeared to be substantially similar. The seated results were almost double the standing results at all locations.

\subsubsection{BREATHING}

The effect of breathing depended on posture for concentrations at the mouth. The same was true for all other locations. As at the mouth, concentrations at all other 
locations generally were slightly higher when breathing through a tube than when breathing normally, especially in the sitting posture. The magnitude of the difference at all locations was much greater when sitting than when standing. 

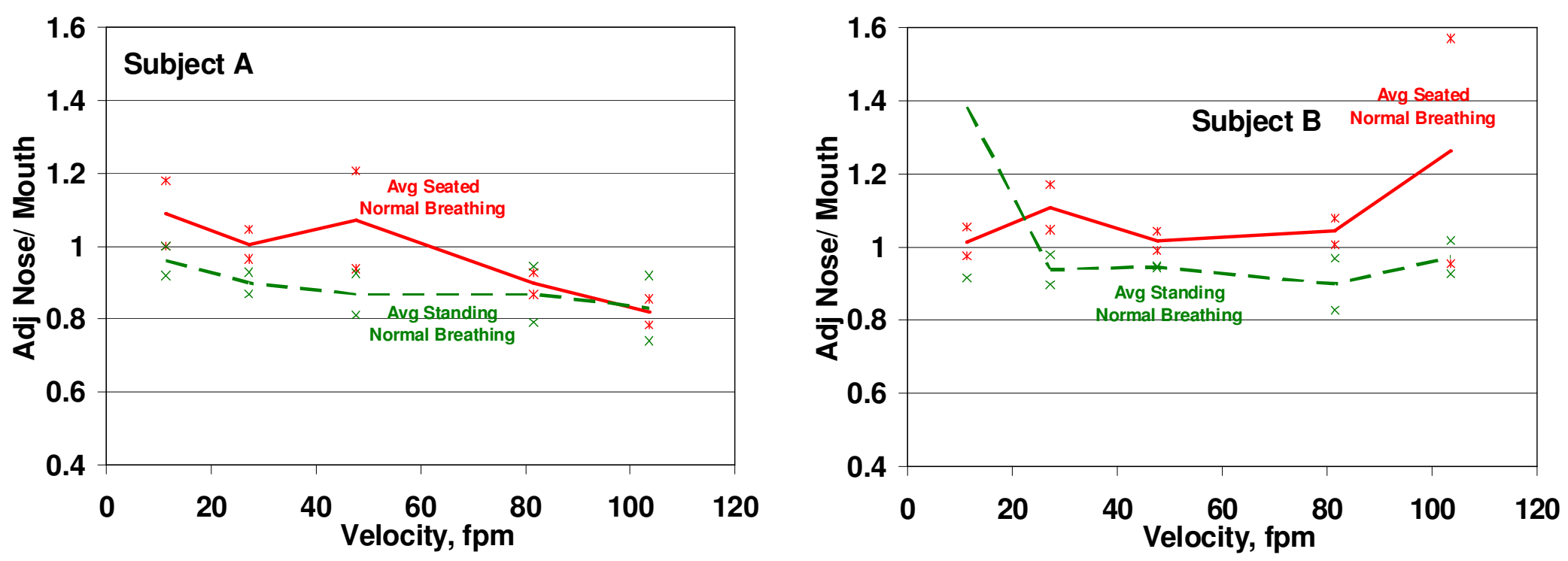

Figure 4.24: Scatter and mean plots of $C_{\text {adj.nose }}$ plotted against wind tunnel velocity for same treatment conditions per subject 

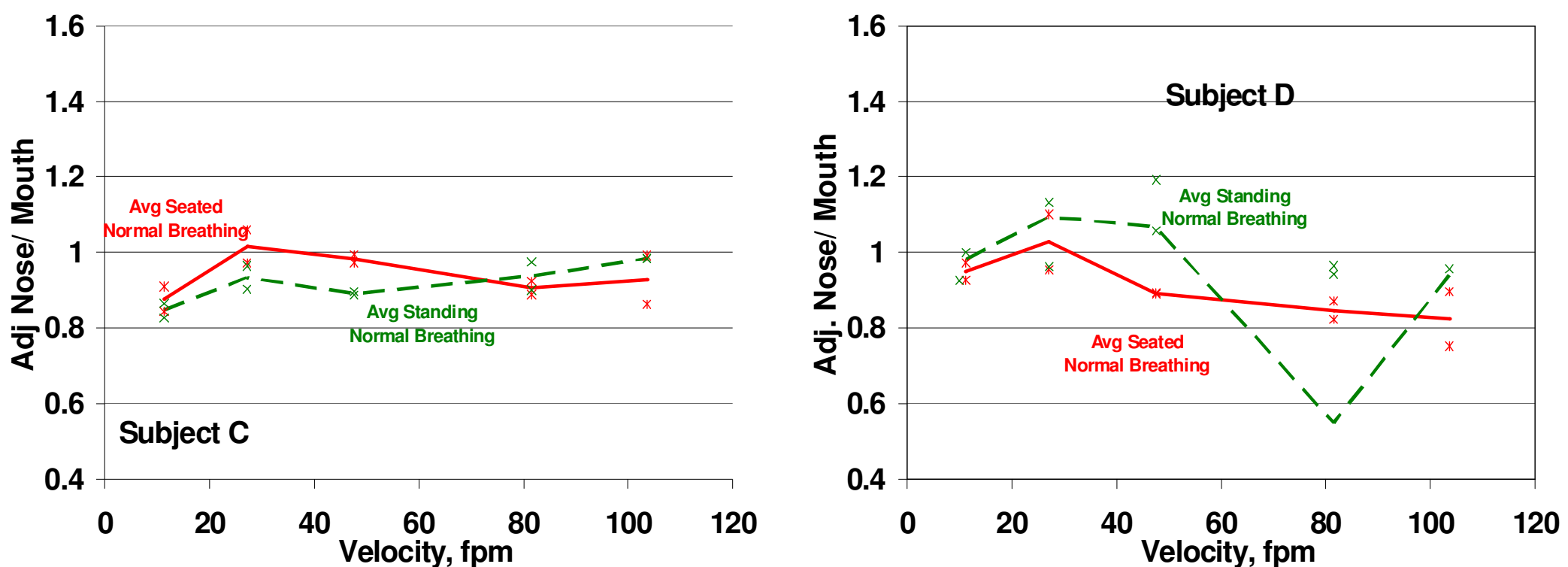

Figure 4.25: Scatter and mean plots of $C_{\text {adj.nose }}$ plotted against wind tunnel velocity for same treatment conditions per subject 

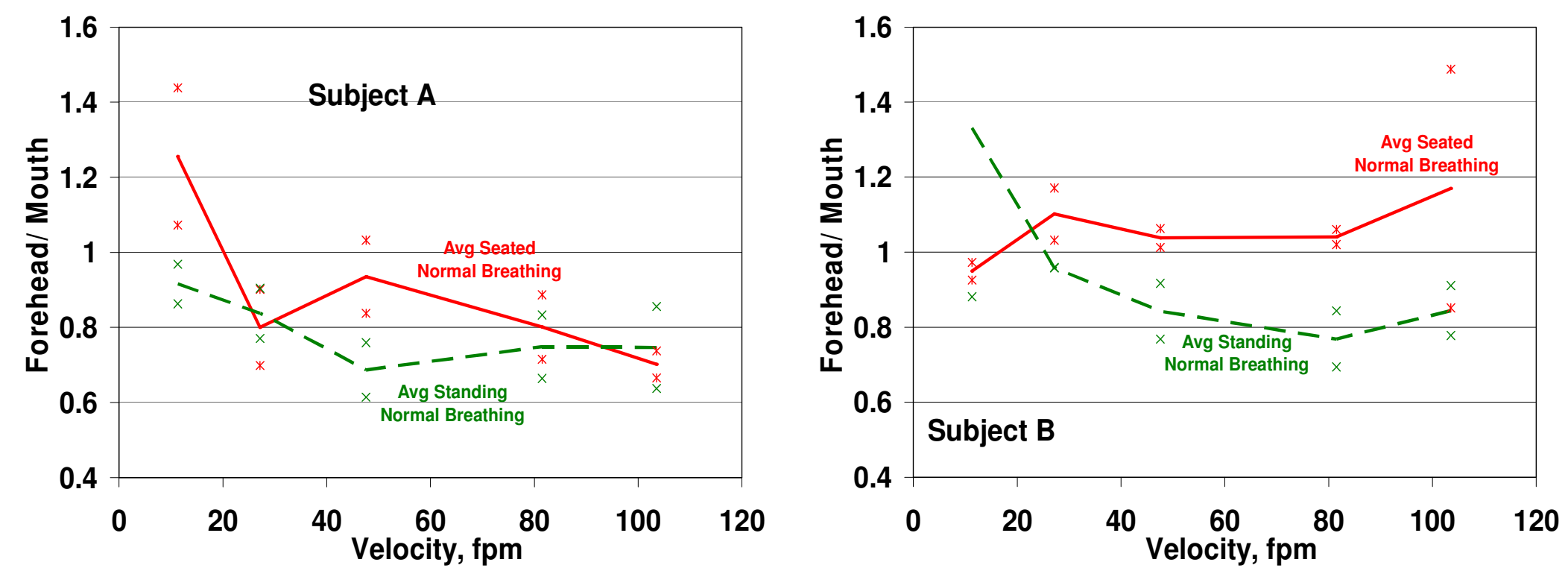

Figure 4.26: Scatter and mean plots of $C_{\text {forehead }}$ plotted against wind tunnel velocity for same treatment conditions per subject 

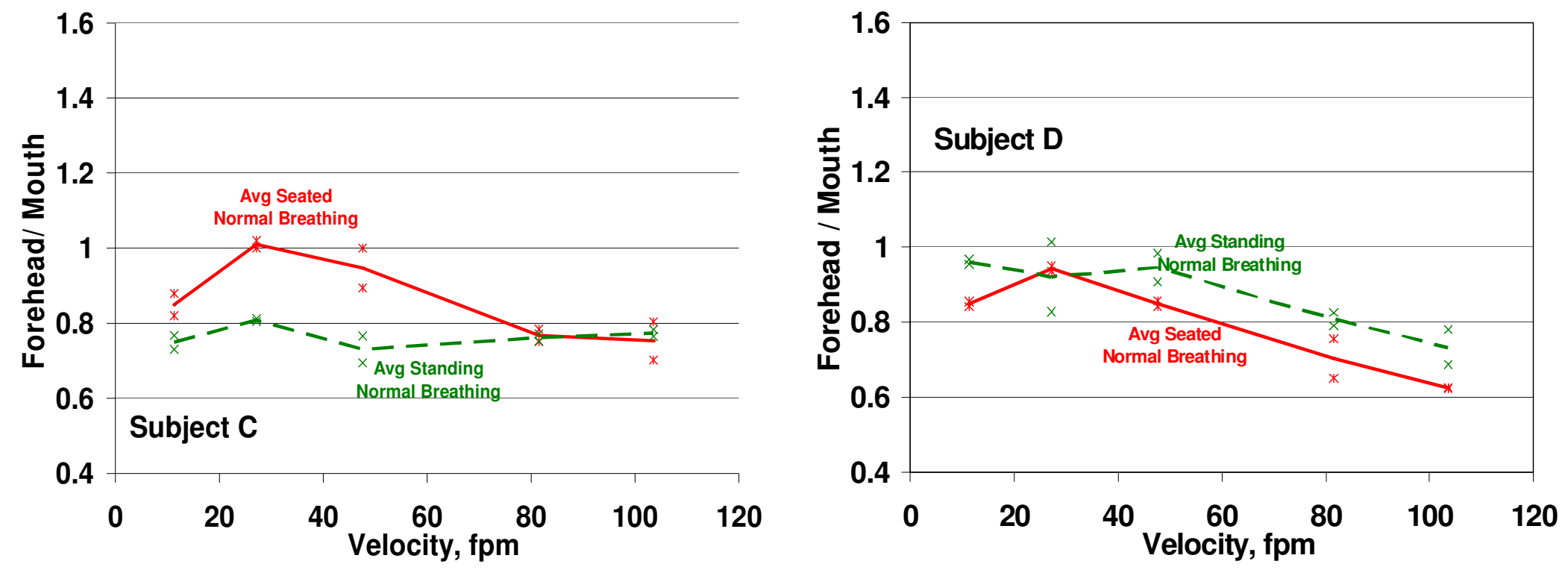

Figure 4.27: Scatter and mean plots of $C_{\text {forehead }}$ plotted against wind tunnel velocity for same treatment conditions per subject 

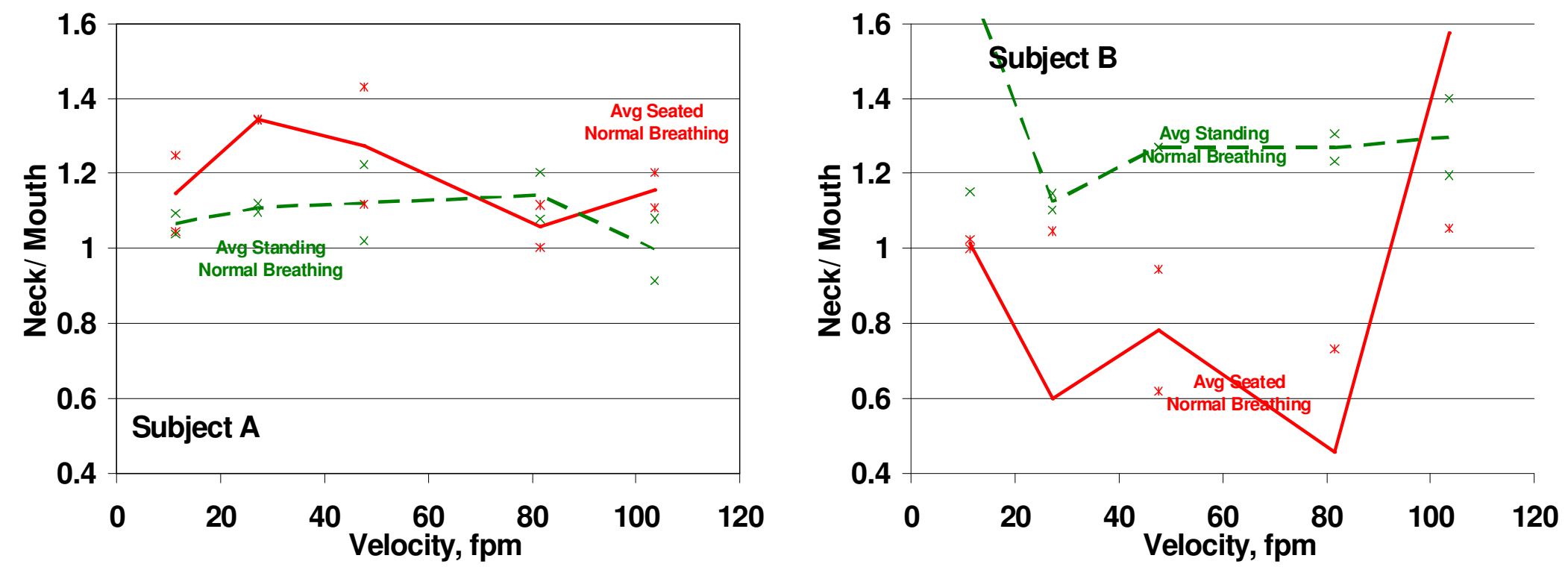

Figure 4.28: Scatter and mean plots of $C_{n e c k}$ plotted against wind tunnel velocity for same treatment conditions per subject 

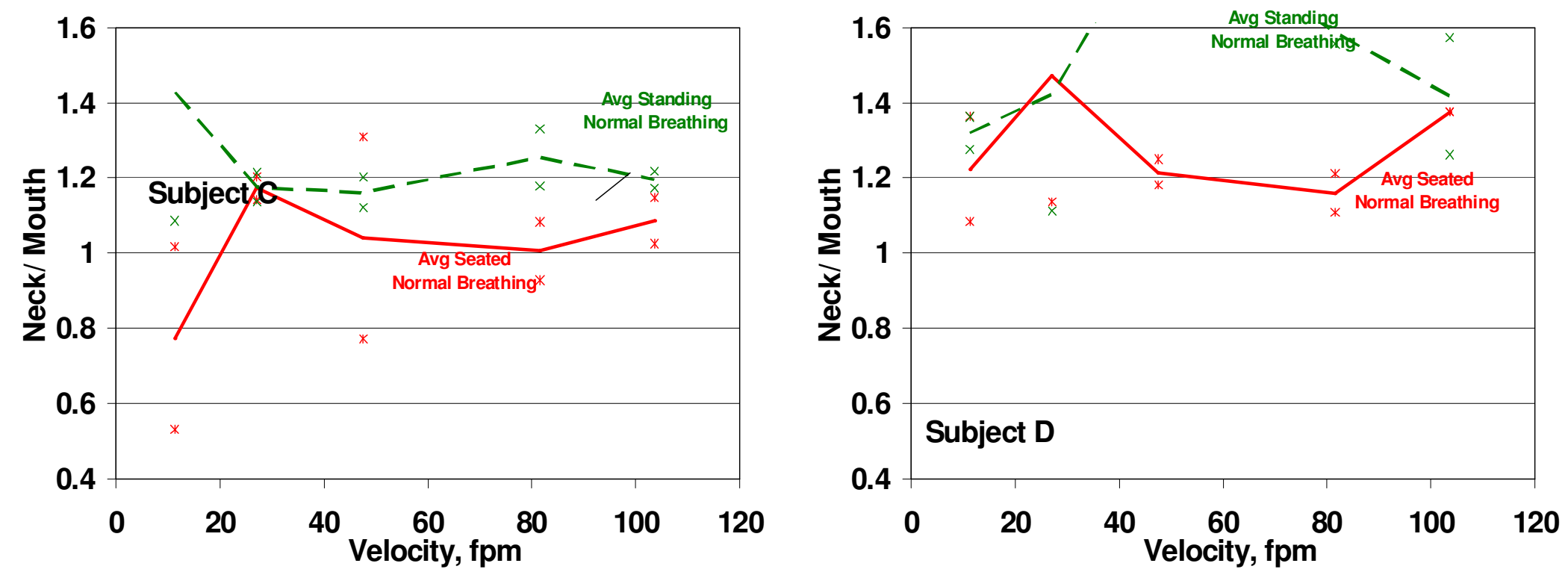

Figure 4.29: Scatter and mean plots of $C_{\text {neck }}$ plotted against wind tunnel velocity for same treatment conditions per subject 

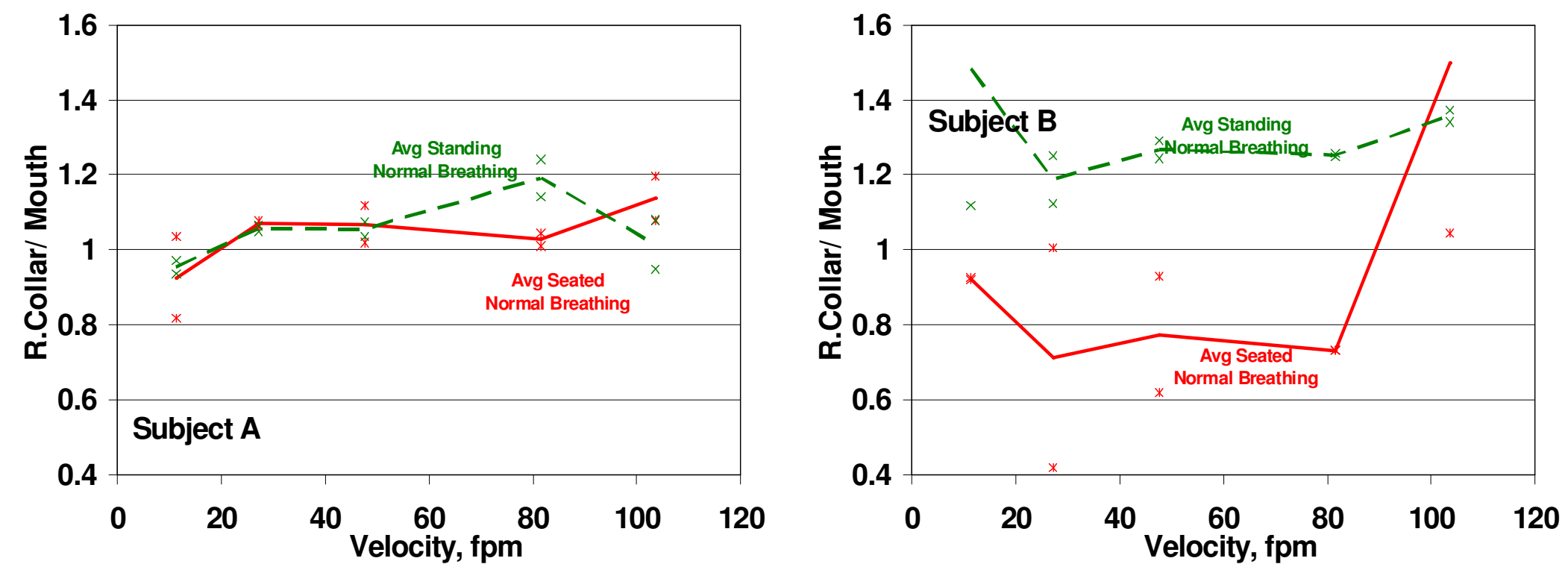

Figure 4.30: Scatter and mean plots of $C_{r . c o l l a r}$ plotted against wind tunnel velocity for same treatment conditions per subject 

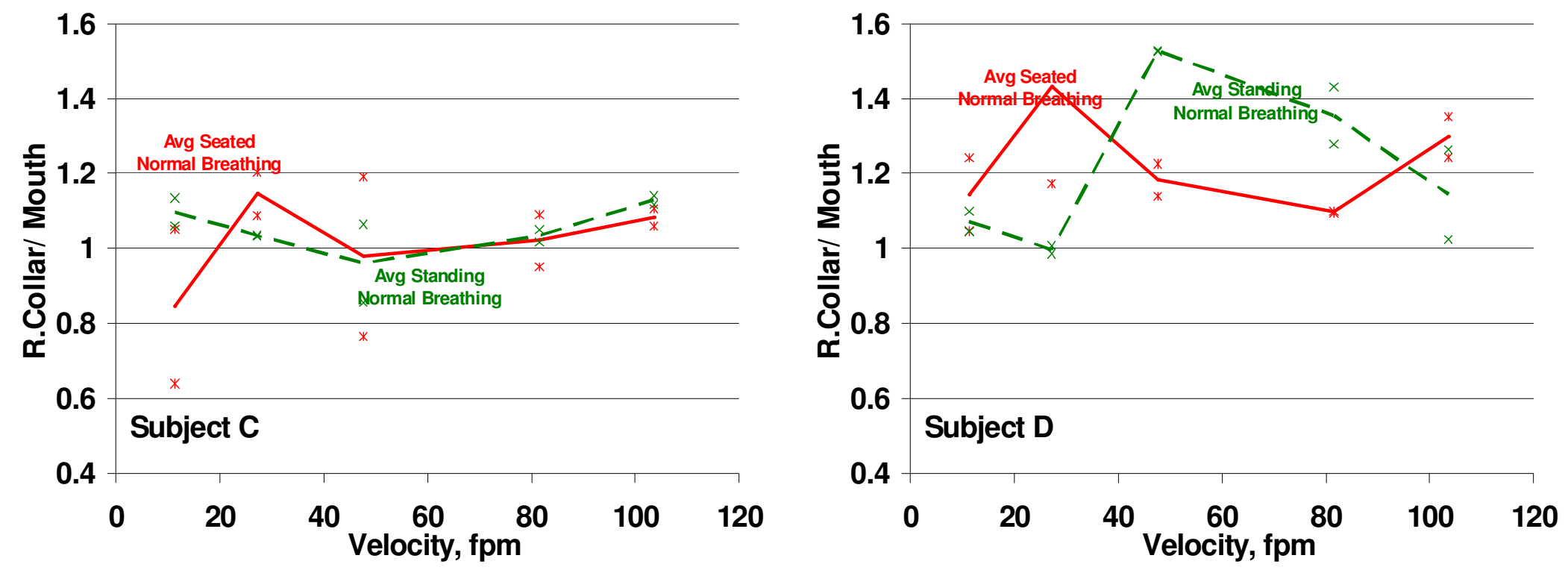

Figure 4.31: Scatter and mean plots of $C_{\text {r.collar }}$ plotted against wind tunnel velocity for same treatment conditions per subject 

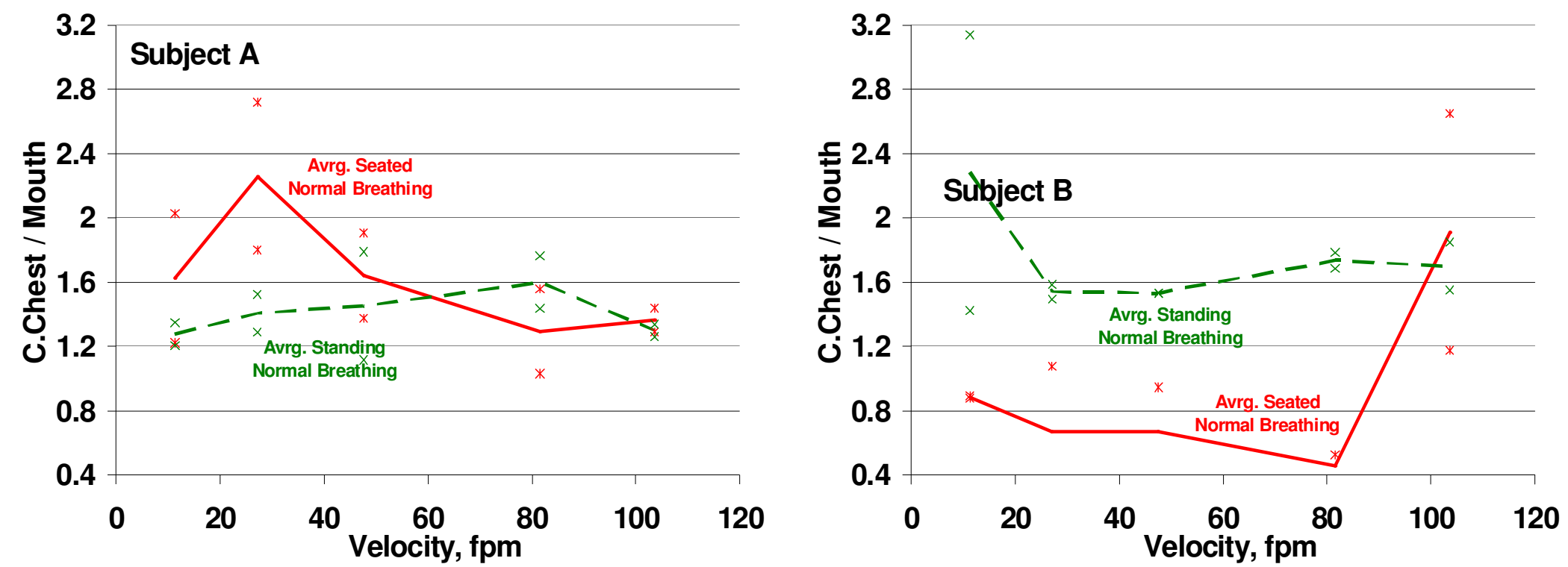

Figure 4.32: Scatter and mean plots of $C_{\text {chest }}$ plotted against wind tunnel velocity for same treatment conditions per subject 

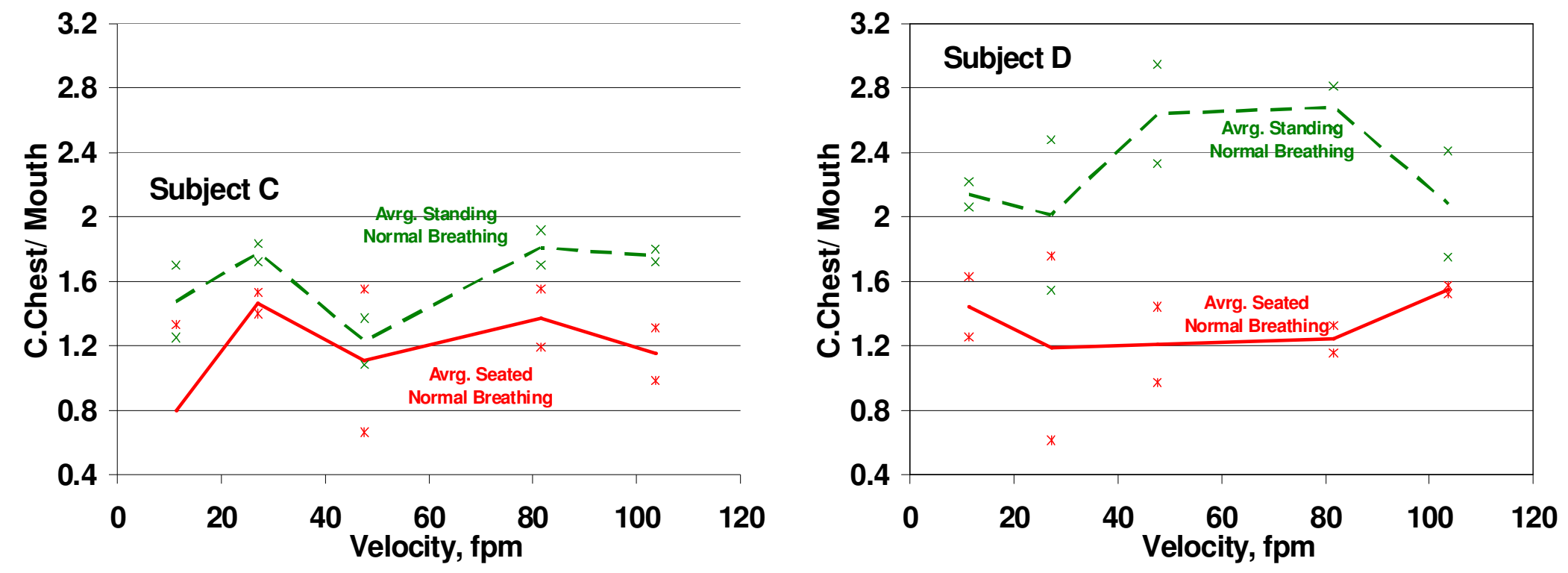

Figure 4.33: Scatter and mean plots of $C_{\text {chest }}$ plotted against wind tunnel velocity for same treatment conditions per subject 

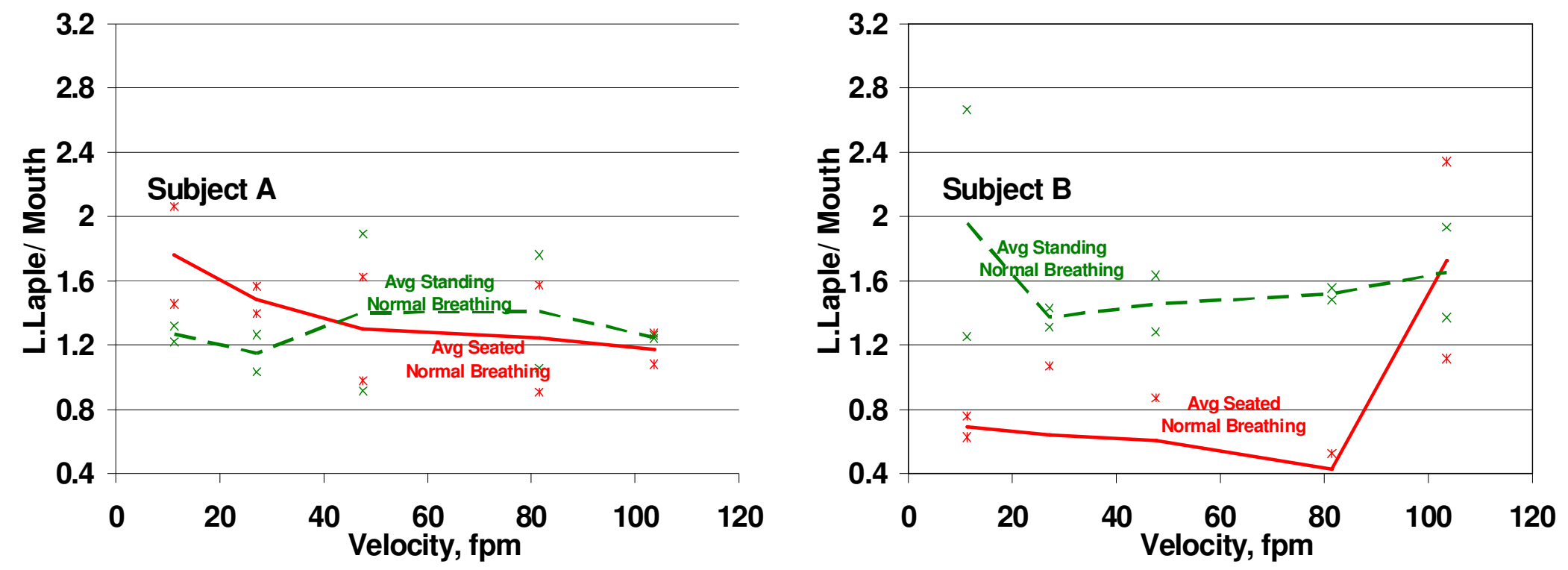

Figure 4.34: Scatter and mean plots of $C_{\text {l.lapel }}$ plotted against wind tunnel velocity for same treatment conditions per subject 

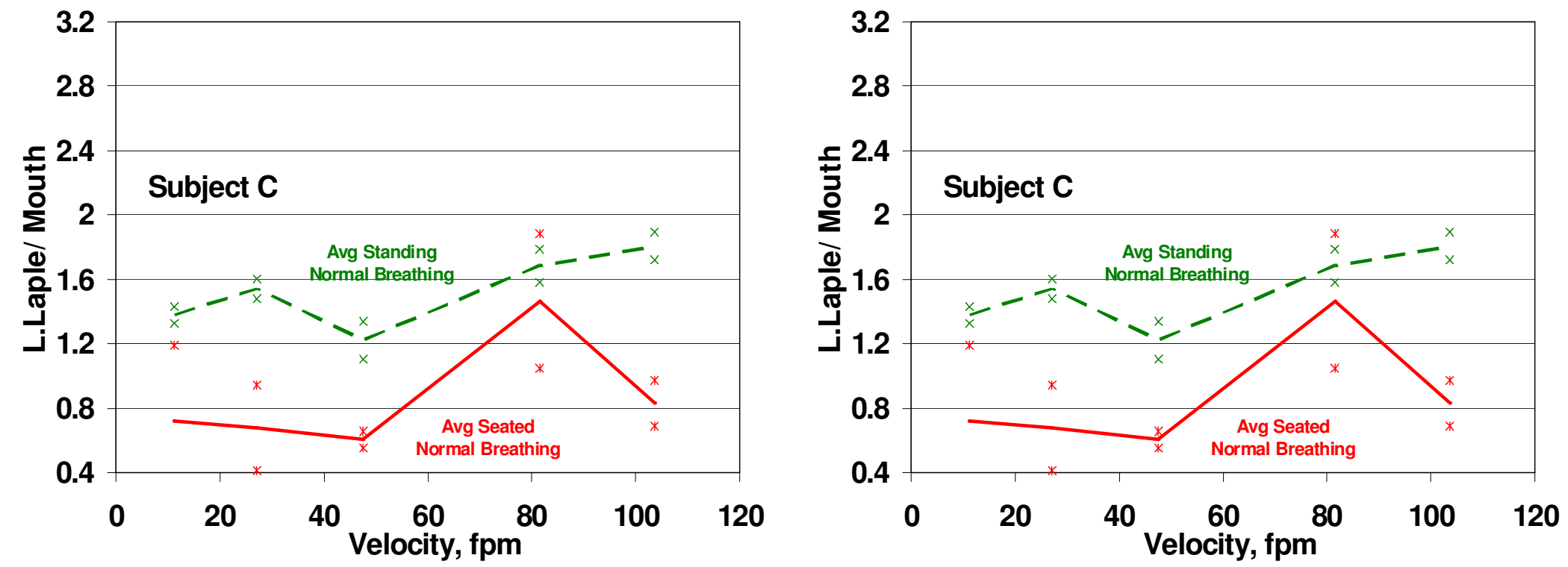

Figure 4.35: Scatter and mean plots of $C_{1 . l a p e l}$ plotted against wind tunnel velocity for same treatment conditions per subject 
Table 4.8: Subjects' concentration of all other locations average ratios to $\mathbf{C}_{\text {mouth }}$

\begin{tabular}{|c|c|c|c|c|c|c|c|c|c|c|c|}
\hline $\begin{array}{l}\frac{d}{0} \\
\frac{d}{0}\end{array}$ & \multicolumn{2}{|c|}{ reatment } & $\cdot \frac{\overrightarrow{0}}{0}$ & $\underset{\mathbb{J}}{\mathbb{J}}$ & \& & & & & & & \\
\hline$A$ & Seated & Tube Breathing & 11.30 & 0.90 & 1.01 & 0.93 & 0.84 & 1.05 & 0.62 & 0.86 & 1.49 \\
\hline$A$ & & & 16 & 0.85 & 1.02 & 21 & 0.89 & 14 & .58 & 03 & 1.48 \\
\hline$A$ & Seated & & 47.55 & 0.87 & .93 & 1.08 & 0.71 & .93 & .77 & .03 & 1.25 \\
\hline$A$ & Seated & Tul & 81.50 & 0.78 & 0.95 & 1.18 & 1.00 & 1.08 & 0.92 & .10 & 1.58 \\
\hline A & Sea & Tuk & 10 & 0.74 & 0.88 & 1.18 & 0.92 & 1.16 & 0.95 & 1.19 & 1.49 \\
\hline $\mathrm{B}$ & Sea & & & .98 & 0.98 & 1.04 & 0.99 & .96 & 0.82 & .96 & 1.19 \\
\hline$B$ & Sea & ng & 27.16 & .95 & 1.02 & .12 & 0.92 & .09 & 0.74 & .06 & 1.38 \\
\hline $\mathrm{B}$ & Sea & $\mathrm{ng}$ & 47.55 & 0.91 & 0.95 & 1.03 & 0.77 & 0.93 & 0.69 & .96 & 1.09 \\
\hline$B$ & Seated & $\mathrm{ng}$ & 81.50 & 0.83 & 0.92 & 0.92 & 0.99 & 0.96 & 0.76 & 0.97 & 1.09 \\
\hline$B$ & Seated & Norr & 103.54 & 0.73 & 0.87 & 1.18 & 1.07 & 1.12 & 1.06 & 1.14 & 1.34 \\
\hline $\mathrm{C}$ & $\overline{\mathrm{ng}}$ & Tube Breathing & 30 & 83 & 92 & 25 & 1.44 & 08 & 1.22 & .00 & 1.61 \\
\hline $\mathrm{C}$ & Standing & $\mathrm{gg}$ & & 82 & 0.93 & .21 & 1.52 & .07 & 1.68 & .09 & 1.73 \\
\hline $\mathrm{C}$ & tanding & & & 0.89 & 1.00 & 1.29 & 1.56 & 1.14 & 1.60 & .18 & 1.80 \\
\hline $\mathrm{C}$ & Star & & & 0.75 & 0.89 & 1.31 & .63 & 21 & 1.80 & .21 & 1.68 \\
\hline $\mathrm{C}$ & Standing & Tube Bre & 103.54 & 0.75 & 0.90 & 1.22 & 1.68 & 1.19 & 1.81 & 1.19 & 1.73 \\
\hline $\mathrm{D}$ & Standing & ing & 30 & 0.89 & 0.95 & 1.26 & 1.51 & 1.11 & 1.40 & .06 & 1.63 \\
\hline $\mathrm{D}$ & Standing & hing & 27.16 & 0.88 & 0.95 & 1.21 & 1.54 & 1.10 & 1.42 & 1.07 & 1.68 \\
\hline $\mathrm{D}$ & Standing & $\mathrm{ng}$ & & 0.76 & 0.91 & 1.28 & 1.57 & 1.19 & 1.50 & 1.14 & 1.60 \\
\hline $\mathrm{D}$ & Standing & Normal Breathing & 81.50 & 0.77 & 0.91 & 1.31 & 1.77 & 1.27 & 1.88 & 1.21 & 1.95 \\
\hline $\mathrm{D}$ & Standing & Normal Breathing & 103.54 & 0.77 & 0.84 & 1.20 & 1.66 & 1.23 & 1.75 & 1.15 & 1.70 \\
\hline
\end{tabular}

Table 4.9: $\mathbf{L o g}$ (concentration of all other location/ $\mathrm{C}_{\text {mouth }}$ )

\begin{tabular}{|c|c|c|c|c|c|c|c|c|c|}
\hline 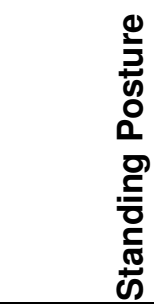 & $\begin{array}{l}\frac{E}{0} \\
\frac{2}{2} \\
\frac{2}{0} \\
\frac{0}{0}\end{array}$ & & 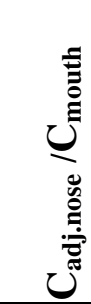 & 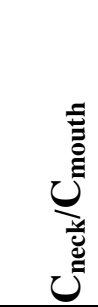 & 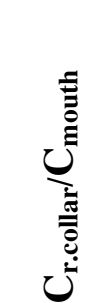 & 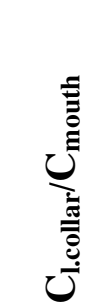 & 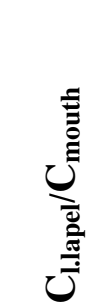 & 离 & 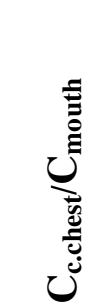 \\
\hline \multirow[t]{5}{*}{ Seated } & 11.3 & 0.97 & 1.04 & 1.03 & 0.94 & 1.06 & 0.96 & 0.73 & 1.45 \\
\hline & 27.2 & 0.91 & 1.03 & 1.18 & 1.06 & 1.13 & 0.91 & 0.67 & 1.44 \\
\hline & 47.5 & 0.91 & 0.96 & 1.08 & 1.01 & 0.95 & 0.77 & 0.74 & 1.20 \\
\hline & 81.5 & 0.82 & 0.96 & 1.08 & 1.07 & 1.05 & 1.02 & 0.87 & 1.38 \\
\hline & 103.5 & 0.77 & 0.92 & 1.24 & 1.22 & 1.20 & 1.06 & 1.05 & 1.49 \\
\hline \multirow[t]{5}{*}{ Standing } & 11.3 & 0.92 & 1.01 & 1.34 & 1.10 & 1.18 & 1.58 & 1.40 & 1.74 \\
\hline & 27.2 & 0.85 & 0.94 & 1.21 & 1.08 & 1.09 & 1.53 & 1.55 & 1.71 \\
\hline & 47.5 & 0.88 & 1.01 & 1.38 & 1.24 & 1.25 & 1.68 & 1.66 & 1.82 \\
\hline & 81.5 & 0.76 & 0.90 & 1.31 & 1.21 & 1.24 & 1.70 & 1.84 & 1.82 \\
\hline & 103.5 & 0.79 & 0.90 & 1.29 & 1.22 & 1.27 & 1.76 & 1.89 & 1.82 \\
\hline
\end{tabular}


Table 4.10: Statistics summary for ratios of concentration of other location to $\mathbf{C}_{\text {mouth }}$

\begin{tabular}{|c|c|c|c|c|c|c|c|c|c|}
\hline & & \multirow[b]{2}{*}{ 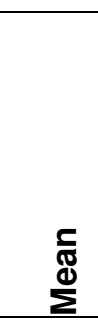 } & \multirow[b]{2}{*}{$\begin{array}{l}\frac{c}{\sigma} \\
\frac{\pi}{\delta} \\
\frac{d}{\Sigma}\end{array}$} & \multirow[b]{2}{*}{ 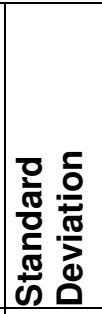 } & \multirow[b]{2}{*}{ 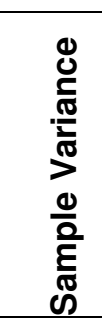 } & \multirow[b]{2}{*}{ 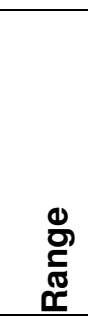 } & \multirow[b]{2}{*}{ 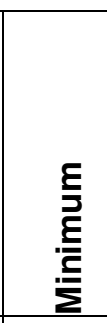 } & \multirow[b]{2}{*}{ 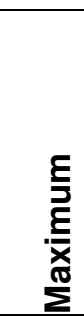 } \\
\hline & & & & & & & & & \\
\hline Seated & Tube Breathing & $\mathrm{C}_{\text {forehead }}$ & 0.83 & 0.85 & 0.07 & 0.00 & 0.16 & 0.74 & 0.90 \\
\hline Seated & Tube Breathing & $C_{\text {nose }}$ & 0.96 & 0.95 & 0.06 & 0.00 & 0.14 & 0.88 & 1.02 \\
\hline Seated & Tube Breathing & $\mathrm{C}_{\text {neck }}$ & 1.12 & 1.18 & 0.12 & 0.01 & 0.29 & 0.93 & 1.21 \\
\hline Seated & Tube Breathing & $\mathrm{C}_{\text {l.lapel }}$ & 0.87 & 0.89 & 0.11 & 0.01 & 0.29 & 0.71 & 1.00 \\
\hline Seated & Tube Breathing & $\mathrm{C}_{\text {r.lapel }}$ & 0.77 & 0.77 & 0.17 & 0.03 & 0.38 & 0.58 & 0.95 \\
\hline Seated & Tube Breathing & $\mathrm{C}_{\text {l.collar }}$ & 1.07 & 1.08 & 0.09 & 0.01 & 0.23 & 0.93 & 1.16 \\
\hline Seated & Tube Breathing & $\mathrm{C}_{\text {r.collar }}$ & 1.04 & 1.03 & 0.12 & 0.02 & 0.33 & 0.86 & 1.19 \\
\hline Seated & Tube Breathing & $\mathrm{C}_{\text {c.chest }}$ & 1.46 & 1.49 & 0.12 & 0.01 & 0.33 & 1.25 & 1.58 \\
\hline Seated & Normal Breathing & $\mathrm{C}_{\text {forehead }}$ & 0.88 & 0.91 & 0.10 & 0.01 & 0.25 & 0.73 & 0.98 \\
\hline Seated & Normal Breathing & Cnose & 0.95 & 0.95 & 0.06 & 0.00 & 0.15 & 0.87 & 1.02 \\
\hline Seated & Normal Breathing & $\mathrm{C}_{\text {neck }}$ & 1.06 & 1.04 & 0.10 & 0.01 & 0.26 & 0.92 & 1.18 \\
\hline Seated & Normal Breathing & $\mathrm{C}_{\text {l.lapel }}$ & 0.95 & 0.99 & 0.11 & 0.01 & 0.30 & 0.77 & 1.07 \\
\hline Seated & Normal Breathing & $\mathrm{C}_{\text {r.lapel }}$ & 0.81 & 0.76 & 0.14 & 0.02 & 0.37 & 0.69 & 1.06 \\
\hline Seated & Normal Breathing & $\mathrm{C}_{\text {l.collar }}$ & 1.01 & 0.96 & 0.09 & 0.01 & 0.20 & 0.93 & 1.12 \\
\hline Seated & Normal Breathing & $\mathrm{C}_{\text {r.collar }}$ & 1.02 & 0.97 & 0.08 & 0.01 & 0.19 & 0.96 & 1.14 \\
\hline Seated & Normal Breathing & $\mathrm{C}_{\text {c.chest }}$ & 1.22 & 1.19 & 0.14 & 0.02 & 0.30 & 1.09 & 1.38 \\
\hline Standing & Tube Breathing & $\mathrm{C}_{\text {forehead }}$ & 0.81 & 0.82 & 0.06 & 0.00 & 0.15 & 0.75 & 0.89 \\
\hline Standing & Tube Breathing & Cnose & 0.93 & 0.92 & 0.04 & 0.00 & 0.11 & 0.89 & 1.00 \\
\hline Standing & Tube Breathing & $\mathrm{C}_{\text {neck }}$ & 1.26 & 1.25 & 0.04 & 0.00 & 0.10 & 1.21 & 1.31 \\
\hline Standing & Tube Breathing & $\mathrm{C}_{\text {l.lapel }}$ & 1.57 & 1.56 & 0.09 & 0.01 & 0.24 & 1.44 & 1.68 \\
\hline Standing & Tube Breathing & $\mathrm{C}_{\text {r.lapel }}$ & 1.62 & 1.68 & 0.24 & 0.06 & 0.59 & 1.22 & 1.81 \\
\hline Standing & Tube Breathing & $\mathrm{C}_{\text {l.collar }}$ & 1.14 & 1.14 & 0.06 & 0.00 & 0.14 & 1.07 & 1.21 \\
\hline Standing & Tube Breathing & $\mathrm{C}_{\text {r.collar }}$ & 1.13 & 1.18 & 0.09 & 0.01 & 0.21 & 1.00 & 1.21 \\
\hline Standing & Normal Breathing & $\mathrm{C}_{\text {c.chest }}$ & 1.71 & 1.73 & 0.07 & 0.01 & 0.20 & 1.61 & 1.80 \\
\hline Standing & Normal Breathing & $\mathrm{C}_{\text {forehead }}$ & 0.81 & 0.77 & 0.07 & 0.00 & 0.13 & 0.76 & 0.89 \\
\hline Standing & Normal Breathing & Cnose & 0.91 & 0.91 & 0.05 & 0.00 & 0.12 & 0.84 & 0.95 \\
\hline Standing & Normal Breathing & $\mathrm{C}_{\text {neck }}$ & 1.25 & 1.26 & 0.05 & 0.00 & 0.11 & 1.20 & 1.31 \\
\hline Standing & Normal Breathing & $\mathrm{C}_{\text {l.lapel }}$ & 1.61 & 1.57 & 0.11 & 0.01 & 0.26 & 1.51 & 1.77 \\
\hline Standing & Normal Breathing & $\mathrm{C}_{\text {r.lapel }}$ & 1.59 & 1.50 & 0.21 & 0.05 & 0.49 & 1.40 & 1.88 \\
\hline Standing & Normal Breathing & $\mathrm{C}_{\text {l.collar }}$ & 1.18 & 1.19 & 0.07 & 0.01 & 0.17 & 1.10 & 1.27 \\
\hline Standing & Normal Breathing & $\mathrm{C}_{\text {r.collar }}$ & 1.12 & 1.14 & 0.06 & 0.00 & 0.15 & 1.06 & 1.21 \\
\hline Standing & Normal Breathing & $\mathrm{C}_{\text {c.chest }}$ & 1.71 & 1.68 & 0.14 & 0.02 & 0.35 & 1.60 & 1.95 \\
\hline
\end{tabular}


Table 4.11: Statistics summary for Table 4.9

\begin{tabular}{|c|c|c|c|c|c|c|c|c|}
\hline Seated Ratios & 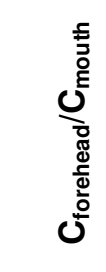 & 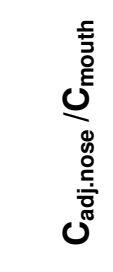 & 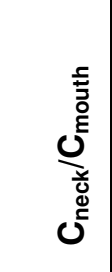 & 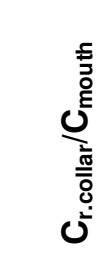 & 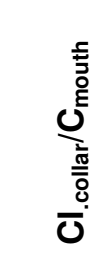 & 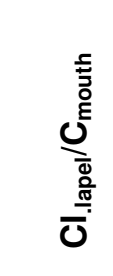 & 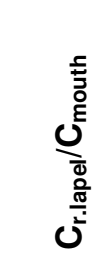 & 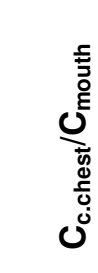 \\
\hline Mean & 0.88 & 0.98 & 1.12 & 1.06 & 1.08 & 0.94 & 0.81 & 1.39 \\
\hline Standard Error & 0.04 & 0.02 & 0.04 & 0.05 & 0.04 & 0.05 & 0.07 & 0.05 \\
\hline Median & 0.91 & 0.96 & 1.08 & 1.06 & 1.06 & 0.96 & 0.74 & 1.44 \\
\hline Standard Deviation & 0.08 & 0.05 & 0.09 & 0.10 & 0.09 & 0.12 & 0.15 & 0.11 \\
\hline Sample Variance & 0.01 & 0.00 & 0.01 & 0.01 & 0.01 & 0.01 & 0.02 & 0.01 \\
\hline Range & 0.20 & 0.12 & 0.21 & 0.28 & 0.24 & 0.29 & 0.38 & 0.29 \\
\hline Minimum & 0.77 & 0.92 & 1.03 & 0.94 & 0.95 & 0.77 & 0.67 & 1.20 \\
\hline Maximum & 0.97 & 1.04 & 1.24 & 1.22 & 1.20 & 1.06 & 1.05 & 1.49 \\
\hline Standing Ratio & 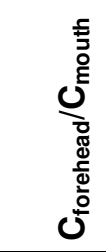 & 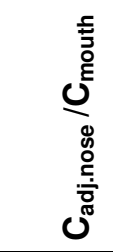 & 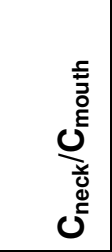 & 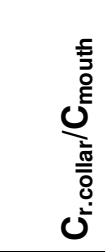 & 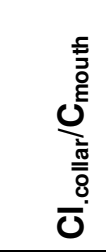 & 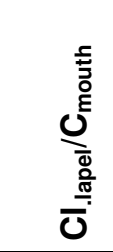 & 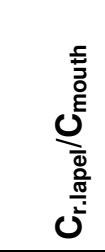 & 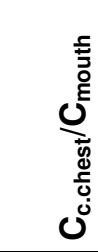 \\
\hline Mean & 0.84 & 0.95 & 1.30 & 1.17 & 1.21 & 1.65 & 1.67 & 1.78 \\
\hline Standard Error & 0.03 & 0.02 & 0.03 & 0.03 & 0.03 & 0.04 & 0.09 & 0.02 \\
\hline Median & 0.85 & 0.94 & 1.31 & 1.21 & 1.24 & 1.68 & 1.66 & 1.82 \\
\hline Standard Deviation & 0.07 & 0.05 & 0.06 & 0.07 & 0.07 & 0.09 & 0.20 & 0.06 \\
\hline Sample Variance & 0.00 & 0.00 & 0.00 & 0.01 & 0.01 & 0.01 & 0.04 & 0.00 \\
\hline Range & 0.16 & 0.11 & 0.17 & 0.16 & 0.18 & 0.23 & 0.49 & 0.12 \\
\hline Minimum & 0.76 & 0.90 & 1.21 & 1.08 & 1.09 & 1.53 & 1.40 & 1.71 \\
\hline Maximum & 0.92 & 1.01 & 1.38 & 1.24 & 1.27 & 1.76 & 1.89 & 1.82 \\
\hline
\end{tabular}




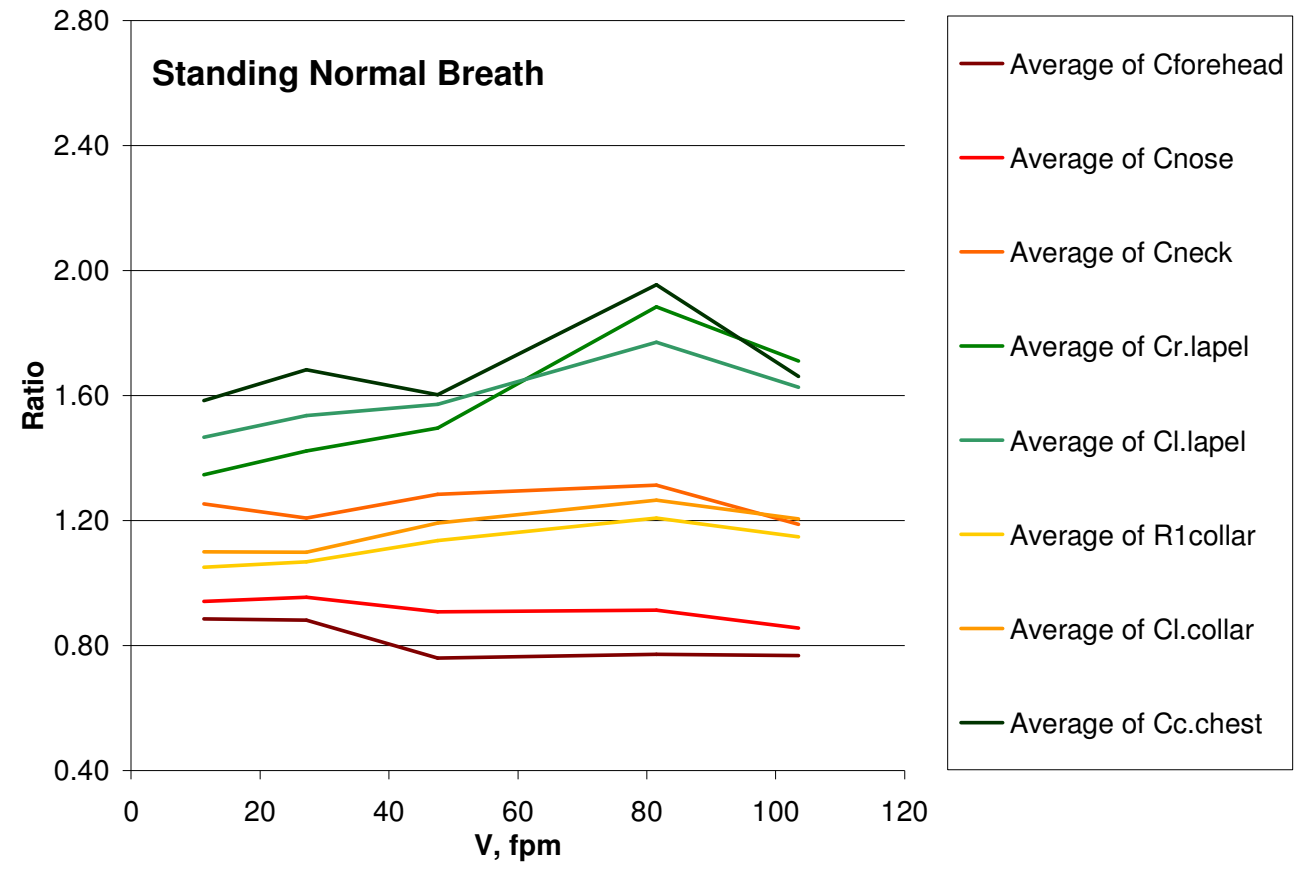

Figure 4.36: Mean plots of all subjects for $C_{\text {location }}$ ratio to $C_{\text {mouth }}$ plotted against wind tunnel velocity for standing $\&$ normal breathing treatment conditions

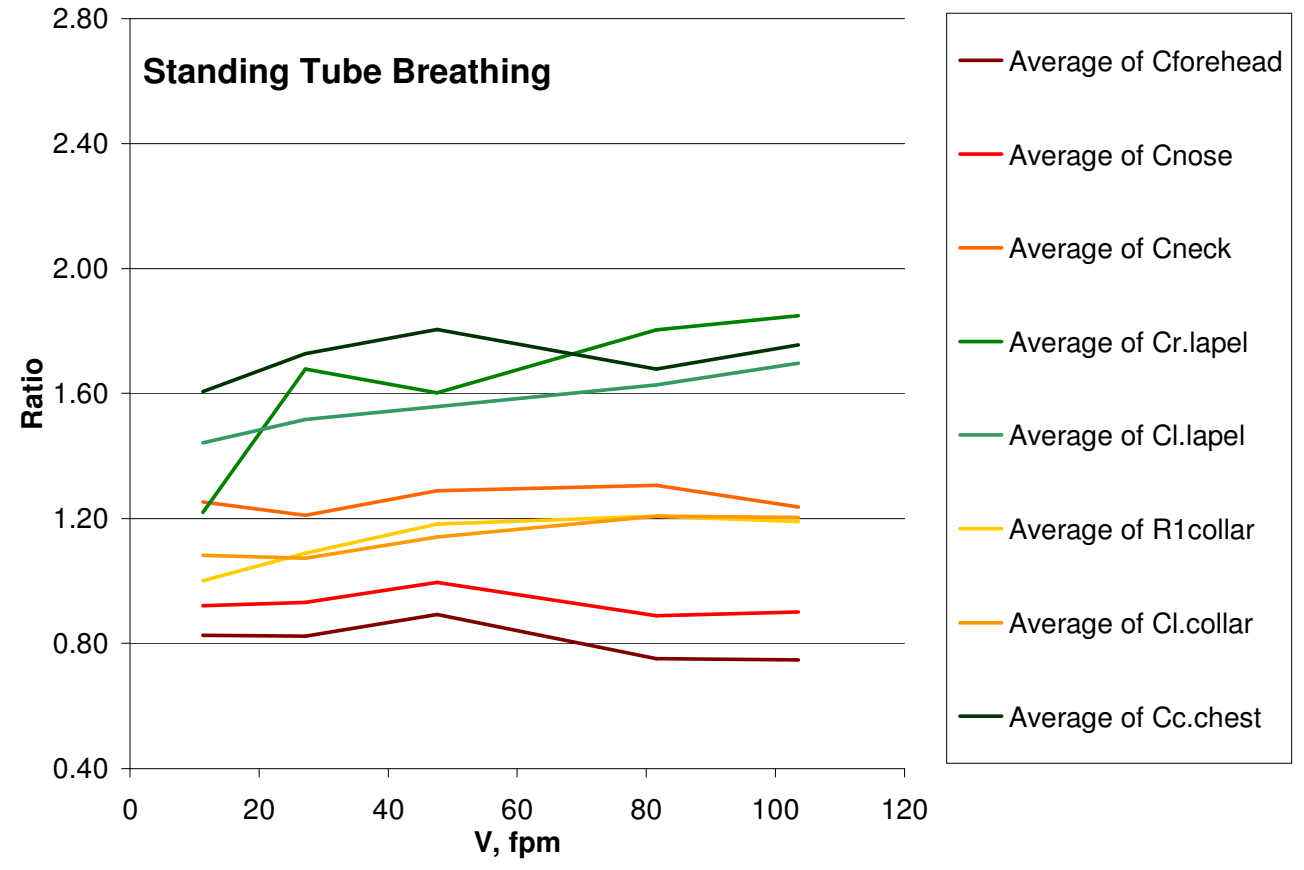

Figure 4.37: Mean plots of all subjects for $C_{\text {location }}$ ratio to $C_{\text {mouth }}$ plotted against wind tunnel velocity for standing $\&$ tube breathing treatment conditions 


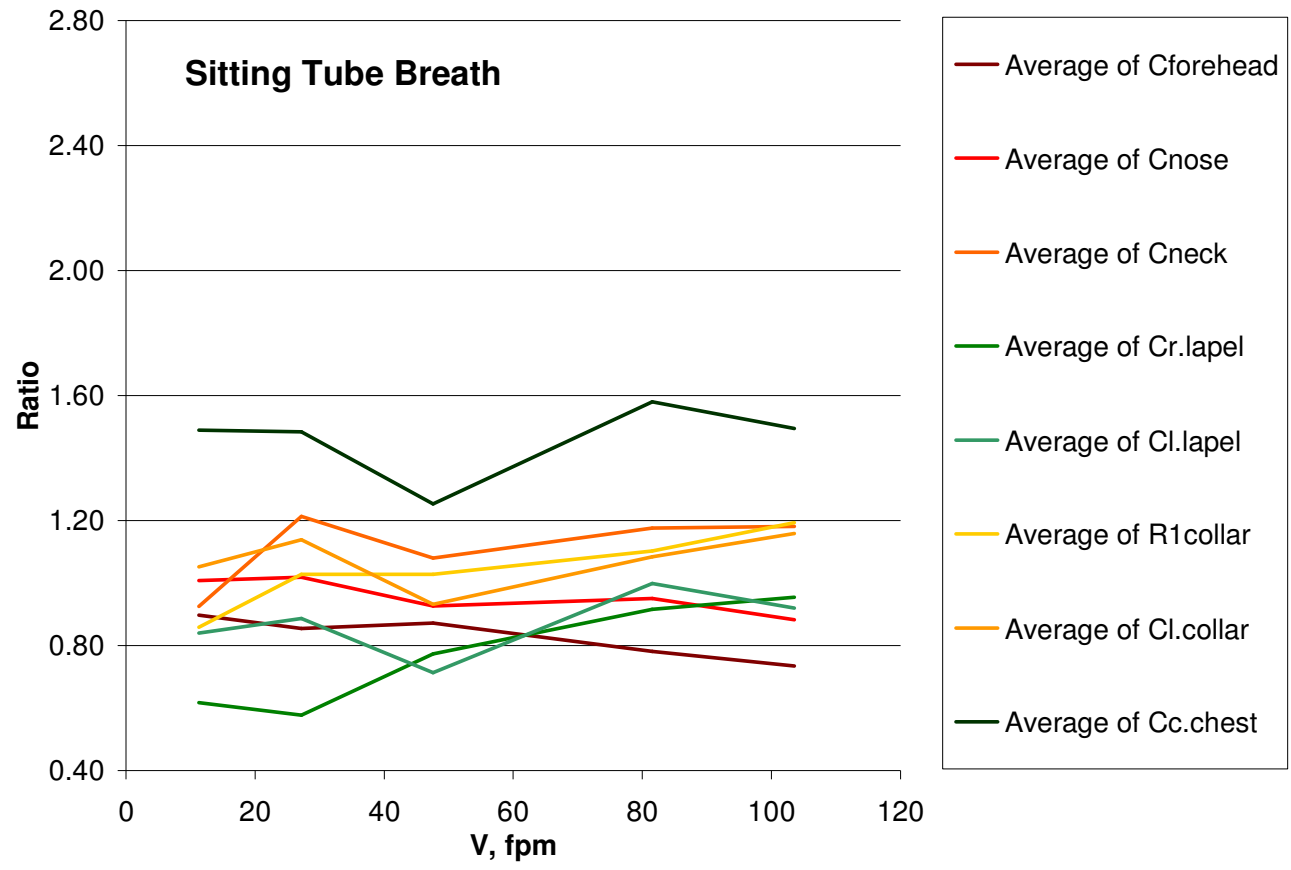

Figure 4.38: Mean plots of all subjects for $C_{\text {location }}$ ratio to $C_{\text {mouth }}$ plotted against wind tunnel velocity for sitting $\&$ tube breathing treatment conditions
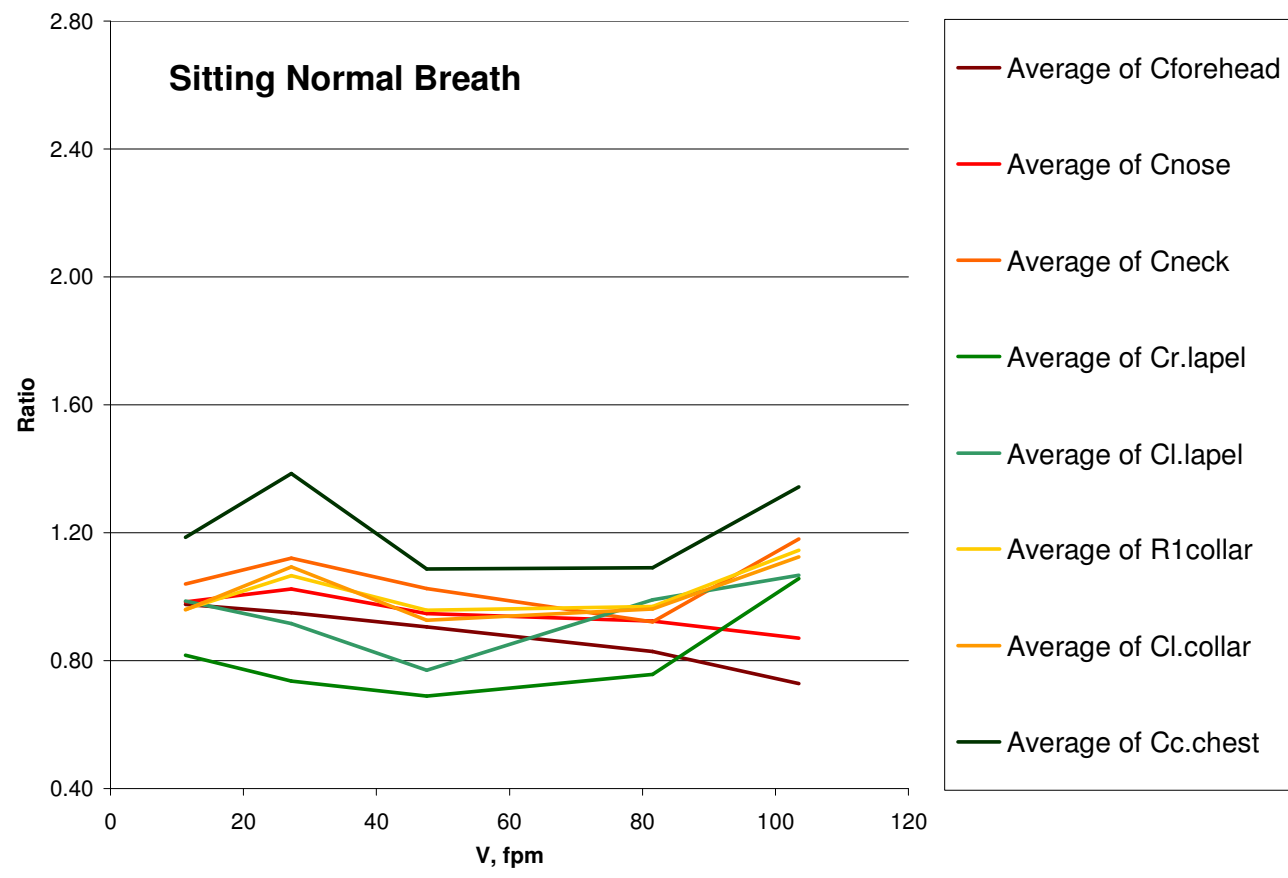

Figure 4.39: Mean plots of all subjects for $C_{\text {location }}$ ratio to $C_{\text {mouth }}$ plotted against wind tunnel velocity for standing \& normal breathing treatment conditions 


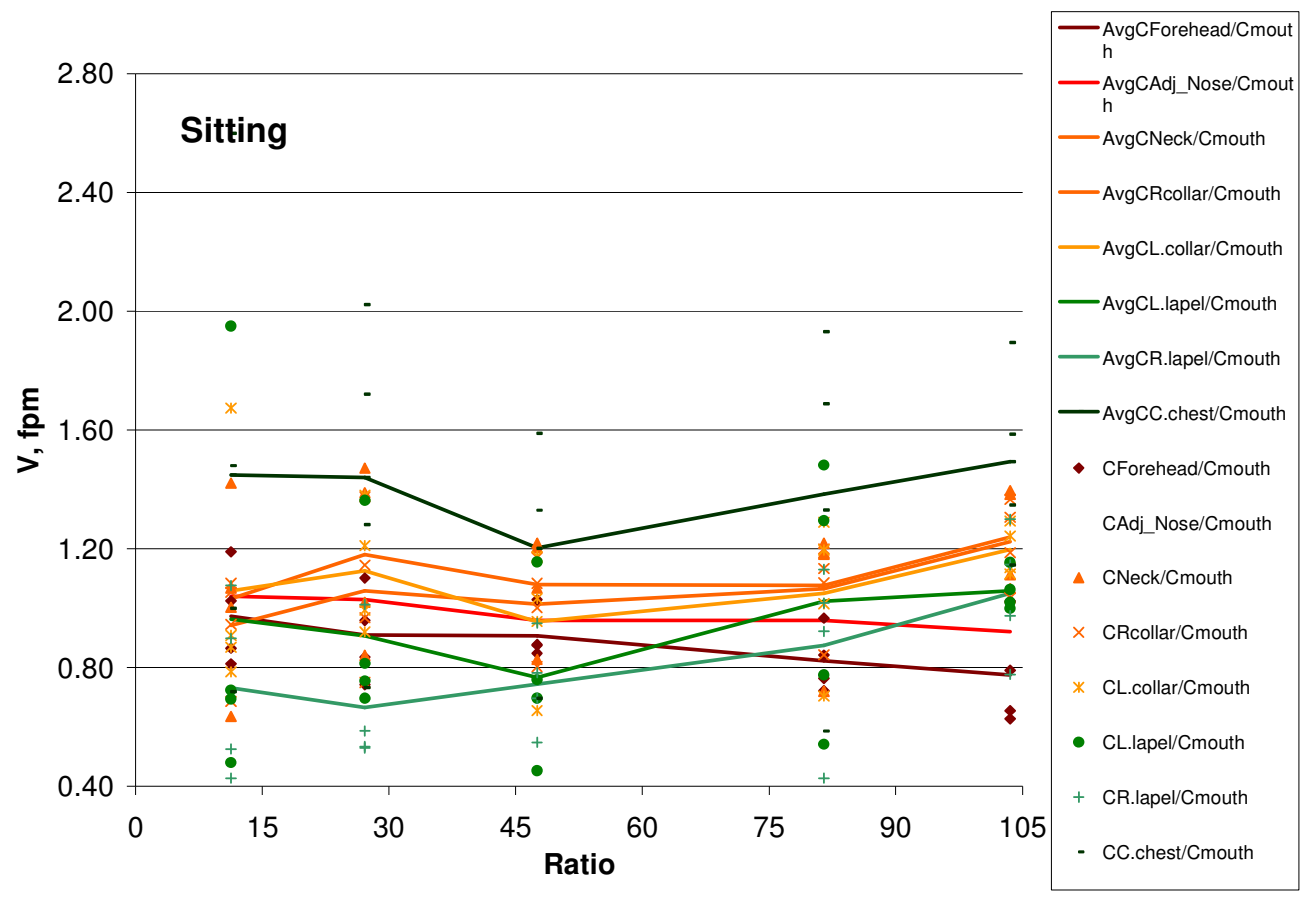

Figure 4.40: Scatter and mean plots of $C_{\text {location }}$ ratio to $C_{\text {mouth }}$ plotted against wind tunnel velocity for sitting treatment conditions

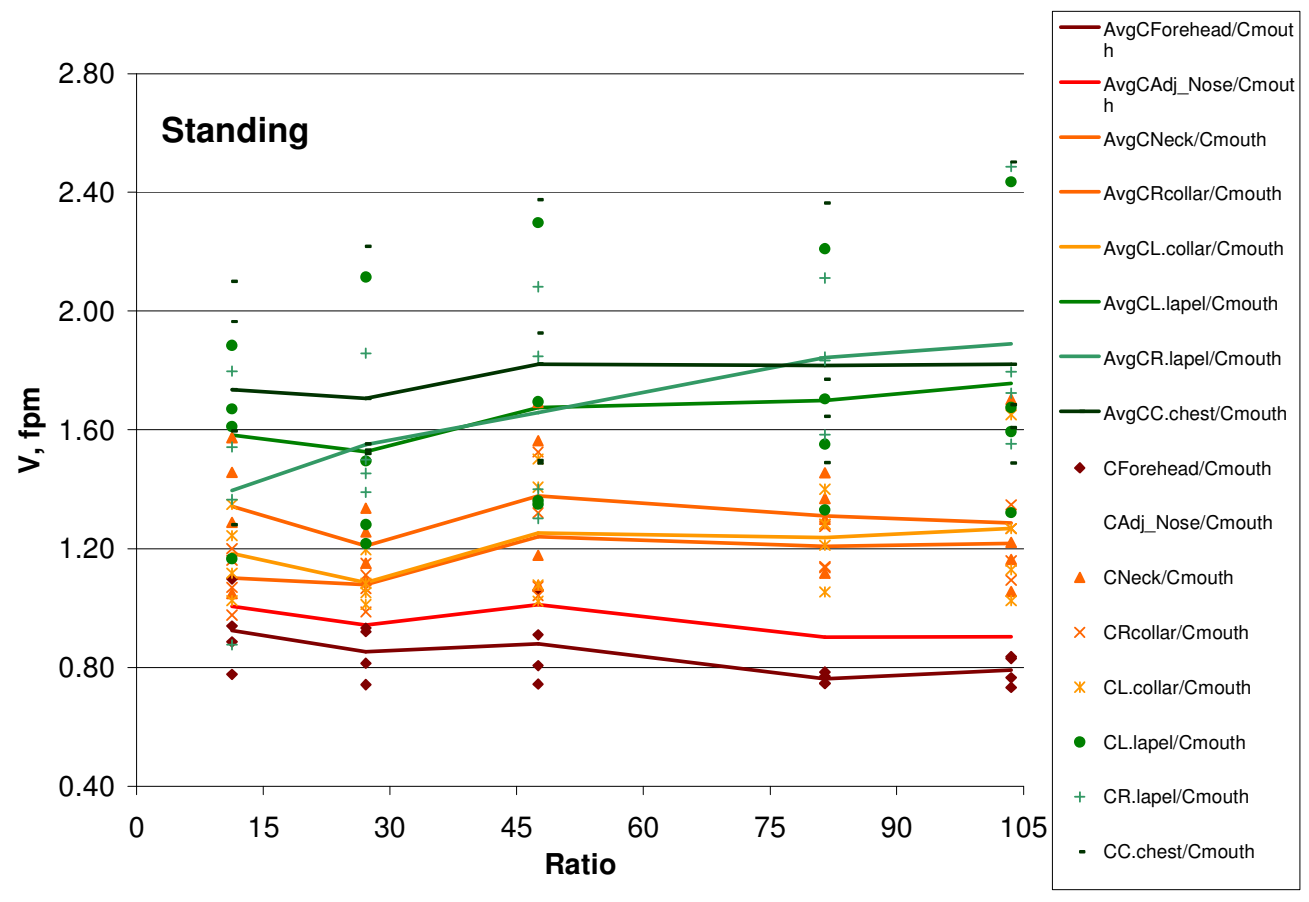

Figure 4.41: Scatter and mean plots of $C_{\text {location }} / C_{\text {mouth }}$ plotted against wind tunnel velocity for standing treatment condition 


\subsection{Effects of Independent Variables on Ratios of Surrogate Concentrations to $\mathbf{C}_{\text {mouth }}$}

The ratios of $\mathrm{C}_{\text {location }}$ to $\mathrm{C}_{\text {mouth }}\left(\mathrm{C}_{\text {ratio }}\right)$ for each subject and its replications for a given set of treatment conditions are shown Figure 4.24 - Figure 4.35. The ratios of $\mathrm{C}_{\text {location }}$ to $\mathrm{C}_{\text {mouth }}\left(\mathrm{C}_{\text {ratio }}\right)$ averaged over all subjects and replications for a given set of treatment conditions are shown in Table 4.8 and Figure 4.36 - Figure 4.39. In general, the ratio was lowest at the forehead and was below unity for both the forehead and adjacent nose. $C_{\text {ratio }}$ values at the level of the neck ranged from $0.92-1.31$, while values at the level of the sternum ranged from $1.09-1.73$.

For the locations below the face, the values of $\mathrm{C}_{\text {ratio }}$ for the left and right collars were the closest to unity with a range of $0.84-1.68$. The greatest deviations from unity were at the lapels and center chest $(0.58-1.88$, and $1.09-1.95$ respectively). In this study, it was assumed the $\mathrm{C}_{\text {mouth }}$ accurately represented inhaled concentrations. Thus, the ratios of the concentrations at other locations to the mouth $\left(\mathrm{C}_{\text {ratio }}\right)$ ideally would be equal to unity for all tested conditions. Ratios below unity represent under-estimation of $\mathrm{C}_{\text {mouth }}$ while ratios above unity represent over-estimation. A candidate location also could be useful if its values of Cratio varied little from a fixed proportion, allowing simple corrections to estimate the concentration at the mouth. 


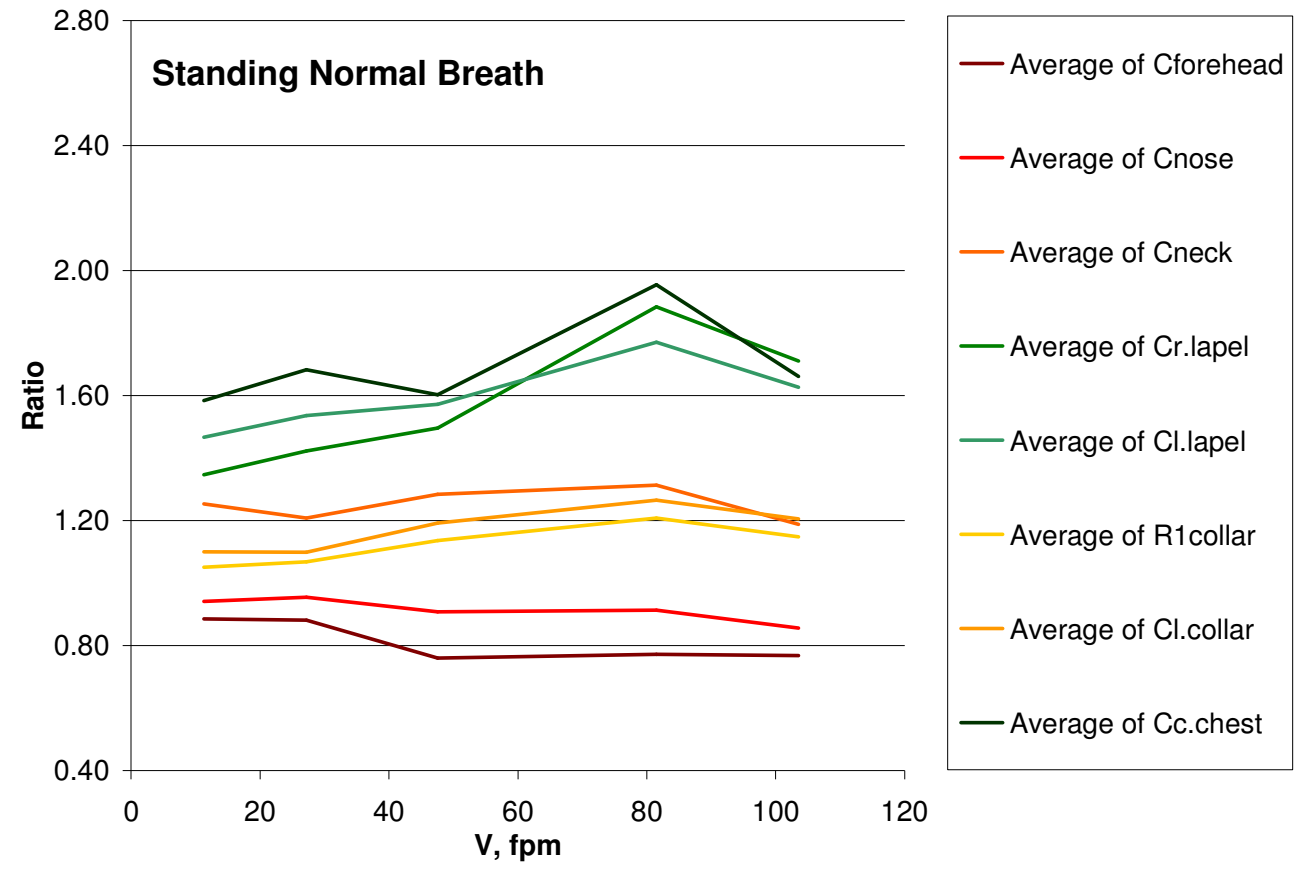

Figure 4.42: Mean plots of all subjects for $C_{\text {location }}$ ratio to $C_{\text {mouth }}$ plotted against wind tunnel velocity for standing $\&$ normal breathing treatment conditions
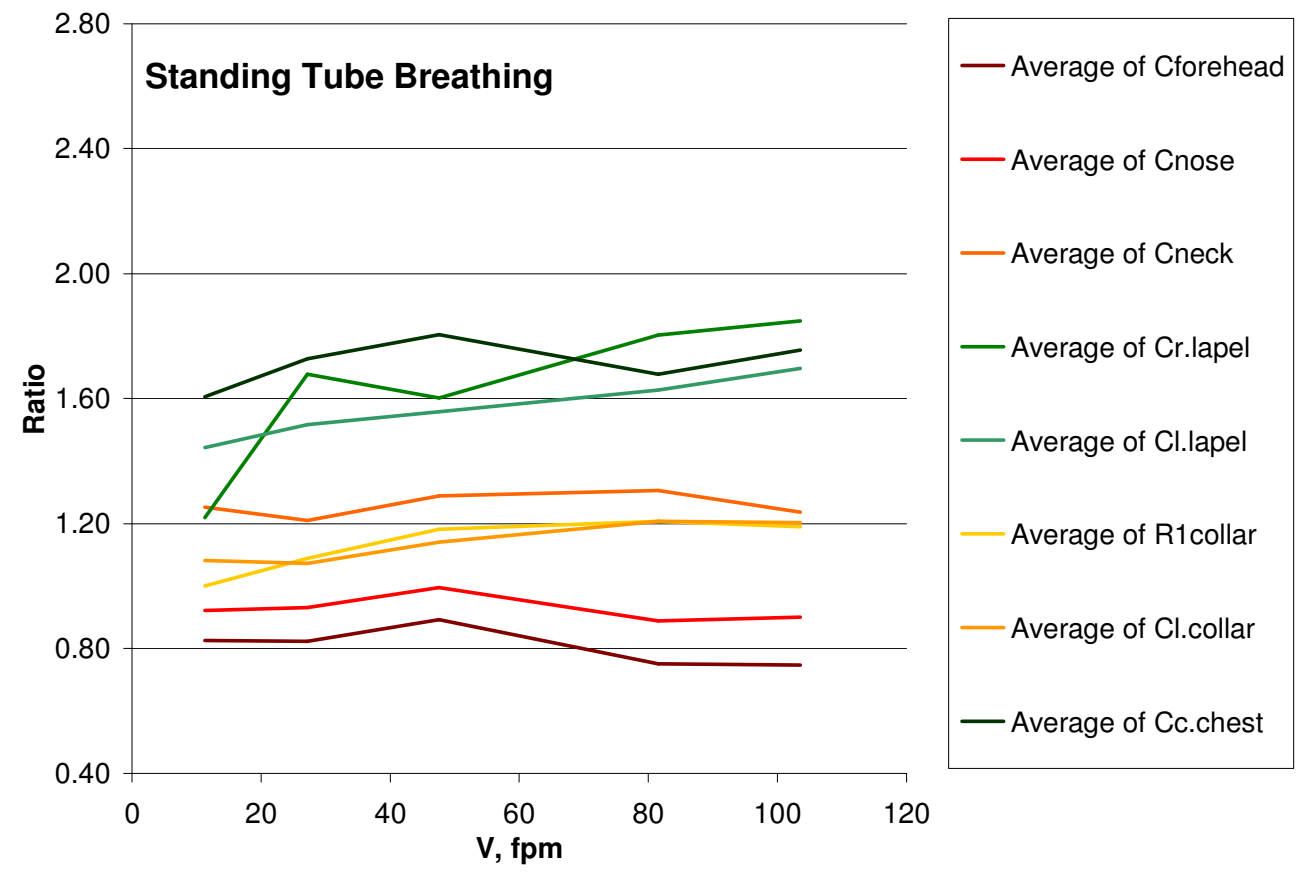

Figure 4.43: Mean plots of all subjects for $C_{\text {location }}$ ratio to $C_{\text {mouth }}$ plotted against wind tunnel velocity for standing \& tube breathing treatment conditions 


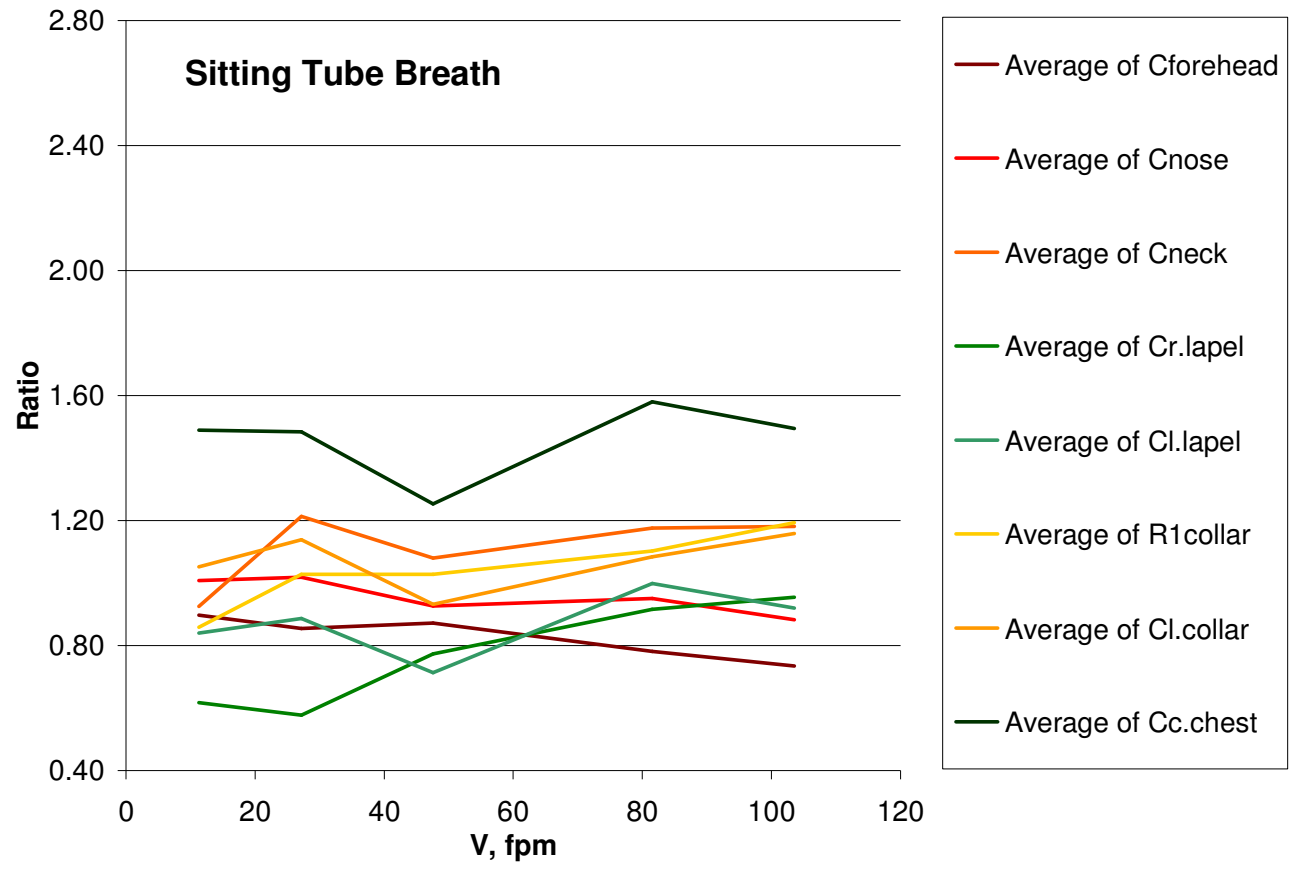

Figure 4.44: Mean plots of all subjects for $C_{\text {location }}$ ratio to $C_{\text {mouth }}$ plotted against wind tunnel velocity for sitting $\&$ tube breathing treatment conditions

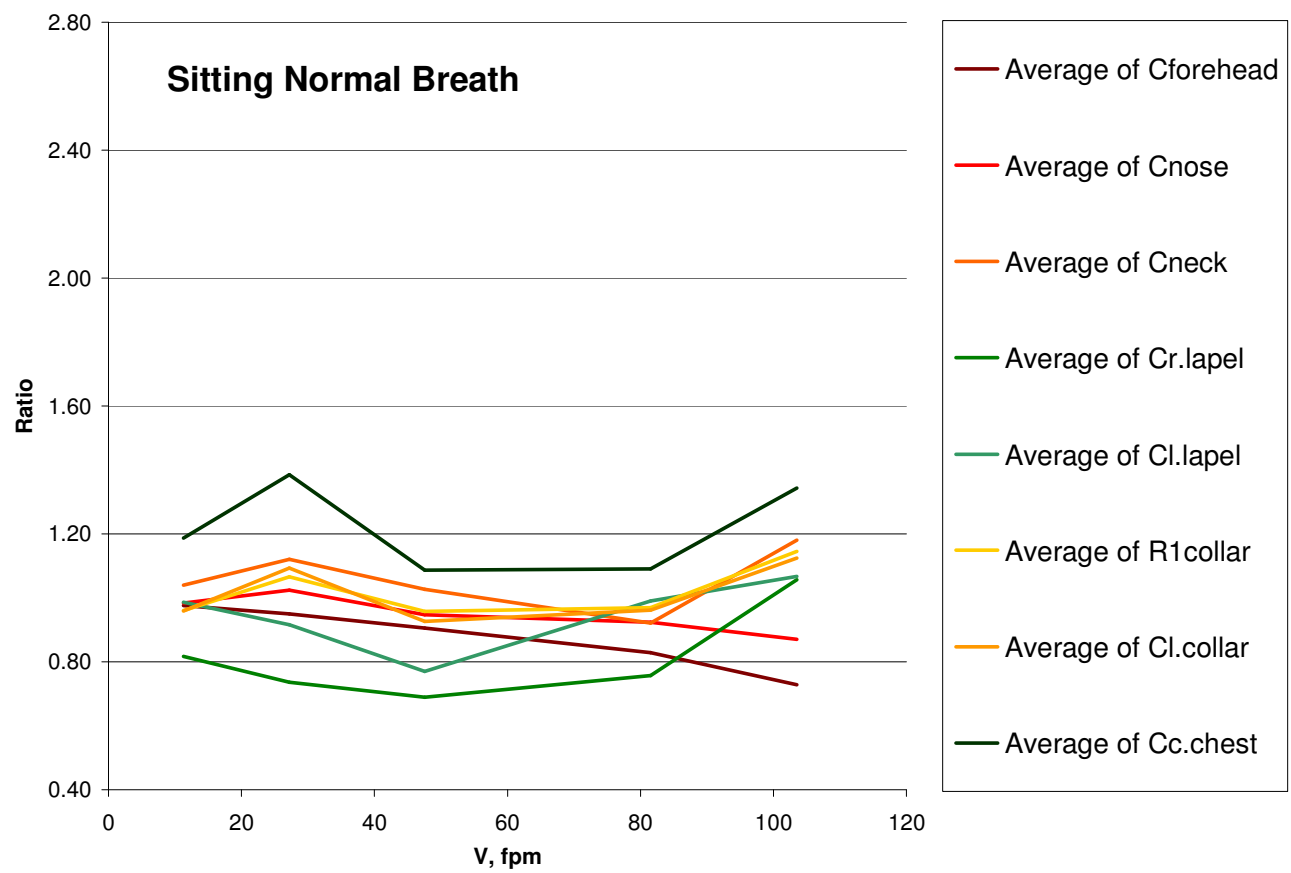

Figure 4.45: Mean plots of all subjects for $C_{\text {location }}$ ratio to $C_{\text {mouth }}$ plotted against wind tunnel velocity for standing \& normal breathing treatment conditions 


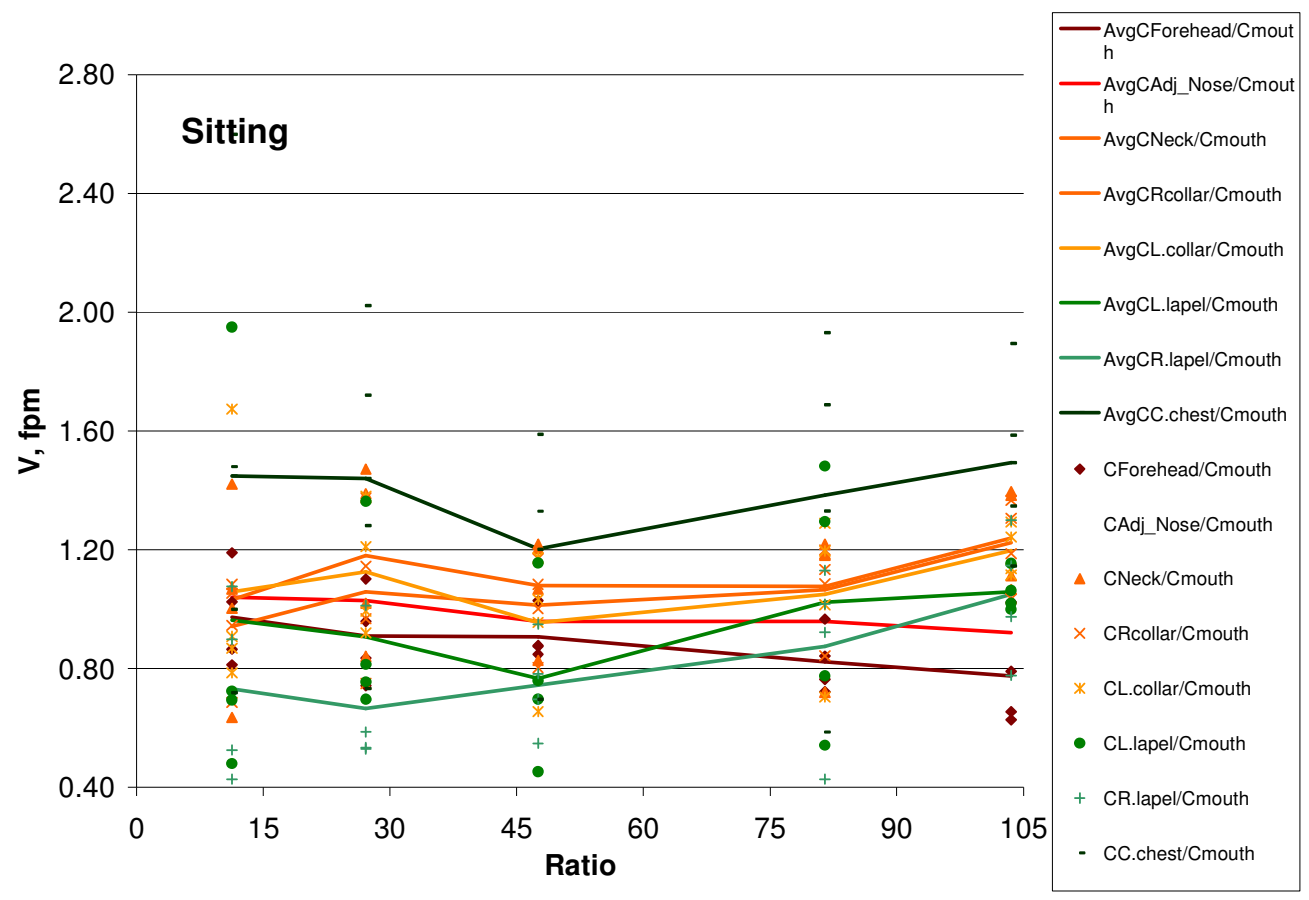

Figure 4.46: Scatter and mean plots of $C_{\text {location }}$ ratio to $C_{\text {mouth }}$ plotted against wind tunnel velocity for sitting treatment conditions

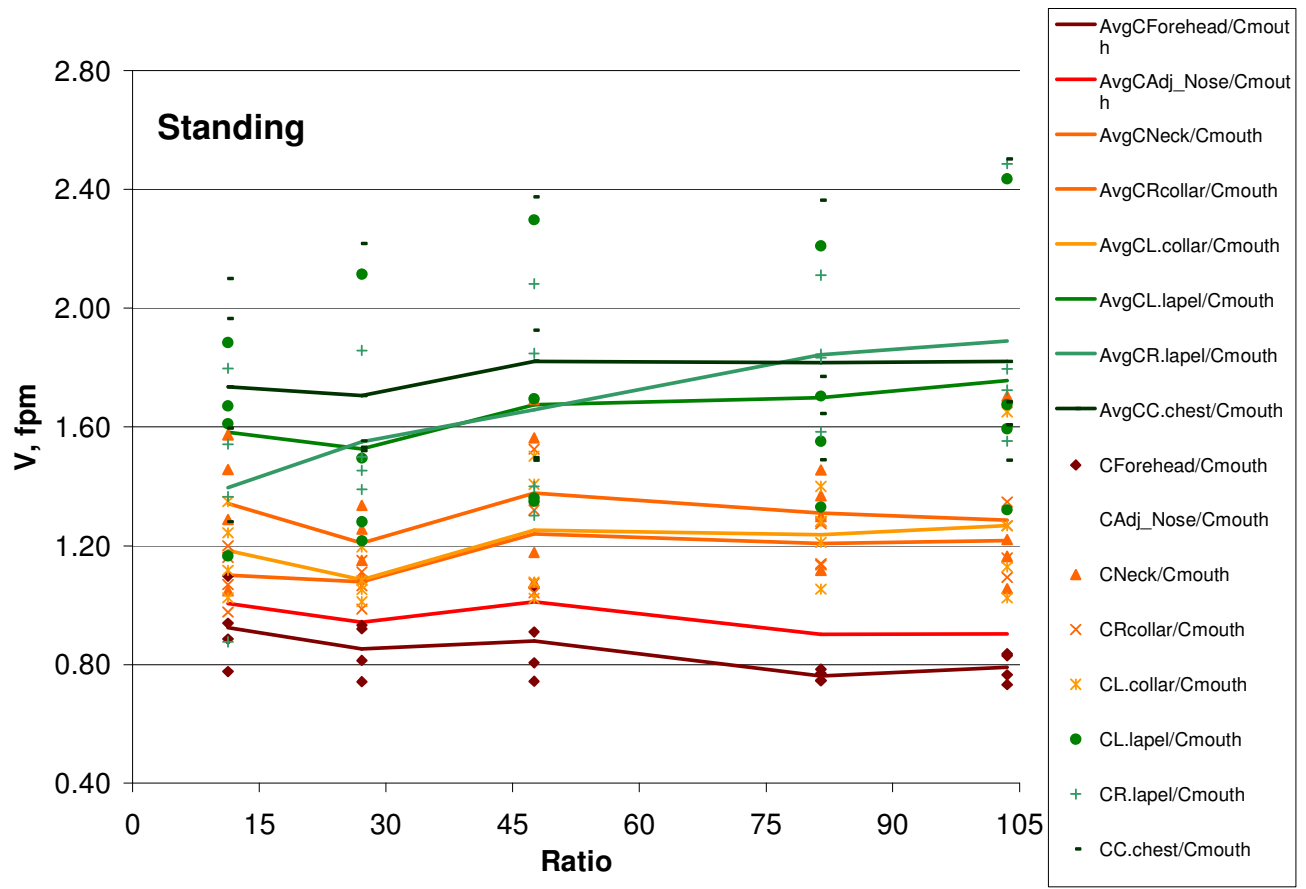

Figure 4.47: Scatter and mean plots of $C_{\text {location }}$ ratio to $C_{\text {mouth }}$ plotted against wind tunnel velocity for standing treatment condition

The results as ratios are shown in Table 4.8 and Figure 4.42 - Figure 4.47 are averages of all the data for the four subjects for a given set of treatment conditions. 
As shown in Figure 4.36 - Figure 4.41 the relation function between concentration of other location and $\mathrm{C}_{\text {mouth }}$ was linear and tends to be parallel to a unity straight line.

For posture standing showed higher peak ratios for the effect of velocity than sitting. Statistically velocity was the least significance of all the independent factors. The forehead and adjacent nose concentrations were the closest to the mouth (i.e., ratios closest to unity). The ratios to the mouth for the chest, left lapel, and right lapel had the greatest variation. For example, the maximum ratio found for the chest was $\mathrm{C}_{\text {ratio }}=1.95$.

For posture sitting showed lower peak ratios for the effect of velocity than standing. Statistically velocity was the least significance of all the independent factors. The adjacent nose concentration was the closest to the mouth (i.e., ratios closest to unity). The ratios to the mouth for the chest, left lapel, and right lapel had the greatest values. For example, the maximum ratio found for the chest was $\mathrm{C}_{\text {ratio }}=1.38$.

\subsubsection{Effects of Independent Variables on Ratios of Surrogate Concentrations to $\mathbf{C}_{\text {mouth }}$}

The values of $\mathrm{C}_{\text {ratio }}$ were lower for sitting than standing. The effects of velocity on $\mathrm{C}_{\text {ratio }}$ were modest for both the sitting and the standing postures. For standing posture, locations at the level of the neck and face, $\mathrm{C}_{\text {ratio }}$ appeared to vary little with velocity (as shown in Table 4.9 - Table 4.11). For locations on the level of the sternum, $\mathrm{C}_{\text {ratio }}$ appeared to vary somewhat with velocity. Tube breathing (as shown in Table 4.8) appeared to have little or no effect on the relationship between velocity and $\mathrm{C}_{\text {ratio. }}$.

For sitting, $\mathrm{C}_{\text {ratio }}$ appeared to vary little with velocity for both normal and tube breathing. As the study conditions levels varies (wind tunnel velocity, posture, and 
subject) as the values of concentrations measured at any location varies as listed in Table 4.8. In this table, the mean concentrations (ppm) results vary with the posture, and varied from one subject to another at similar conditions.

A primary goal was to investigate the agreement concentrations at the mouth and concentrations at the lapels, collars, center chest, nose, neck, and forehead sampling. The ratio showed the highest values for the seated posture and the lowest values for the standing posture. Ratios at forehead location were under estimating mouth concentrations, almost unity at the nose location, and were overestimating mouth concentration at torso locations. The effect of velocity for the breathing and no breathing conditions was not substantial when compared to the substantial effects of velocity for standing and seated conditions as well as to the subject differences

In summary, it appears that the center of the chest and lapels produce remarkably poor agreement with $\mathrm{C}_{\text {mouth}}$. The Log differences are strongly affected by subject, and posture and their 2-way interactions.

It was concluded from Figure 4.36 - Figure 4.37 that for standing posture there were three regions that compiled the sampling location ratios. The forehead and the adjacent nose lied in the lowest region and were named of the facial region. The neck, left collar, and right collar location ratio results were also so close and bundled in a region that was named the torso group region. Finally, the center chest, left lapel, and right lapel were close and bundled in a group called the torso group.

As shown Figure 4.38 - Figure 4.39, the sitting posture the facial region and the shoulder regions were all bundled together and ranged with same ratios. The torso region 
the chest remained at the highest level and the lapels ratios dropped tremendously but still had the same pattern of the center chest. 


\section{CHAPTER 5: DISCUSSION}

The first major goal of the study was to determine how Posture, Velocity, and Breathing affect concentrations measured at the mouth and at other sampling locations. The second objective was to compare concentrations at other locations to $\mathrm{C}_{\text {mouth }}$ and judge which location was most suitable as a surrogate for $\mathrm{C}_{\text {mouth }}$. If the concentrations differed from $\mathrm{C}_{\text {mouth}}$, a related objective was to determine how the independent variables affected the differences among them.

Another objective was to compare the results from this study's human subjects to the results from El Nahas' study with a heated, breathing, anthropometrically proportioned manikin tested under the same condition. If they compared well, then one could use a manikin as a surrogate for human subjects with more confidence. However, providing simulated breathing to a manikin is not an easy task. This brings up the related topic of testing whether breathing is an important consideration in these studies. In this study, that was evaluated with human subjects by the expedient of having subject exhale through a long tube or not.

The effects of posture were tested for two extremes, sitting and standing. In both cases, subjects were doing a make-work task for lengthy periods. Within the constraint of sitting or standing, subjects were allowed to adjust their body position as they wished. 
Table 5.1: Randomized factorial design of experiments

\begin{tabular}{|c|c|c|c|c|c|c|c|}
\hline \multirow[t]{2}{*}{ Subject } & \multirow[t]{2}{*}{ Breathing } & \multirow[t]{2}{*}{ Posture } & \multicolumn{5}{|c|}{ Velocity, fpm } \\
\hline & & & 11.3 & 27.2 & 47.5 & 81.5 & 103.5 \\
\hline \multirow[t]{8}{*}{ A } & Normal & Sitting & ++ & ++ & ++ & ++ & ++ \\
\hline & & Standing & ++ & ++ & ++ & ++ & ++ \\
\hline & & Sitting & ++ & ++ & ++ & ++ & ++ \\
\hline & & Standing & ++ & ++ & ++ & ++ & ++ \\
\hline & Tube & Sitting & ++ & ++ & ++ & ++ & ++ \\
\hline & & Standing & ++ & ++ & ++ & ++ & ++ \\
\hline & & Sitting & ++ & ++ & ++ & ++ & ++ \\
\hline & & Standing & ++ & ++ & ++ & ++ & ++ \\
\hline \multirow[t]{8}{*}{$B$} & Normal & Sitting & ++ & ++ & ++ & ++ & ++ \\
\hline & & Standing & ++ & ++ & ++ & ++ & ++ \\
\hline & & Sitting & ++ & ++ & ++ & ++ & ++ \\
\hline & & Standing & ++ & ++ & ++ & ++ & ++ \\
\hline & Tube & Sitting & ++ & ++ & ++ & ++ & ++ \\
\hline & & Standing & ++ & ++ & ++ & ++ & ++ \\
\hline & & Sitting & ++ & ++ & ++ & ++ & ++ \\
\hline & & Standing & ++ & ++ & ++ & ++ & ++ \\
\hline \multirow[t]{8}{*}{$\mathrm{C}$} & Normal & Sitting & ++ & ++ & ++ & ++ & ++ \\
\hline & & Standing & ++ & ++ & ++ & ++ & ++ \\
\hline & & Sitting & ++ & ++ & ++ & ++ & ++ \\
\hline & & Standing & ++ & ++ & ++ & ++ & ++ \\
\hline & Tube & Sitting & ++ & ++ & ++ & ++ & ++ \\
\hline & & Standing & ++ & ++ & ++ & ++ & ++ \\
\hline & & Sitting & ++ & ++ & ++ & ++ & ++ \\
\hline & & Standing & ++ & ++ & ++ & ++ & ++ \\
\hline \multirow[t]{8}{*}{$\mathrm{D}$} & Normal & Sitting & ++ & ++ & ++ & ++ & ++ \\
\hline & & Standing & ++ & ++ & ++ & ++ & ++ \\
\hline & & Sitting & ++ & ++ & ++ & ++ & ++ \\
\hline & & Standing & ++ & ++ & ++ & ++ & ++ \\
\hline & Tube & Sitting & ++ & ++ & ++ & ++ & ++ \\
\hline & & Standing & ++ & ++ & ++ & ++ & ++ \\
\hline & & Sitting & ++ & ++ & ++ & ++ & ++ \\
\hline & & Standing & ++ & ++ & ++ & ++ & ++ \\
\hline
\end{tabular}




\subsection{Analysis and Discussion of $\mathbf{C}_{\text {mouth }}$ Results}

Examination of Figure 4.11 - Figure 4.18 suggest that concentrations at the mouth vary substantially with Subject, Posture, Breathing, Velocity, and Subject. It was also apparent from Table 4.2 that results differed strongly for the standing and sitting postures when types of breathing were compared and when levels of velocity were compared. These results were suggesting interactive effects between Posture and Breathing and Posture and Velocity.

Concentrations at the mouth $\left(\mathrm{C}_{\text {mouth }}\right)$ changed in an inverted $\mathrm{V}$ shape (see Figure 4.2 - Figure 4.5) with velocity much greater symmetry for the standing than for the sitting. Likewise, the effect of exhaling through a tube (see Figure 4.11 - Figure 4.18) appeared to be much stronger for sitting than standing. Furthermore, the interaction of breathing with velocity was strongly affected by Posture. As shown in Figure 4.6, the

effects of Breathing were much stronger for higher velocities in sitting posture but not the standing posture.

The effects of the major variables were substantial as well as statistically significant. Exposures for sitting on the average were roughly 1.5 the exposures when standing (see to Table 4.7). Exposures at the peak achieved at $47.5 \mathrm{ft} / \mathrm{min}$ were 2.25 times the concentrations at lower velocities. When sitting and breathing through a tube, concentrations were $33 \%$ higher than when sitting and breathing normally.

\subsubsection{Analysis of Variance (ANOVA) for $\mathrm{C}_{\text {mouth }}$}

The significance of the study variables was determined using Data Desk (Version 6, Data Description Inc., Ithaca, NY) software was used to do ANOVA and hypothesis 
testing. The dependent variable was $\mathrm{C}_{\text {mouth }}$, the concentration measured at the edge of the mouth. The independent variables for this study were five levels of velocity $(11.3,27.5$, 47.5, 81.5, and $103.5 \mathrm{fpm}$ ), four levels of subject (A, B, C, and D), two levels of breathing (breathing Normal, breathing through tube), and two levels of posture (seated, standing).

All independent variables were treated as discrete rather than continuous.

Although velocity is a continuous variable, it was treated as discrete because its effects proved to be decidedly non-linear.

As shown in Table 5.1, the design was a factorial one, with two replications for each treatment. Experiments were done in randomized order for a given subject. The linear statistical model used for the analysis of variance is illustrated by the following equation:

$$
\begin{aligned}
\mathrm{Y}_{\mathrm{imzko}}= & \mu+(\psi)_{\mathrm{i}}+(\Omega)_{\mathrm{m}}+(\varepsilon)_{\mathrm{z}}+(\omega)_{\mathrm{k}}+(\psi \omega)_{\mathrm{ik}}+(\psi \Omega)_{\mathrm{im}}+(\psi \varepsilon)_{\mathrm{iz}}+(\omega \varepsilon)_{\mathrm{kz}}+(\varepsilon \Omega)_{\mathrm{zm}}+(\omega \Omega)_{\mathrm{km}} \\
& +(\psi \omega \varepsilon)_{\mathrm{ikz}}+(\psi \omega \Omega)_{\mathrm{ikz}}+(\psi \Omega \varepsilon)_{\mathrm{imz}}+(\omega \Omega \varepsilon)_{\mathrm{kmz}}+\varepsilon_{\mathrm{imzko}}
\end{aligned}
$$

Where: $\mathrm{i}=1,2 ; \mathrm{m}=1,2 ; \mathrm{z}=1,2,3,4 ; \mathrm{k}=1,2,3,4,5 ; \quad \mathrm{o}=2$

$\mathrm{Y}_{\text {imzko }}=\mathrm{C}_{\text {mouth }}$ for a given test

$\mu=$ constant

$\varepsilon_{\text {imzko }}=$ random error

Posture $=\psi_{\mathrm{i}}$, categorical variable

Breathing $=\Omega_{\mathrm{m}}$, categorical variable

Subject $=\varepsilon_{\mathrm{z}}$, categorical variable 
Velocity $=\omega_{\mathrm{k}}$ treated as a categorical variable

$(\psi \omega)_{\mathrm{ik},}(\psi \Omega)_{\mathrm{im},}(\psi \varepsilon)_{\mathrm{iz}},(\omega \varepsilon)_{\mathrm{kz}},(\varepsilon \Omega)_{\mathrm{zm}}$, and $(\omega \Omega)_{\mathrm{km}}$ are the two-way interaction

effects of the four independent variables

$(\psi \omega \varepsilon)_{\mathrm{k} z},(\psi \omega \Omega)_{\mathrm{kz} z},(\psi \Omega \varepsilon)_{\mathrm{imz}},(\omega \Omega \varepsilon)_{\mathrm{kmz}}$ are the three-way interaction effects of the

four independent variables

\section{Table 5.2: P-values from ANOVA's for concentrations at each location including sitting and standing}

\begin{tabular}{|c|c|c|c|c|c|c|c|c|c|c|}
\hline Source & $d f$ & U⿺辶ّ & Ũ & ڤั & ঠั & نَّ & & $\underbrace{\overrightarrow{\underline{E}}}$ & $\underbrace{\frac{u ̈}{\mathscr{U}}}$ & 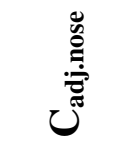 \\
\hline Constant & 1 & $<0.0001$ & $<0.0001$ & $<0.0001$ & $<0.0001$ & $<0.0001$ & $<0.0001$ & $<0.0001$ & $<0.0001$ & $<0.0001$ \\
\hline Posture & 1 & $<0.0001$ & $<0.0001$ & $<0.0001$ & 0.01 & $<0.0001$ & 0.10 & $<0.0001$ & $<0.0001$ & $<0.0001$ \\
\hline Velocity & 4 & $<0.0001$ & $<0.0001$ & $<0.0001$ & $<0.0001$ & $<0.0001$ & $<0.0001$ & $<0.0001$ & $<0.0001$ & $<0.0001$ \\
\hline $\begin{array}{l}\text { Posture * } \\
\text { Velocity }\end{array}$ & 4 & $<0.0001$ & $<0.0001$ & $<0.0001$ & $<0.0001$ & $<0.0001$ & $<0.0001$ & $<0.0001$ & $<0.0001$ & $<0.0001$ \\
\hline Breathing & 1 & $<0.0001$ & $<0.0001$ & $<0.0001$ & 0.08 & $<0.0001$ & $<0.0001$ & $<0.0001$ & $<0.0001$ & $<0.0001$ \\
\hline $\begin{array}{l}\text { Posture * } \\
\text { Breathing }\end{array}$ & 1 & 0.03 & $<0.0001$ & $<0.0001$ & 0.26 & $<0.0001$ & 0.11 & 0.01 & $<0.0001$ & 0.01 \\
\hline Subject & 3 & $<0.0001$ & $<0.0001$ & $<0.0001$ & $<0.0001$ & $<0.0001$ & $<0.0001$ & $<0.0001$ & $<0.0001$ & $<0.0001$ \\
\hline $\begin{array}{l}\text { Posture * } \\
\text { Subject }\end{array}$ & 3 & $<0.0001$ & $<0.0001$ & $<0.0001$ & $<0.0001$ & $<0.0001$ & $<0.0001$ & $<0.0001$ & $<0.0001$ & $<0.0001$ \\
\hline $\begin{array}{l}\text { Velocity * } \\
\text { Subject }\end{array}$ & 12 & 0.06 & 0.02 & 0.16 & 0.74 & 0.25 & 0.25 & 0.65 & 0.11 & 0.10 \\
\hline $\begin{array}{l}\text { Posture * } \\
\text { Velocity * } \\
\text { Subject }\end{array}$ & 12 & 0.14 & 0.05 & 0.04 & 0.70 & 0.23 & 0.13 & 0.73 & 0.21 & 0.24 \\
\hline $\begin{array}{l}\text { Posture * } \\
\text { Velocity * } \\
\text { Breathing }\end{array}$ & 4 & 0.19 & 0.11 & 0.13 & 0.83 & 0.32 & 0.16 & 0.30 & 0.21 & 0.24 \\
\hline $\begin{array}{l}\text { Subject* } \\
\text { Breathing }\end{array}$ & 3 & 0.07 & 0.21 & 0.06 & 0.20 & 0.08 & 0.12 & 0.18 & 0.11 & 0.16 \\
\hline $\begin{array}{l}\text { Posture * } \\
\text { Breathing } \\
* \text { Subject }\end{array}$ & 3 & 0.21 & 0.33 & 0.31 & 0.58 & 0.35 & 0.44 & 0.20 & 0.25 & 0.24 \\
\hline $\begin{array}{l}\text { Velocity * } \\
\text { Breathing } \\
* \text { Subject }\end{array}$ & 12 & 0.58 & 0.44 & 0.18 & 0.77 & 0.21 & 0.16 & 0.21 & 0.14 & 0.37 \\
\hline $\begin{array}{l}\text { Velocity* } \\
\text { Breathing }\end{array}$ & 4 & 0.26 & 0.48 & 0.37 & 0.97 & 0.62 & 0.51 & 0.72 & 0.55 & 0.52 \\
\hline
\end{tabular}


Table 5.3: P-values from ANOVA's for individual concentrations for normal breathing, only

\begin{tabular}{|c|c|c|c|c|c|c|c|c|c|c|}
\hline Source & $d f$ & 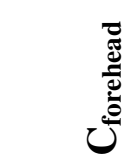 & 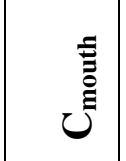 & 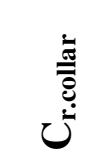 & 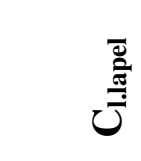 & نَّ & 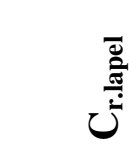 & ن & $u^{\check{\Xi}}$ & 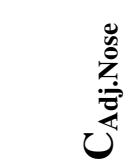 \\
\hline Const & 1 & $<0.0001$ & $<0.0001$ & 0.0001 & $<0.0001$ & $<0.0001$ & $<0.0001$ & $<0.0001$ & $<0.0001$ & $<0.0001$ \\
\hline Posture & 1 & $<0.0001$ & $<0.0001$ & 0.0001 & 0.24 & $<0.0001$ & 0.96 & $<0.0001$ & $<0.0001$ & $<0.0001$ \\
\hline Velocity & 4 & $<0.0001$ & $<0.0001$ & 0.0001 & $<0.0001$ & $<0.0001$ & $<0.0001$ & $<0.0001$ & $<0.0001$ & $<0.0001$ \\
\hline $\begin{array}{l}\text { Posture * } \\
\text { Velocity }\end{array}$ & 4 & 0.06 & 0.01 & 0.01 & 0.05 & 0.06 & $<0.0001$ & 0.25 & 0.04 & 0.06 \\
\hline Subject & 3 & 0.06 & $<0.0001$ & 0.0001 & $<0.0001$ & $<0.0001$ & $<0.0001$ & $<0.0001$ & $<0.0001$ & 0.02 \\
\hline Posture*Subject & 3 & 0.12 & $<0.0001$ & 0.0001 & 0.02 & 0.01 & $<0.0001$ & 0.02 & $<0.0001$ & 0.06 \\
\hline Velocity*Subject & 12 & 0.31 & 0.40 & 0.59 & 0.75 & 0.40 & 0.27 & 0.62 & 0.51 & 0.40 \\
\hline $\begin{array}{l}\text { Posture * } \\
\text { Velocity * } \\
\text { Subject }\end{array}$ & 12 & 0.07 & 0.02 & 0.13 & 0.12 & 0.09 & 0.19 & 0.18 & 0.12 & 0.06 \\
\hline
\end{tabular}

The results for ANOVA for $\mathrm{C}_{\text {mouth }}$ (see Table 5.2) shows that Posture, Velocity, Subject, Breathing, Posture*Velocity, Posture*Breathing, and Posture*Subject all were highly statistically significant $(\mathrm{p}<0.001)$. Velocity $*$ Subject and Posture * Velocity * Subject were significant $(\mathrm{p}<0.05)$. All other second and third order interactions were non-significant.

The data was re-analyzed with tube breathing removed to make certain that this unnatural condition did not skew the effects of Velocity and Posture. As show in Table 5.3, for $\mathrm{C}_{\mathrm{mouth}}$, Posture, Velocity, Subject and Posture * Subject remained very highly significant $(\mathrm{p}<0.001)$ while Posture * Velocity and Posture * Velocity * Subject were significant $(\mathrm{p}<0.05)$. Hence, the tube-breathing condition did not distort the findings when combined with normal breathing. 
The significance of breathing is important because of its implication that manikins used as surrogates for humans should be equipped with normal breathing. The main effects for breathing and its interactions with velocity and posture were statistically significant. However, examination of Figure 4.6, Table 5.4, and Table 5.5 show that the strong effects of Breathing occurred only for sitting. For sitting, the effect of breathing through a tube was substantially at higher velocities than at lower velocities.

Furthermore, the effects of Velocity were strongly affected by posture, as is shown in Figure 4.6.

Table 5.4: P-values from ANOVA for individual concentrations in sitting conditions

\begin{tabular}{|c|c|c|c|c|c|c|c|c|c|c|}
\hline Source & $d f$ & & 畜 & نُّ & : & & 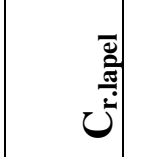 & ن & $\underbrace{\frac{\pi}{\ddot{U}}}$ & 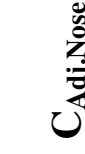 \\
\hline Const & 1 & \multicolumn{5}{|c|}{$<0.0001<0.0001<0.0001$} & \multicolumn{4}{|c|}{$\mid<0.0001<0.0001<0.0001<0.000$} \\
\hline Velocity & 4 & \multicolumn{5}{|c|}{$<0.0001<0.0001<0.0001$} & \multirow{2}{*}{\multicolumn{4}{|c|}{ 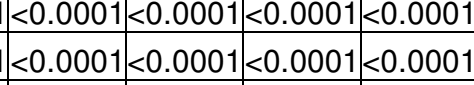 }} \\
\hline Subject & 3 & \multicolumn{3}{|c|}{$<0.0001<0.0001<0.0001$} & $<0.0001<$ & 0.0001 & & & & \\
\hline Breathing & 1 & \multicolumn{3}{|c|}{$|<0.0001<0.0001|<0.0001$} & \multicolumn{2}{|c|}{$0.14<0.0001$} & \multicolumn{2}{|c|}{$0.0100<0.0001$} & \multicolumn{2}{|c|}{$1 \mid<0.0001<0.0001$} \\
\hline Velocity*Subject & 12 & 0.47 & 0.09 & 0.08 & 0.91 & 0.37 & 0.21 & 0.76 & 0.17 & 0.53 \\
\hline Velocity * Breathi & 12 & 0.36 & 0.04 & 0.03 & 0.58 & 0.05 & 0.16 & 0.12 & 0.02 & 0.12 \\
\hline Subject * Breathing & 3 & 0.09 & 0.16 & 0.09 & 0.39 & 0.14 & 0.26 & 0.17 & 0.11 & 0.14 \\
\hline Velocity * Breathing & 4 & 0.18 & 0.14 & 0.14 & 0.92 & 0.36 & 0.30 & 0.46 & 0.24 & 0.29 \\
\hline
\end{tabular}

Table 5.5: P-values from ANOVA's for individual concentrations in standing conditions

\begin{tabular}{|c|c|c|c|c|c|c|c|c|c|c|}
\hline Source & $d f$ & ن⿺辶ّ & 音 & تُّ & 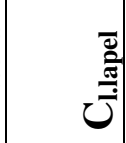 & تُّت & & نُ & ن & \\
\hline Const & 1 & $<0.0001$ & $<0.0001$ & $<0.0001$ & $<0.0001$ & $<0.0001$ & $<0.0001$ & $<0.0001$ & $<0.0001$ & $<0.0001$ \\
\hline Velocity & 4 & $<0.0001$ & $<0.0001$ & $<0.0001$ & $<0.0001$ & $<0.0001$ & $<0.0001$ & $<0.0001$ & $<0.0001$ & $<0.0001$ \\
\hline Subject & 3 & 0.02 & $<0.0001$ & 0.0100 & $<0.0001$ & 0.02 & $<0.0001$ & 0.0100 & $<0.0001$ & $<0.0001$ \\
\hline Velocity*Subject & 12 & $<0.0001$ & $<0.0001$ & $<0.0001$ & 0.0100 & $<0.0001$ & 0.02 & $<0.0001$ & $<0.0001$ & $<0.0001$ \\
\hline Velocity * Breathing & 4 & 0.64 & 0.58 & 0.56 & 0.78 & 0.58 & 0.17 & 0.23 & 0.55 & 0.64 \\
\hline Velocity $*$ Breathing $*$ Subject & 12 & 0.93 & 0.53 & 0.58 & 0.85 & 0.76 & 0.19 & 0.85 & 0.76 & 0.87 \\
\hline Breathing & 1 & 0.10 & 0.18 & 0.05 & 0.34 & 0.27 & 0.02 & 0.06 & 0.18 & 0.06 \\
\hline Subject $*$ Breathing & 3 & 0.52 & 0.65 & 0.18 & 0.16 & 0.08 & 0.05 & 0.18 & 0.18 & 0.76 \\
\hline
\end{tabular}


Since Posture showed such strong interactions with both Breathing and Velocity, ANOVA was done again for Sitting only and Standing only. As shown on Table 5.4 and Table 5.5, when ANOVA was done for sitting and for standing separately, exhaling and its interaction terms were non-significant for standing. For sitting, exhaling was highly significant and was significant for Velocity * Breathing * Subject.

Since when sampling workers one cannot be certain in many cases that they will exclusively sit or stand, the fact that Breathing is important when the worker is sitting suggests that it would be prudent to equip manikins with artificial breathing and employ it at all times.

On the assumption that both workers and manikins should be breathing when sampled, the rest of the analyses in this section uses normal breathing, only, for examination of the effects of cross-draft velocity. As listed in Table 5.2, velocity and the interaction of velocity with posture had a highly significant effect on $\mathrm{C}_{\text {mouth. }}$. For that reason, it is important to consider the effect of Velocity on $\mathrm{C}_{\text {mouth }}$ for each posture separately as shown in both tables Table 5.4 and Table 5.5.

In attempt to linearize the inverted $\mathrm{V}$ relationship with velocity, a new, contrived variable $\left(\mathrm{V}_{\text {contrived }}\right)$ was added:

\section{The regression model for $\mathrm{C}_{\text {mouth }}$ is:}

$$
\begin{aligned}
& C_{\text {mouth }}=\beta_{0}+\beta_{1} \cdot \text { Velocity }+ \beta_{2} \cdot V_{\text {contrived }} \\
& \mathrm{V}_{\text {contrived }}=(\text { Velocity }-47.5) * \text { Xfactor } \\
& \text { Where: } \text { Xfactor }=1 \quad \text { if Velocity }>48 \\
& \text { Xfactor }=0 \quad \text { if Velocity } \leq 48
\end{aligned}
$$


Table 5.6: Regression coefficients for standing and sitting condition:

\begin{tabular}{|l|l|l|l|}
\hline For Standing & \multicolumn{2}{|l|}{ Dependent variable is: $\mathrm{C}_{\text {mouth }}$} & Adj. $\mathrm{R}^{2}=42.6 \%$ \\
\hline Coefficient & $\beta_{0}=4.47104$ & $\beta_{1}=0.281378$ & $\beta_{2}=-0.4835$ \\
\hline $\mathrm{P}-$ Values & 0.0314 & 0.0001 & 0.0001 \\
\hline For Sitting & Dependent variable is: $\mathrm{C}_{\text {mouth }}$ & Adj. $\mathrm{R}^{2}=23.8 \%$ \\
\hline Coefficient & $\beta_{0}=6.92256$ & $\beta_{1}=0.393608$ & $\beta_{2}=-0.455784$ \\
\hline $\mathrm{P}-$ Values & 0.0734 & 0.0014 & 0.0100 \\
\hline
\end{tabular}

As shown in Table 5.6 for the regression of $\mathrm{C}_{\text {mouth }}$, for both Sitting and Standing both Velocity and $\mathrm{V}_{\text {contrived }}$ were statistically significant at $\mathrm{p}<0.01$ or less. As expected, the $\mathrm{R}^{2}$ value for standing (43\%) was much better than for sitting (24\%).

This study could not reveal why Breathing, Posture, and Velocity affected $\mathrm{C}_{\text {mouth }}$ as they did. However, one can speculate. The effect of Posture may be due to different effects on the movement of air heated by the body with sitting and standing. Body heat is well known to produce an upward movement of air up the torso and past the head, reaching as much as $0.5 \mathrm{~m} / \mathrm{s}(100 \mathrm{fpm})$ at the top of the head. It is plausible that sitting would produce a lower upward velocity than standing. It would seem plausible that a lower upward velocity would: a) reduce exposures by carrying contaminant away more quickly, or b) increase exposures at the face by carrying contaminant near the face instead of directly downstream. 


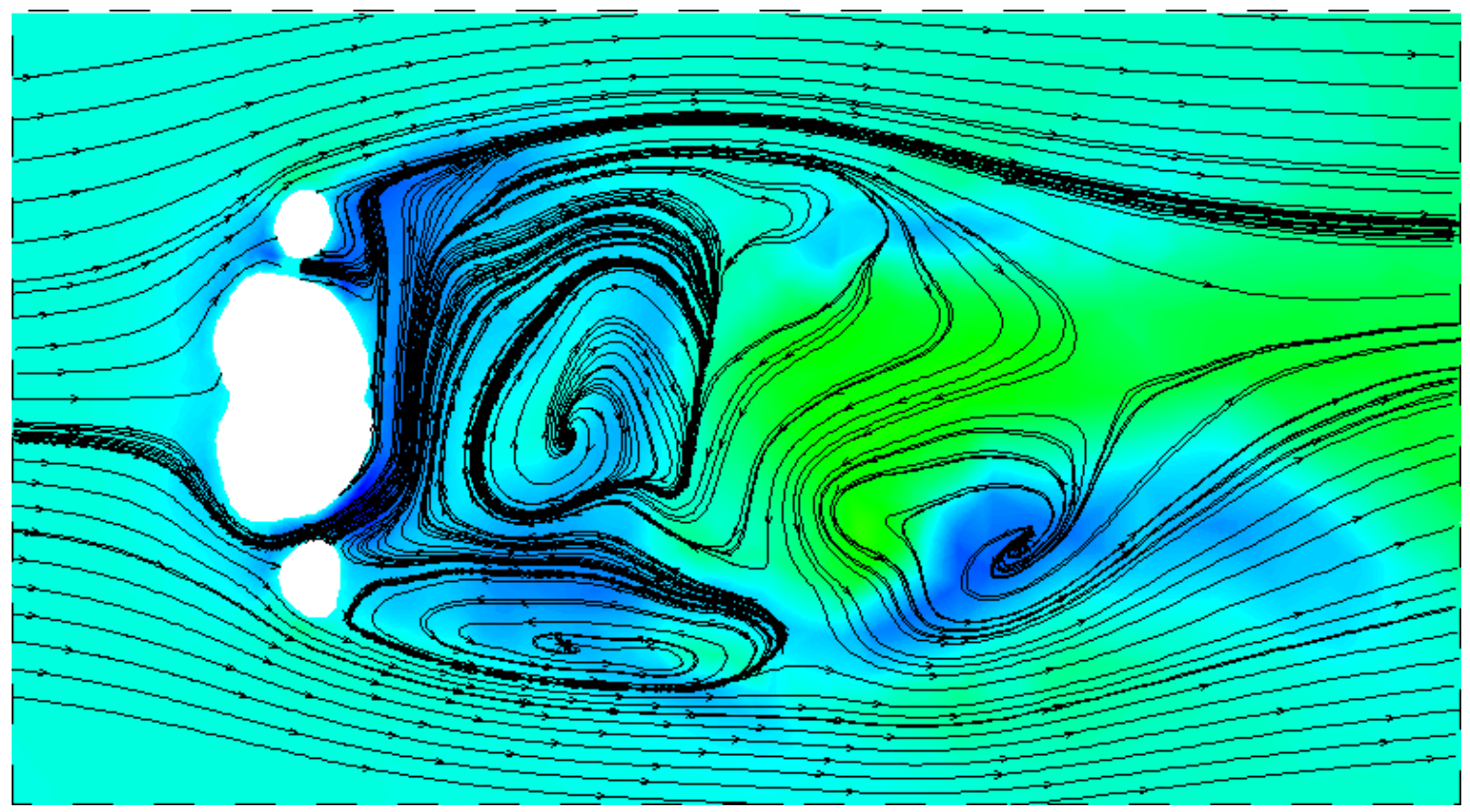

Figure 5.1: Wake zones downstream of subject at air flow velocity of $20 \mathrm{fpm}$ (taken from Li, 2005)

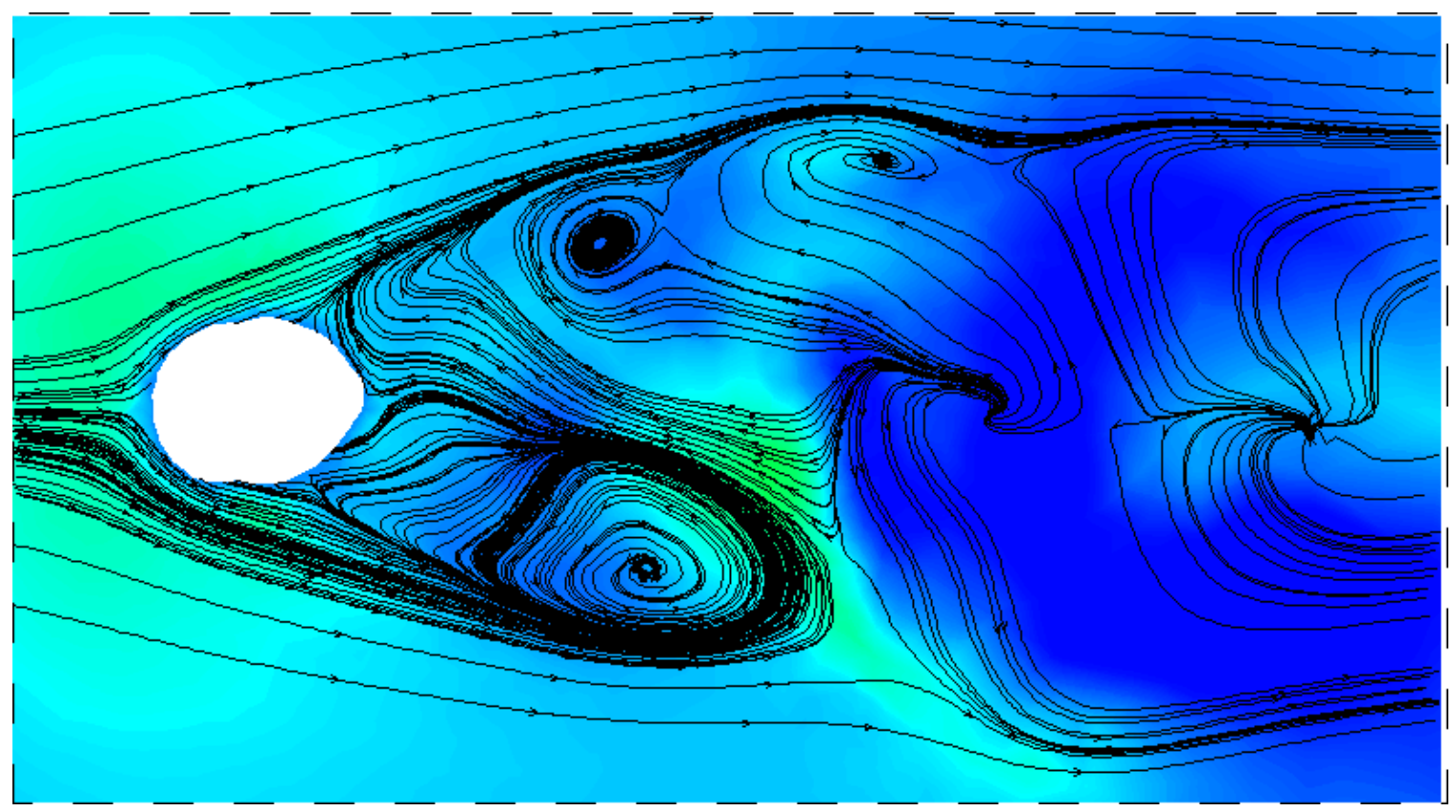

Figure 5.2: Wake zones downstream of subject at air flow velocity of $50 \mathrm{fpm}$ (taken from Li, 2005

In this case, concentrations at the face were lower when standing, which would seem to favor the second argument. However, it is probably not that simple. As can be 
seen in Figure 5.1 and Figure 5.2 the flow of air in the wake zone is extremely complex. One would expect sitting and standing to have greatly different effects on that wake. Hence, one would expect posture to a very important variable. Exactly how each would affect exposures is not at all clear from Figure 5.1 and Figure 5.2.

Likewise, one would expect cross-draft velocity to be very important. One would expect the exchange between the wake and the passing cross draft to be greater at greater velocities, possible producing a monotonically decreasing concentration with increasing velocity. Indeed, Kamala (1996) Kim and Flynn, (1992) observed exponentially declining concentrations with increasing velocities when testing unheated manikins. However, El Nahas (2005) demonstrated that the declining exponential relationship occurred only with his unheated manikin. When the manikin was heated, El Nahas observed an inverted $\mathrm{V}$ relationship similar to the results found here with human subjects. 


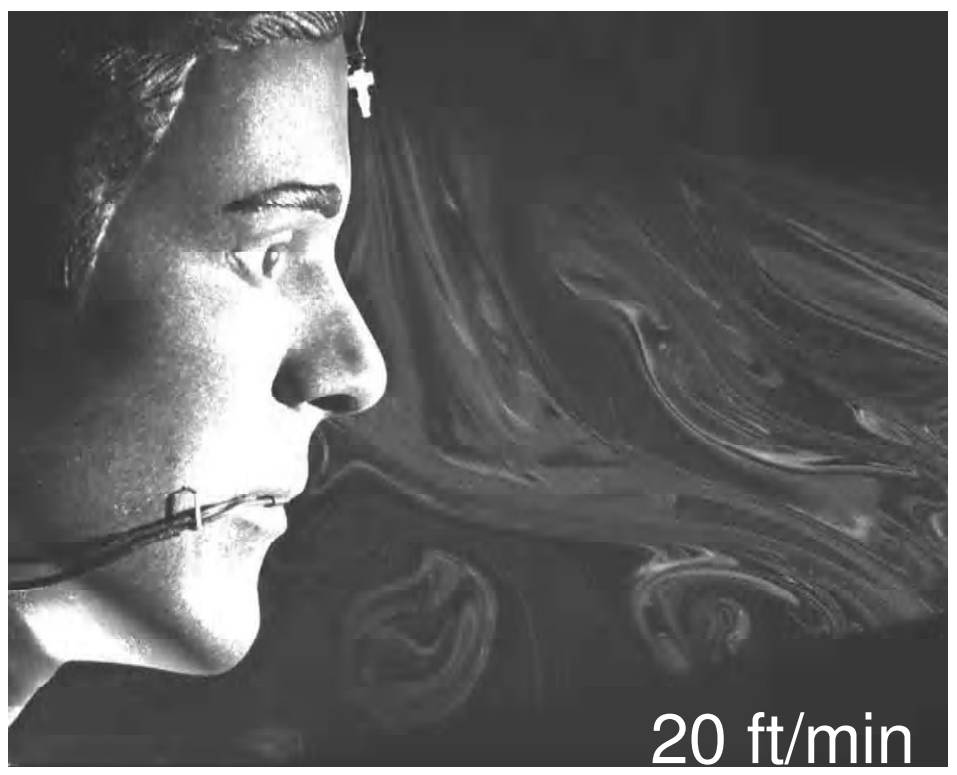

Figure 5.3: A PIV photo at $20 \mathrm{ft} / \mathrm{min}$

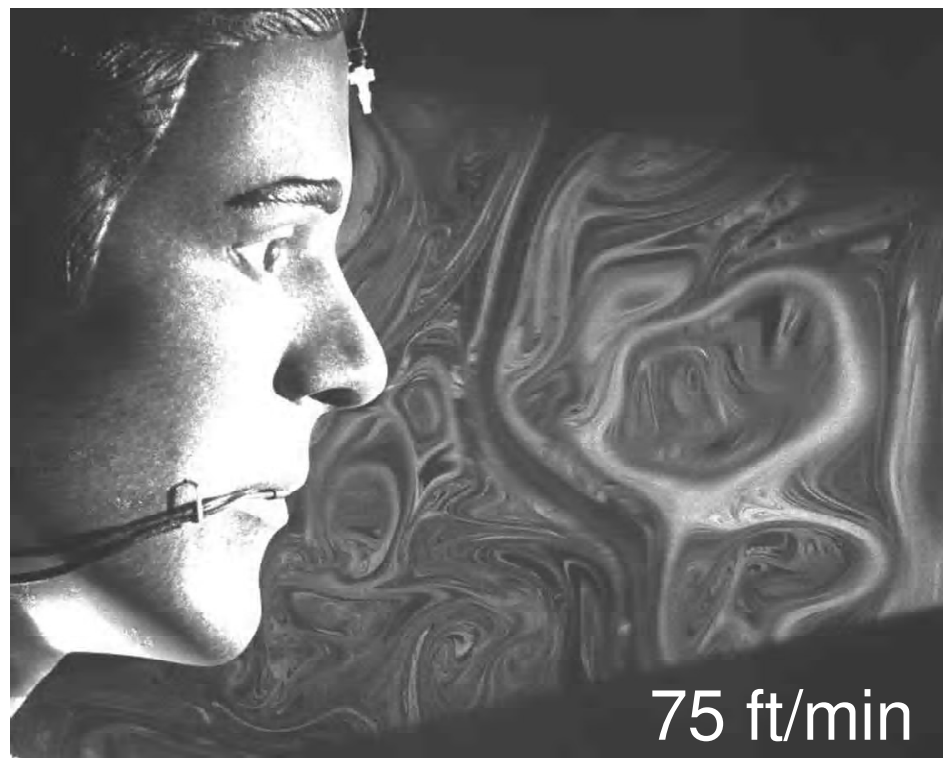

Figure 5.4: A PIV photo at $75 \mathrm{ft} / \mathrm{min}$

The inverted $\mathrm{V}$ relationship could plausibly be attributed to the effects of increased velocity moving contaminant up the torso to the face more and more energetically with increased cross-draft velocity but counter-acted by the increasing dilution of the body wake with increasing cross-draft velocities. At $47.5 \mathrm{fpm}$, the combination produced the highest exposures. As seen in Figure 5.3 and Figure 5.4, the 
eddies near the face can be dramatically different for different velocities. At $20 \mathrm{ft} / \mathrm{min}$ the flow from the back follows the surface of the head down past the forehead to the nose, there meeting an upward flow, causing both to separate from the face at the nose. The flows at $75 \mathrm{ft} / \mathrm{min}$ are radically different. The flow strikes the back of the head and its momentum causes it to separate there, thus producing air movement from the forehead towards the top of the head. The entire face is well within a complex wake consisting of several re-circulating zones. Thus, the inverted V could be completely attributable to complex effects on the wake transport.

If the latter is true, exposures could be strongly affected by things that change the flow around the head, including the subjects' hair length, head size, roundness of head, size of the neck, etc. Likewise, the movement of contaminant from its source below the waist could be strongly affected by body size and roundness, clothing, and body movement and posture. Since each subject could be expected to have somewhat different faces and bodies, patterns of motion, and different postures in both sitting and standing, one would also expect substantial subject differences.

Since when sampling workers one cannot be certain in many cases that they will exclusively sit or stand, the fact that Breathing is important when the worker is sitting suggests that it would be prudent to equip manikins with artificial breathing and employ it at all times, whatever the posture being tested..

On the assumption that both workers and manikins should be breathing when sampled, the rest of the analyses in this section uses normal breathing, only, for examination of the effects of cross-draft velocity. As listed in Table 5.2, velocity and the interaction of velocity with posture had a highly significant effect on $\mathrm{C}_{\text {mouth }}$. For that 
reason, it is important to consider the effect of Velocity on $\mathrm{C}_{\text {mouth }}$ for each posture separately as shown in both tables Table 5.4 and Table 5.5.

\subsection{Comparison of Differences in Concentrations Observed at Different Sampling Locations}

In sampling for worker exposures, industrial hygienists place the inlets of airsampling devices on the torso anywhere from the collar down to the mid-sternum level (see Figure 3.4) and particularly on the "lapel". In previous sections, it has been demonstrated that concentrations at the mouth vary greatly with Subject, Posture, Velocity, and with interactions of Posture and Velocity. Breathing significantly affects $\mathrm{C}_{\text {mouth }}$ for Sitting but not standing. Concentrations when standing were roughly half as much as sitting, and for both Postures and types of breathing, $\mathrm{C}_{\text {mouth }}$ levels varied in an inverse V relationship with Velocity.

In summary, it appears that the center of the chest and lapels produce remarkably poor agreement with $\mathrm{C}_{\text {mouth. }}$. The Log differences are strongly affected by subject, and posture and their 2-way interactions.

It was concluded from Figure 4.36 - Figure 4.39 that for standing posture there were three regions that compiled the sampling location ratios. The forehead and the adjacent nose lied in the lowest region and were given a name of the facial region. The

neck, left collar, and right collar location ratio results were also so close and bundled in a region that was named the torso group region. Finally, the center chest, left lapel, and right lapel were close and bundled in a group called the torso group 
As for the sitting posture the facial region and the shoulder regions were all bundled together and ranged with same ratios. The torso region the chest remained at the highest level and the lapels ratios dropped tremendously but still had the same pattern of the center chest.

Velocity was not substantially affecting $\mathrm{C}_{\text {mouth }}$. Using the Manova, it was proved that the velocity was affecting the ratios of the $\log \left(\mathrm{C}_{\text {forehead }} / \mathrm{C}_{\text {mouth }}, \mathrm{C}_{\text {nose }} / \mathrm{C}_{\text {mouth }}\right.$, $\mathrm{C}_{\text {l.collar }} / \mathrm{C}_{\text {mouth }}, \mathrm{C}_{\text {r.collar }} / \mathrm{C}_{\text {mouth }}$, and $\mathrm{C}_{\text {neck }} / \mathrm{C}_{\text {mouth }}$ ) only, with no effect on the $\mathrm{C}_{\text {c.chest }}$ and the lapels ratios to mouth (as shown in Table 5.7).

\subsection{Concentrations at Different Locations}

The results for other locations had different magnitudes from each other and from $\mathrm{C}_{\text {mouth}}$. It is not surprising that concentrations would increase for locations increasing further down the body since they are also increasingly close to the source. In addition, the flows around the face and over the top of the head could be expected to reduce the concentrations at the face whereas the locations on the torso are solidly within the wake of the body. 


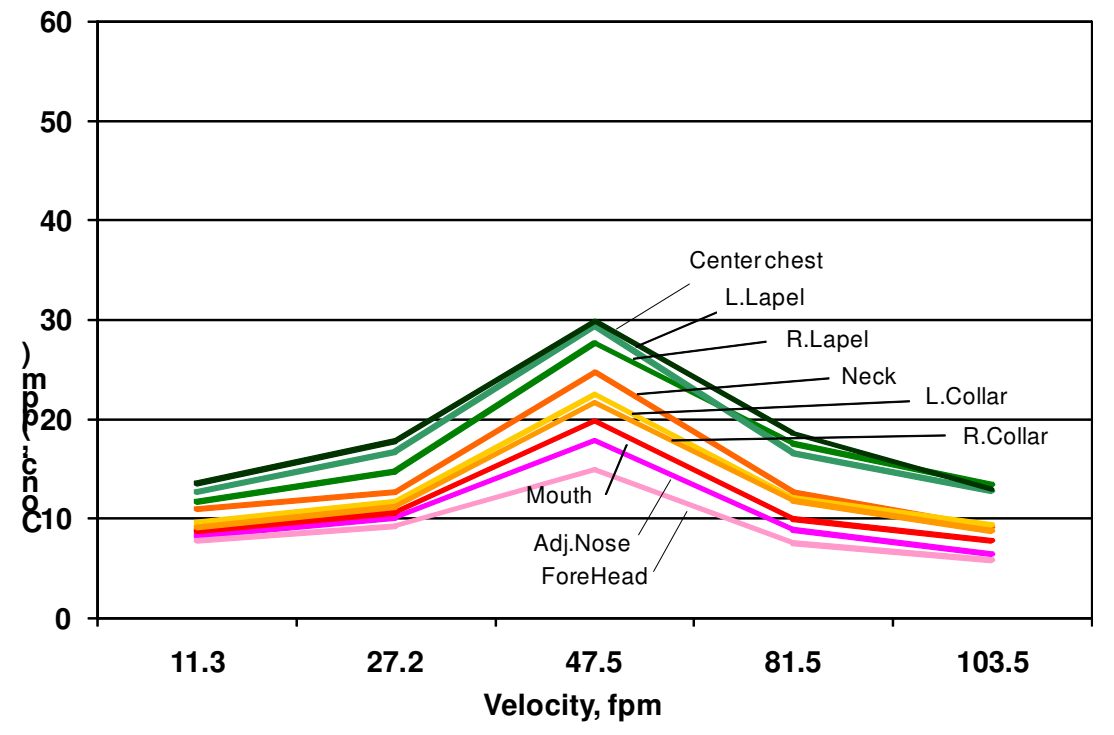

Figure 5.5: Four subjects' $C_{\text {location }}$ average versus velocity for standing \& normal breathing treatments

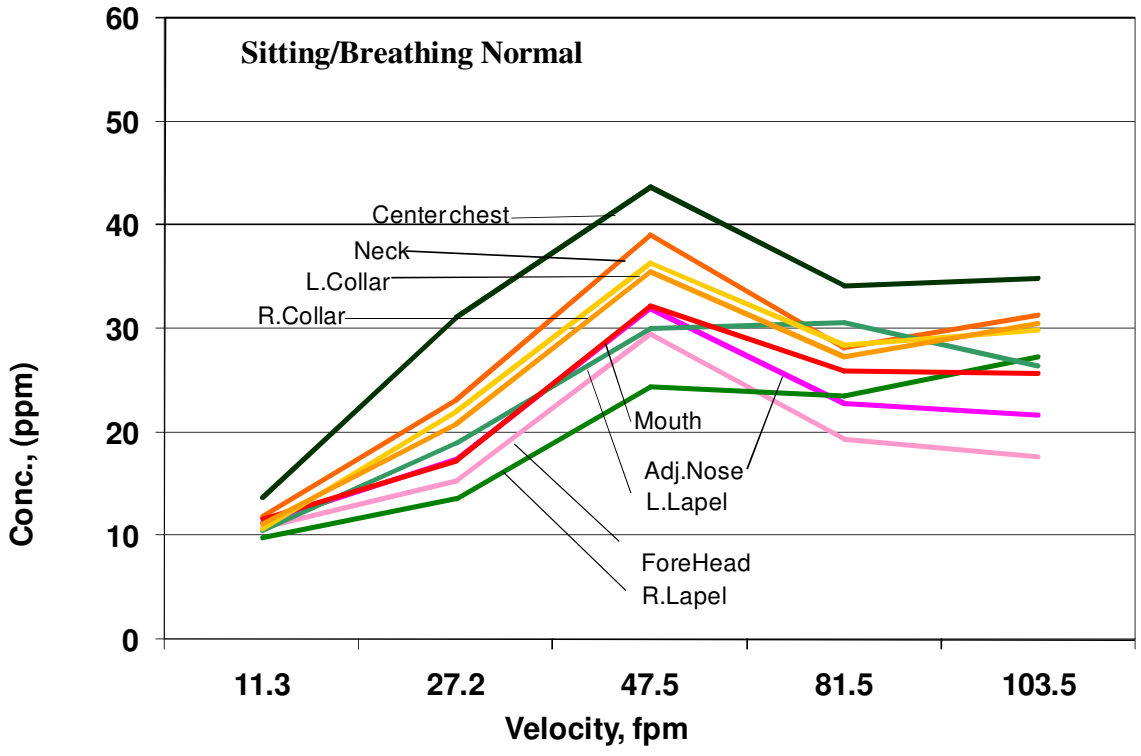

Figure 5.6: Four subjects' $C_{\text {location }}$ average versus velocity for sitting $\&$ normal breathing treatments 


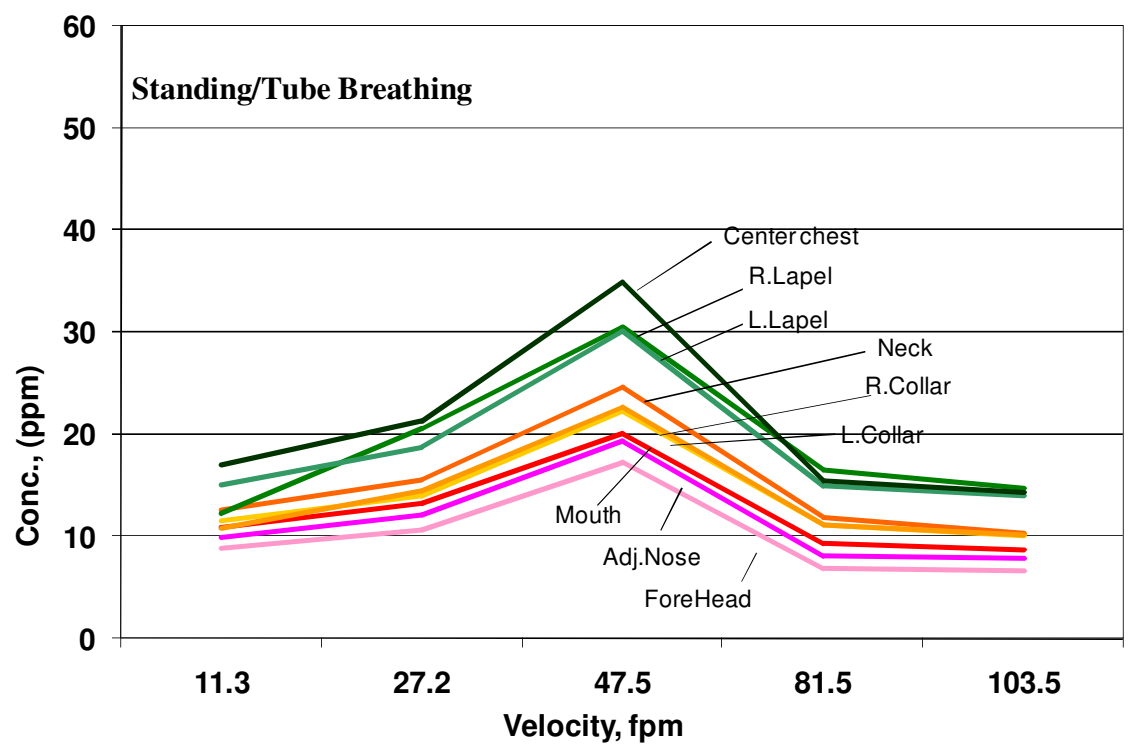

Figure 5.7: Four subjects' $C_{\text {location }}$ average versus velocity for standing $\&$ tube breathing treatments

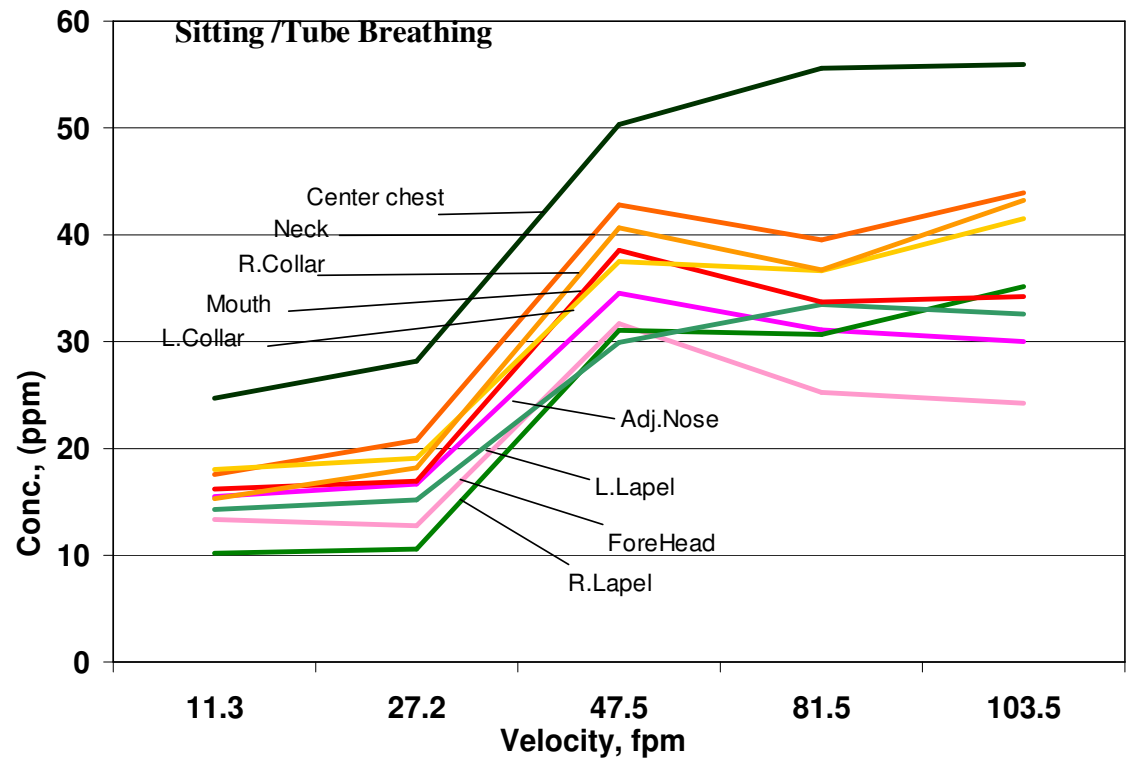

Figure 5.8: Four subjects' $C_{\text {location }}$ average versus velocity for sitting $\&$ tube breathing treatments

\section{$\underline{\text { 5.3.1 Effects of Independent Variables on } \mathrm{C}_{\text {location }}}$}

Although magnitudes of concentrations at different locations varied over a wide range, they nevertheless showed patterns of change for Posture, Velocity, and Breathing that are strikingly similar to $\mathrm{C}_{\text {mouth }}$. This is seen very clearly in Figure 5.5 through Figure 
5.8 where the averages across all subjects and replications are shown. As with $\mathrm{C}_{\text {mouth }}$, the velocity associated with the peak concentration was $47.5 \mathrm{ft} / \mathrm{min}$. As with $\mathrm{C}_{\text {mouth }}$, each value of $\mathrm{C}_{\text {location }}$ formed an inverted $\mathrm{V}$ with velocity. Likewise, concentrations were symmetrical about $\mathrm{V}=43.7 \mathrm{ft} / \mathrm{min}$ for standing and were asymmetrical for sitting. As listed in Table 5.2, Posture, Velocity, and Breathing and their interactions showed roughly the same levels of statistical significance as $\mathrm{C}_{\text {mouth. }}$.

It is somewhat surprising that the similarities to $\mathrm{C}_{\text {mouth }}$ are so great since one could plausibly believe breathing, for example, would have very different effects at the face, shoulder level, and mid-sternum level. Likewise, when sitting at the table with their arms forward, the subjects' bodies would tend to create more of a concave volume than when standing. Hence, one would expect somewhat different effects of posture on lower locations than at the face.

The only locations where $\mathrm{C}_{\text {location }}$ values diverge from the patterns observed for $\mathrm{C}_{\text {mouth }}$ are the two lapel locations. As listed on Table 4.2, they were higher than $\mathrm{C}_{\text {mouth }}$ when standing and lower than $\mathrm{C}_{\text {mouth }}$ when sitting. It is not at all obvious why this should be so at the lapels but not between them at the sternum. 
Table 5.7: Statistics summary for other locations ratios to $\mathbf{C}_{\text {mouth }}$

\begin{tabular}{|c|c|c|c|c|c|c|c|c|}
\hline & & & $\begin{array}{l}\mathbb{E} \\
\mathbb{\mathbb { N }} \\
\sum\end{array}$ & $\begin{array}{l}\frac{c}{\sigma} \\
\frac{0}{0} \\
\mathbb{d} \\
\Sigma\end{array}$ & 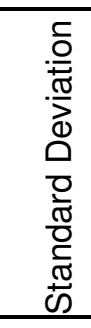 & 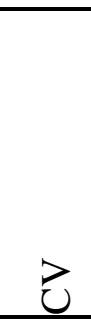 & 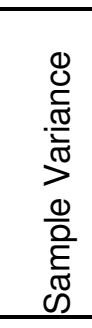 & 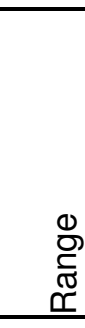 \\
\hline Seated & Tube Breathing & $\mathrm{C}_{\text {forehead }}$ & 0.83 & 0.85 & 0.07 & 0.08 & 0 & 0.16 \\
\hline Seated & Tube Breathing & $C_{\text {nose }}$ & 0.96 & 0.95 & 0.06 & 0.06 & 0 & 0.14 \\
\hline Seated & Tube Breathing & $\mathrm{C}_{\text {neck }}$ & 1.12 & 1.18 & 0.12 & 0.11 & 0.01 & 0.29 \\
\hline Seated & Tube Breathing & $\mathrm{C}_{\text {l.lapel }}$ & 0.87 & 0.89 & 0.11 & 0.13 & 0.01 & 0.29 \\
\hline Seated & Tube Breathing & $\mathrm{C}_{\text {r.lapel }}$ & 0.77 & 0.77 & 0.17 & 0.22 & 0.03 & 0.38 \\
\hline Seated & Tube Breathing & $\mathrm{C}_{\text {l.collar }}$ & 1.07 & 1.08 & 0.09 & 0.08 & 0.01 & 0.23 \\
\hline Seated & Tube Breathing & $\mathrm{C}_{\text {r.collar }}$ & 1.04 & 1.03 & 0.12 & 0.12 & 0.02 & 0.33 \\
\hline Seated & Tube Breathing & $\mathrm{C}_{\text {c.chest }}$ & 1.46 & 1.49 & 0.12 & 0.08 & 0.01 & 0.33 \\
\hline Seated & Normal Breathing & $\mathrm{C}_{\text {forehead }}$ & 0.88 & 0.91 & 0.1 & 0.11 & 0.01 & 0.25 \\
\hline Seated & Normal Breathing & Cnose & 0.95 & 0.95 & 0.06 & 0.06 & 0 & 0.15 \\
\hline Seated & Normal Breathing & $\mathrm{C}_{\text {neck }}$ & 1.06 & 1.04 & 0.1 & 0.09 & 0.01 & 0.26 \\
\hline Seated & Normal Breathing & $\mathrm{C}_{\text {l.lapel }}$ & 0.95 & 0.99 & 0.11 & 0.12 & 0.01 & 0.3 \\
\hline Seated & Normal Breathing & $\mathrm{C}_{\text {r.lapel }}$ & 0.81 & 0.76 & 0.14 & 0.17 & 0.02 & 0.37 \\
\hline Seated & Normal Breathing & $\mathrm{C}_{\text {l.collar }}$ & 1.01 & 0.96 & 0.09 & 0.09 & 0.01 & 0.2 \\
\hline Seated & Normal Breathing & $\mathrm{C}_{\text {r.collar }}$ & 1.02 & 0.97 & 0.08 & 0.08 & 0.01 & 0.19 \\
\hline Seated & Normal Breathing & $\mathrm{C}_{\text {c.chest }}$ & 1.22 & 1.19 & 0.14 & 0.11 & 0.02 & 0.3 \\
\hline Standing & Tube Breathing & $\mathrm{C}_{\text {forehead }}$ & 0.81 & 0.82 & 0.06 & 0.07 & 0 & 0.15 \\
\hline Standing & Tube Breathing & Cnose & 0.93 & 0.92 & 0.04 & 0.04 & 0 & 0.11 \\
\hline Standing & Tube Breathing & $\mathrm{C}_{\text {neck }}$ & 1.26 & 1.25 & 0.04 & 0.03 & 0 & 0.1 \\
\hline Standing & Tube Breathing & $\mathrm{C}_{\text {l.lapel }}$ & 1.57 & 1.56 & 0.09 & 0.06 & 0.01 & 0.24 \\
\hline Standing & Tube Breathing & $\mathrm{C}_{\text {r.lapel }}$ & 1.62 & 1.68 & 0.24 & 0.15 & 0.06 & 0.59 \\
\hline Standing & Tube Breathing & $\mathrm{C}_{\text {l.collar }}$ & 1.14 & 1.14 & 0.06 & 0.05 & 0 & 0.14 \\
\hline Standing & Tube Breathing & $\mathrm{C}_{\text {r.collar }}$ & 1.13 & 1.18 & 0.09 & 0.08 & 0.01 & 0.21 \\
\hline Standing & Normal Breathing & $\mathrm{C}_{\text {c.chest }}$ & 1.71 & 1.73 & 0.07 & 0.04 & 0.01 & 0.2 \\
\hline Standing & Normal Breathing & $\mathrm{C}_{\text {forehead }}$ & 0.81 & 0.77 & 0.07 & 0.09 & 0 & 0.13 \\
\hline Standing & Normal Breathing & Cnose & 0.91 & 0.91 & 0.05 & 0.05 & 0 & 0.12 \\
\hline Standing & Normal Breathing & $\mathrm{C}_{\text {neck }}$ & 1.25 & 1.26 & 0.05 & 0.04 & 0 & 0.11 \\
\hline Standing & Normal Breathing & $\mathrm{C}_{\text {l.lapel }}$ & 1.61 & 1.57 & 0.11 & 0.07 & 0.01 & 0.26 \\
\hline Standing & Normal Breathing & $\mathrm{C}_{\text {r.lapel }}$ & 1.59 & 1.5 & 0.21 & 0.13 & 0.05 & 0.49 \\
\hline Standing & Normal Breathing & $\mathrm{C}_{\text {l.collar }}$ & 1.18 & 1.19 & 0.07 & 0.06 & 0.01 & 0.17 \\
\hline Standing & Normal Breathing & $\mathrm{C}_{\text {r.collar }}$ & 1.12 & 1.14 & 0.06 & 0.05 & 0 & 0.15 \\
\hline Standing & Normal Breathing & $\mathrm{C}_{\text {c.chest }}$ & 1.71 & 1.68 & 0.14 & 0.08 & 0.02 & 0.35 \\
\hline
\end{tabular}


Table 5.8: Mean values of $C_{\text {location }} / \mathbf{C}_{\text {mouth }}$ averaged over all subjects and velocities for normal breathing

\begin{tabular}{|c|c|c|c|c|c|c|c|c|}
\hline 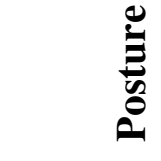 & & $\tilde{E}^{\mathscr{E}}$ & نَّ & نَّ & 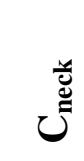 & & U & ن. \\
\hline Both & 0.85 & 0.93 & 1.07 & 1.09 & 1.15 & 1.19 & 1.27 & 1.46 \\
\hline Seated & 0.88 & 0.95 & 1.02 & 1.01 & 1.06 & 0.81 & 0.95 & 1.22 \\
\hline Standing & 0.81 & 0.91 & 1.12 & 1.17 & 1.25 & 1.57 & 1.59 & 1.70 \\
\hline
\end{tabular}

\subsection{Ratios of concentrations to $\mathrm{C}_{\text {mouth }}$ at different locations}

Ideally, samples taken at the surrogate locations would equal concentrations at the mouth. If that were true, the ratio of $\mathrm{C}_{\text {location }}$ to $\mathrm{C}_{\text {mouth }}\left(\mathrm{C}_{\text {ratio }}\right)$ would always equal unity. As shown in Table 5.8, the ratios varied from 0.81 to 1.70 . Less ideal but workable would be the case where the concentrations at a surrogate location varied within a narrow range about some specific proportion of concentrations at the mouth and did not vary substantially by Subject, Posture, or Velocity. In other words, it would be convenient if $\mathrm{C}_{\text {ratio }}$ was fixed for each location even if values of $\mathrm{C}_{\text {ratio }}$ varied from location to location.

Table 5.9: Statistics summary for sampling locations for each posture condition and across all velocities and for normal breathing conditions:

\begin{tabular}{|c|c|c|c|c|c|c|c|c|c|}
\hline Posture & Statistics & 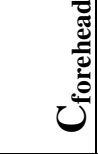 & 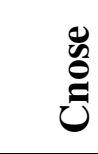 & ن̈ & نَّ & نَ & نَّ & نَّ & نُّن \\
\hline \multirow[t]{6}{*}{ Seated } & Mean & 0.88 & 0.95 & 1.06 & 0.81 & 0.95 & 1.02 & 1.01 & 1.22 \\
\hline & Standard Error & 0.04 & 0.03 & 0.04 & 0.06 & 0.05 & 0.04 & 0.04 & 0.06 \\
\hline & Median & 0.91 & 0.95 & 1.04 & 0.76 & 0.99 & 0.97 & 0.96 & 1.19 \\
\hline & Standard Deviation & 0.10 & 0.06 & 0.10 & 0.14 & 0.11 & 0.08 & 0.09 & 0.14 \\
\hline & Minimum & 0.73 & 0.87 & 0.92 & 0.69 & 0.77 & 0.96 & 0.93 & 1.09 \\
\hline & Maximum & 0.98 & 1.02 & 1.18 & 1.06 & 1.07 & 1.14 & 1.12 & 1.38 \\
\hline \multirow[t]{6}{*}{ Standing } & Mean & 0.81 & 0.91 & 1.25 & 1.57 & 1.59 & 1.12 & 1.17 & 1.70 \\
\hline & Standard Error & 0.03 & 0.02 & 0.02 & 0.10 & 0.05 & 0.03 & 0.03 & 0.07 \\
\hline & Median & 0.77 & 0.91 & 1.25 & 1.50 & 1.57 & 1.14 & 1.19 & 1.66 \\
\hline & Standard Deviation & 0.06 & 0.04 & 0.05 & 0.22 & 0.11 & 0.06 & 0.07 & 0.15 \\
\hline & Minimum & 0.76 & 0.86 & 1.19 & 1.35 & 1.47 & 1.05 & 1.10 & 1.58 \\
\hline & Maximum & 0.88 & 0.95 & 1.31 & 1.88 & 1.77 & 1.21 & 1.27 & 1.95 \\
\hline
\end{tabular}


If values of $\mathrm{C}_{\text {ratio }}$ could be determined with confidence, one could "correct" values obtained at other locations to match the inhaled concentration (i.e., $\mathrm{C}_{\text {mouth }}$ ). In actuality, for this study $\mathrm{C}_{\text {ratio }}$ fell within relatively narrow ranges (see Table 5.9) for locations on the face and over broad ranges for locations increasingly further down the body. For example, the ratios for $\mathrm{C}_{\text {forehead }}$ ranged from 0.5 to 1.4 while ratios for $\mathrm{C}_{\mathrm{c} . \text { chest }}$ varied from 0.8 to 2.3. The most stunning results are for the lapels, which vary from 0.4 to 2.1 because the ratios are less than unity for Sitting and greater than unity for Standing.

Given the short distance from the mouth to the adjacent nose location, it may surprise some that there were differences from the mouth that were as high as $10 \%$. However, as shown on Figure 5.2 and Figure 5.3, the air patterns near the face are extremely complex, which tends to challenge simplistic expectations.

Perhaps equally surprising to some is the very large deviations from the mouth observed on the torso. Field studies (Martinelli et al. 1983, and Malek 1999) found concentrations that would compute to $\mathrm{C}_{\text {ratio }}=1.25$. The much narrow differences found in the field probably attest to very different tasks for sampled workers and, perhaps, much greater diversity in postures and in cross-draft conditions. The wind tunnel used in this study allowed for good control and repeatability at the cost of providing a possibly unrealistically uniform flow that was always flowed directly from the back of the subjects.

\subsubsection{ANOVA for Cratio}

The values of $\mathrm{C}_{\text {ratio }}$ were not constant for any location. Instead, as shown on

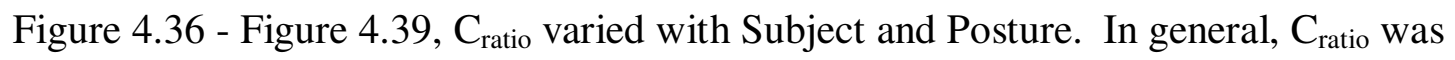


highest for the standing posture and the lowest values for the seated posture (see Table 4.9 - Table 4.11). The effect of velocity did not show a clear pattern. Breathing did not appear to be an important factor.

To evaluate the significance of the independent variables, ANOVA was done using Datadesk software to test the following model:

$$
\begin{aligned}
\mathrm{Y}_{\mathrm{imzko}}= & \mu(\psi)_{\mathrm{i}}+(\Omega)_{\mathrm{m}}+(\varepsilon)_{\mathrm{z}}+(\omega)_{\mathrm{k}}+(\psi \omega)_{\mathrm{ik}}+(\psi \Omega)_{\mathrm{im}}+(\psi \varepsilon)_{\mathrm{iz}}+(\omega \varepsilon)_{\mathrm{kz}}+(\varepsilon \Omega)_{\mathrm{zm}}+(\omega \Omega)_{\mathrm{km}} \\
& +(\psi \omega \varepsilon)_{\mathrm{ikz}}+(\psi \omega \Omega)_{\mathrm{ikz}}+(\psi \Omega \varepsilon)_{\mathrm{imz}}+(\omega \Omega \varepsilon)_{\mathrm{kmz}}+\varepsilon_{\mathrm{imzko}}
\end{aligned}
$$

Where: $\mathrm{i}=1,2 ; \mathrm{m}=1,2 ; \mathrm{z}=1,2,3,4 ; \mathrm{k}=1,2,3,4,5 ; \mathrm{o}=2$

$\mathrm{Y}_{\mathrm{imzko}}=\log \left(\mathrm{C}_{\text {locationi }} / \mathrm{C}_{\text {mouth }}\right)$ for a given test

$\mu=$ constant

$\varepsilon_{\text {imzko }}=$ random error

Posture $=\psi_{\mathrm{i}}$, categorical variable

Breathing $=\Omega_{\mathrm{m}}$, categorical variable

Subject $=\varepsilon_{z}$, categorical variable

Velocity $=\omega_{\mathrm{k}}$ treated as a categorical variable

$(\psi \omega)_{\mathrm{ik}},(\psi \Omega)_{\mathrm{im},}(\psi \varepsilon)_{\mathrm{iz}},(\omega \varepsilon)_{\mathrm{kz}},(\varepsilon \Omega)_{\mathrm{zm}}$, and $(\omega \Omega)_{\mathrm{km}}$ are the two-way interaction effects of the four independent variables

$(\psi \omega \varepsilon)_{\mathrm{k} z},(\psi \omega \Omega)_{\mathrm{kkz}},(\psi \Omega \varepsilon)_{\mathrm{imz}},(\omega \Omega \varepsilon)_{\mathrm{kmz}}$ are the three-way interaction effects of the four independent variables 
Table 5.10: P-values from ANOVA for $\log \left(\mathrm{C}_{\text {location }} / \mathrm{C}_{\text {mouth }}\right)$ in sitting and standing Conditions

\begin{tabular}{|c|c|c|c|c|c|c|c|c|c|}
\hline Source & $d f$ & 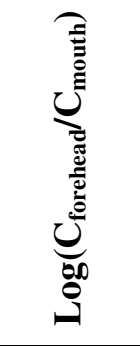 & 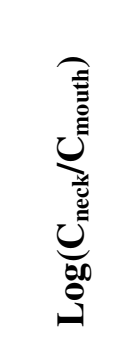 & 咅产 & 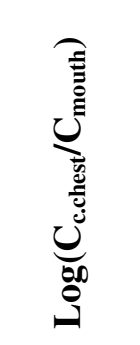 & 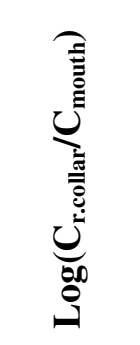 & & 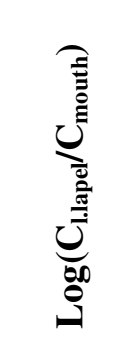 & 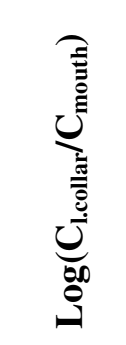 \\
\hline Const & 1 & $<0.0001$ & $<0.0001$ & 0.03 & $<0.0001$ & $<0.0001$ & 0.05 & $<0.0001$ & $<0.0001$ \\
\hline Posture & 1 & 0.05 & $<0.0001$ & 0.23 & $<0.0001$ & 0.01 & $<0.0001$ & $<0.0001$ & $<0.0001$ \\
\hline Subject & 3 & $<0.0001$ & 0.01 & 0.16 & $<0.0001$ & 0.02 & $<0.0001$ & 0.02 & 0.01 \\
\hline Posture*Subject & 3 & 0.05 & 0.01 & 0.97 & $<0.0001$ & $<0.0001$ & 0.09 & $<0.0001$ & $<0.0001$ \\
\hline Velocity & 4 & $<0.0001$ & 0.52 & 0.19 & 0.68 & 0.19 & 0.04 & 0.37 & 0.33 \\
\hline Velocity*Subject & 12 & 0.3 & 0.21 & 0.25 & 0.15 & 0.16 & 0.52 & 0.25 & 0.04 \\
\hline Posture * Velocity & 4 & 0.56 & 0.29 & 0.55 & 0.41 & 0.12 & 0.25 & 0.65 & 0.14 \\
\hline
\end{tabular}

The ratios were log-transformed for two reasons: 1) it improved the normality of the residuals; and 2) since $\log (\mathrm{y} / \mathrm{z})=\log (\mathrm{y})-\log (\mathrm{z})$, it avoids problems due to small denominators.

As shown on Table 5.10, the effects of velocity were much less important for the ratio than for the concentrations themselves, as could be expected from the similarity of their profiles with velocity (see Figure 4.42- Figure 4.47). The exceptions were the forehead and the right lapel. However, posture was highly statistically significant $(\mathrm{p}<0.001)$ or significant $(\mathrm{p}<0.05)$ for all locations except Adjacent Nose. In other words, the human subjects and their different interaction with posture were statistically significant (to highly significant) for all but Adjacent Nose location. 
Table 5.11: Correction factor (i.e., $\mathbf{C}_{\text {mouth }} / \mathbf{C}_{\text {location }}$ ) for every sampled location

\begin{tabular}{|c|c|c|c|c|c|c|c|c|}
\hline 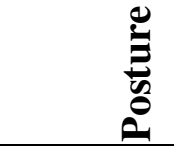 & 胥 & $\underbrace{\stackrel{0}{*}}$ & نَّ & 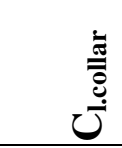 & نِّ & 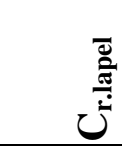 & 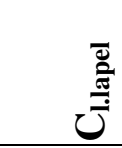 & ن. \\
\hline Both & 1.18 & 1.08 & 0.93 & 0.92 & 0.87 & 0.84 & 0.79 & 0.68 \\
\hline Seated & 1.14 & 1.05 & 0.98 & 0.99 & 0.94 & 1.23 & 1.05 & 0.82 \\
\hline Standing & 1.23 & 1.10 & 0.89 & 0.85 & 0.80 & 0.64 & 0.63 & 0.59 \\
\hline
\end{tabular}

\subsection{Manikin}

The manikin raw data for this comparison were taken from a previous study done by El Nahas (2005). El Nahass' study established that heating and breathing strongly affected concentrations at the same locations sampled in this study. Indeed, the effect of heating was so profound that only one or the other could possibly compare well to humans, not both. It is reasonable to assume that results for the manikin would compare best to human results for the cases where the manikin was both heated and breathing, as opposed to when it was only one or neither. If that proved true, it would be reasonable to recommend that manikin used in future studies should be heated and provided with lifelike breathing. If the results for humans did not match any of the combinations of heating and breathing, then one must be gravely concerned about whether a non-moving manikin could be an effective surrogate for a human in exposure studies.

The results of this study generally agreed with the manikin studies by ElNahas (2005) for a heated, breathing, anthropometrically correct manikin tested under identical conditions using the same apparatus. In general, the results for the manikin showed similar relationships to the independent variables as were found for humans in this study. For both seated and standing conditions (see Figure 59 - Figure 5 12), the peak 
concentrations in both studies occurred at $47.5 \mathrm{ft} / \mathrm{min}$, forming an inverted $\mathrm{V}$ pattern in both studies. However, the El Nahas study found much greater symmetry for the seated conditions than did the human subject study.

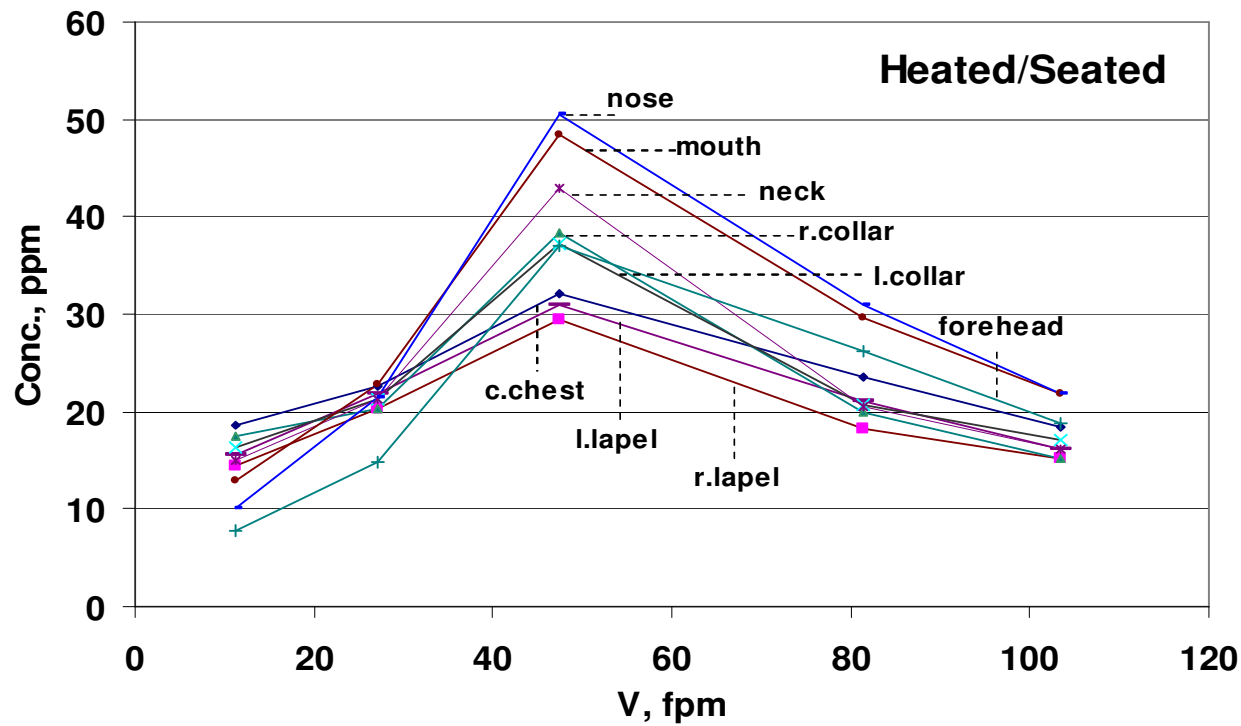

Figure 5 9: Manikin seated locations concentration Vs velocity (taken from El Nahas, 2005)

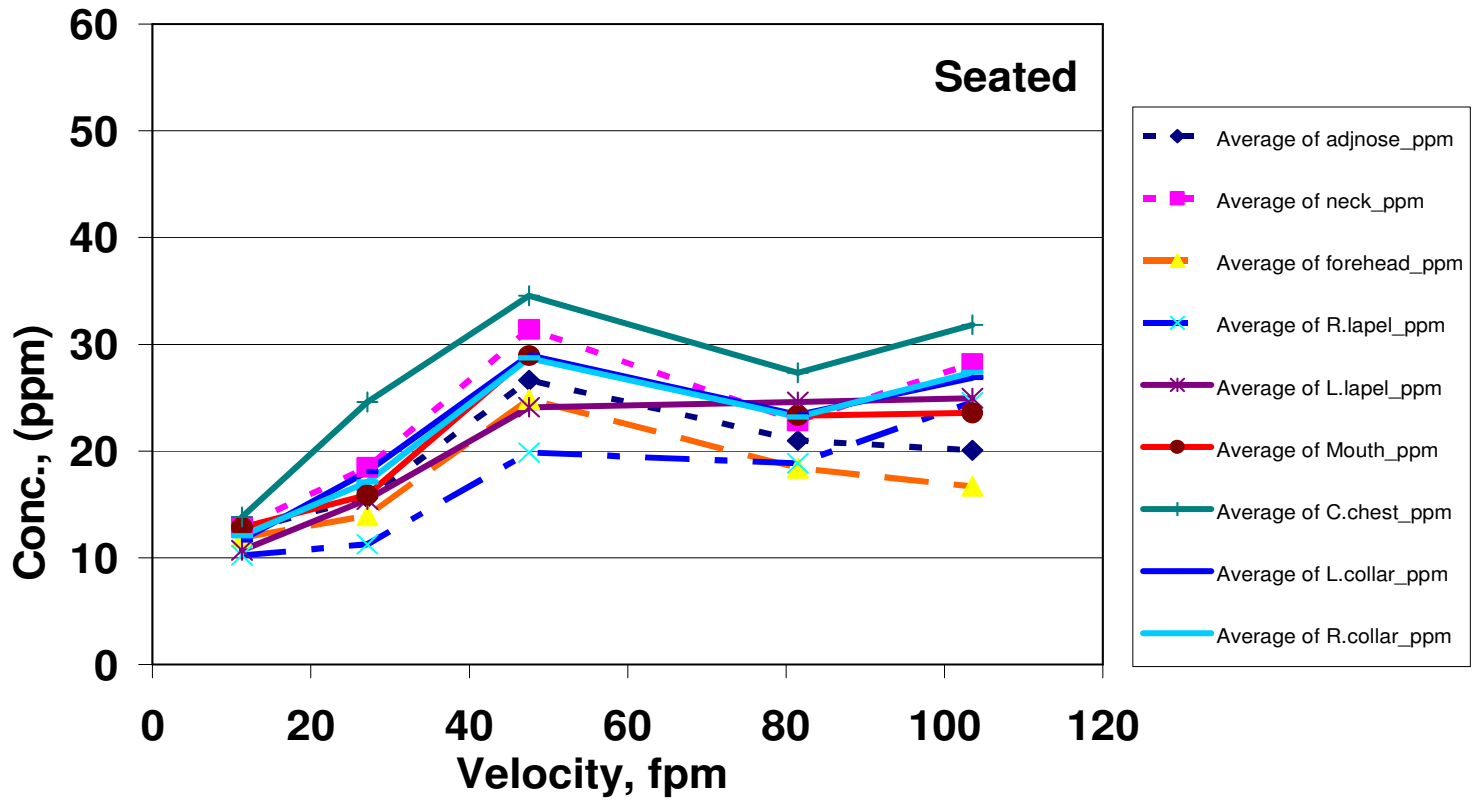

Figure 5 10: Human subject seated locations concentration Vs velocity 


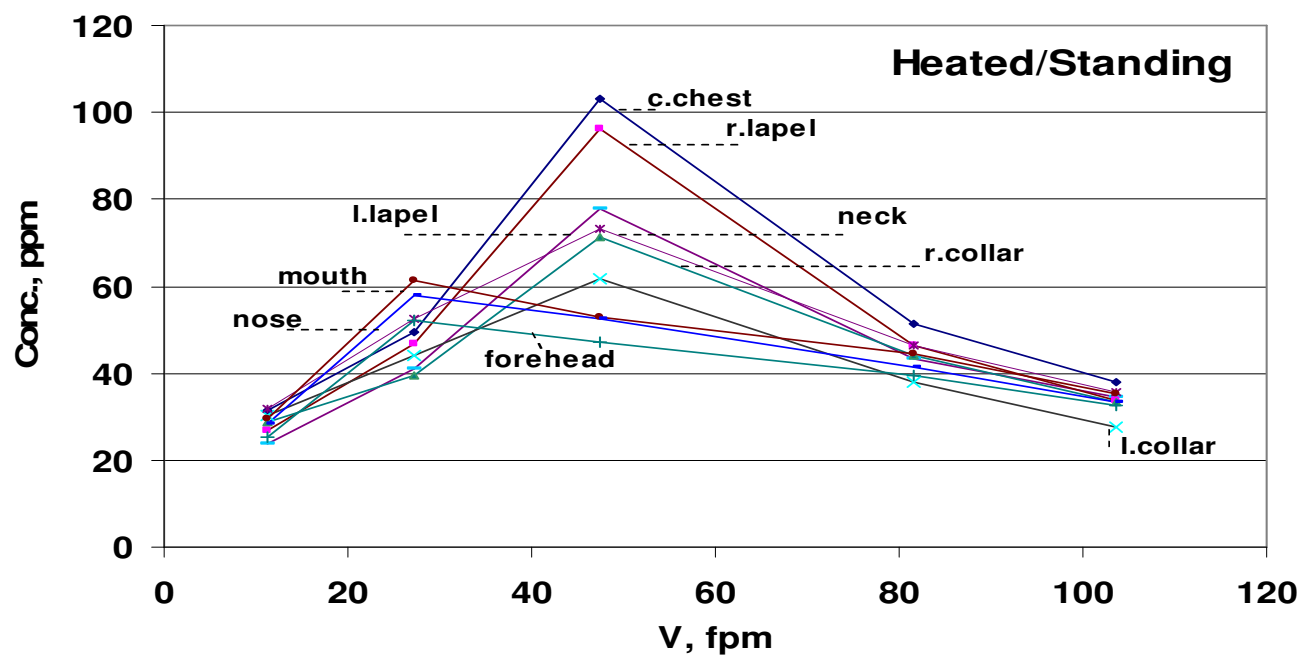

Figure 5 11: Manikin standing locations concentration Vs velocity (taken from El Nahas, 2005)

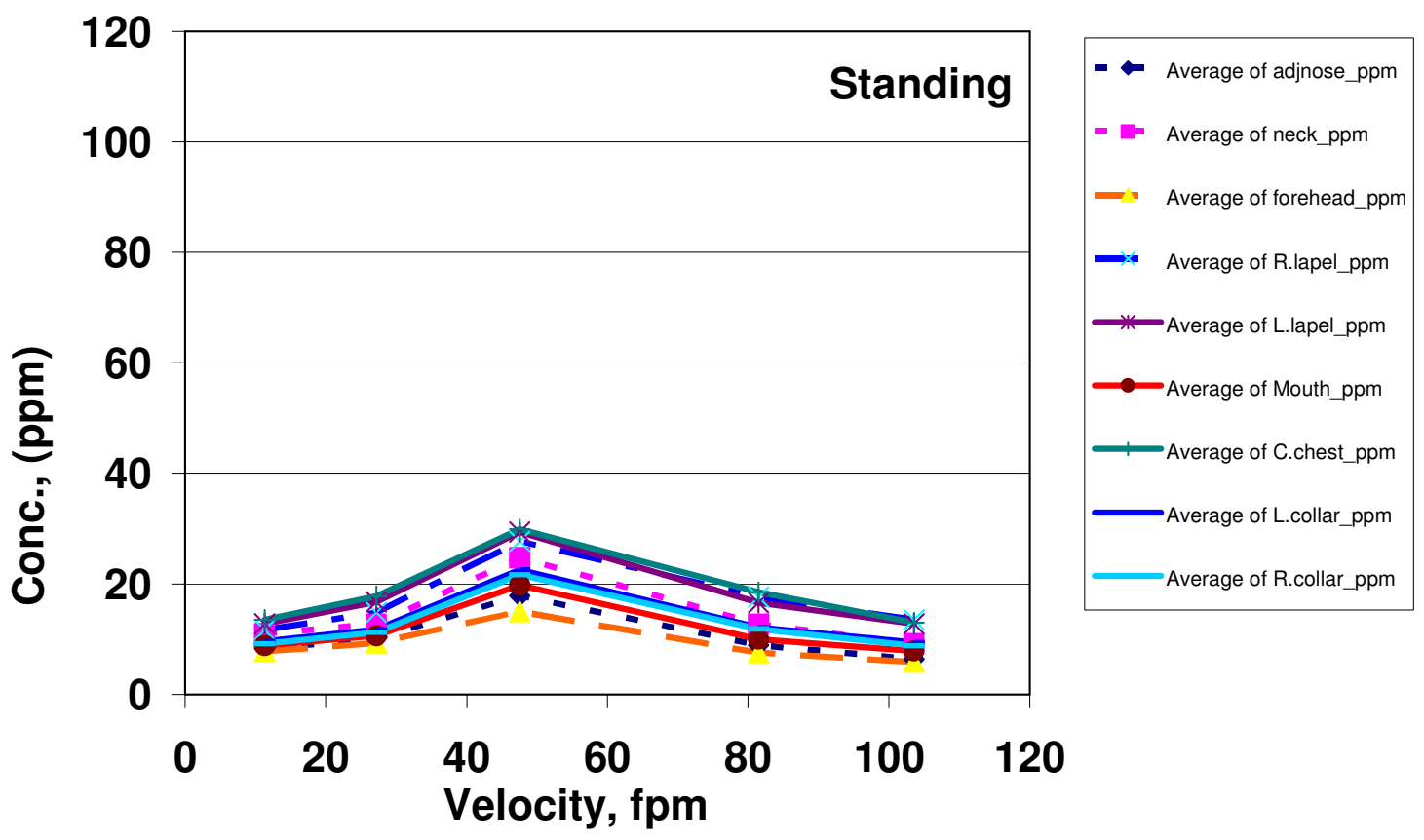

Figure 5 12: Human subject standing locations concentration Vs velocity 


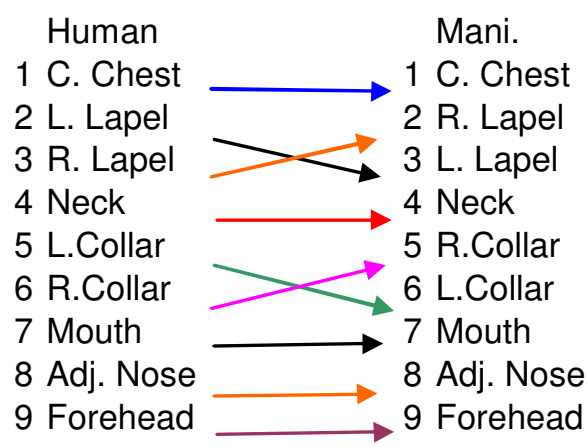

Figure 5.13: Change in rank during seated condition

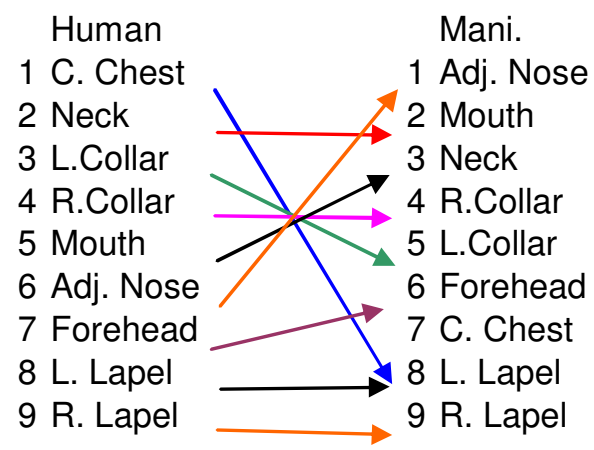

Figure 5.14: Change in rank during standing condition

More importantly, as shown in Figure 5.13 and Figure 5.14, the rank order of locations was very different for the two studies for the standing conditions. Indeed, El Nahas found that center chest went from nearly twice $C_{\text {mouth }}$ when standing to roughly one-half when sitting. Likewise, the rank of Adjacent Nose was radically different for the manikin and the human subjects. 


\section{CHAPTER 6: CONCLUSIONS AND RECOMMENDATIONS}

\subsection{Conclusions}

The conclusions reached from this study were:

1. Exposures observed at the edge of the mouth $\left(\mathrm{C}_{\text {mouth }}\right)$ varied with high significance with Posture, Velocity, and Subject and with interactions of Posture and Velocity.

2. $\mathrm{C}_{\text {mouth }}$ was nearly twice as high for Sitting and for Standing.

3. $\mathrm{C}_{\text {mouth }}$ varied with velocities in an inverted $\mathrm{V}$ relationship so that the highest exposures occurred at $47.5 \mathrm{ft} / \mathrm{min}$. The $\mathrm{V}$ was symmetrical for Standing and asymmetric for Sitting.

4. $\mathrm{C}_{\text {mouth }}$ varied significantly with breathing (exhaling through tube/normal breathing) for Sitting but not for the Standing posture.

5. Concentrations $\left(\mathrm{C}_{\text {location }}\right)$ at sampling sites on the face, shoulder level, and midsternum level were remarkably similar to $C_{\text {mouth }}$ in the effects of Posture, Velocity, and Breathing.

6. The ratio of $\mathrm{C}_{\text {location }}$ to $\mathrm{C}_{\text {mouth }}$ was near unity adjacent to the nose and roughly 0.9 at the forehead.

7. The ratio was 1.06 to 1.25 at the neck and shoulders and 1.20 to 1.70 at midsternum. 
8. The ratio at the lapels was 0.81 to 1.57 , showing ratios lower than unity for Sitting and higher than unity for Standing.

9. Although there were strong similarities between results for a manikin and the four human subjects, the results for the manikin were generally much higher, the effects at the lower chest were somewhat different, and the posture treatment affected the human subject results inversely when compared to the Manikin results. 


\subsection{Recommendations}

The collars showed the lowest deviations from concentrations measured at the mouth. They should be the preferred surrogate locations if the sampling inlet cannot be placed near the mouth

The strong effects of Velocity, Subject, and Posture on ratios make predictions of $\mathrm{C}_{\text {mouth }}$ from concentrations measured on the torso (especially at the Chest and lapels) highly uncertain. For that reason, it is prudent to sample near the mouth, if possible, and near the neck or collars, if not. The lapels should be avoided.

Results from manikin studies should be used with great caution, especially if the manikin is not heated or if it is not "breathing". Given that the heated, breathing, anthropometric manikin used in this study show substantial deviations from results for the human subjects, additional steps may be necessary to make the manikin still more lifelike. In particular, it is possible that to be an accurate surrogate for humans, a manikin will have to simulate human movements.

\subsection{Caveats}

This study was done with a limited number of human subjects and was compared to only one manikin. It is likely that a larger and more diverse range of human subjects and manikins would produce even greater ranges of results. The study was done within a large wind tunnel whose flow is more uniform that the more chaotic and varied conditions at workplaces. It is likely that more turbulent and non-uniform flows would produce lower ratios between sampling locations. In real work, people generally go 
through diverse motions and postures throughout the day, during which the cross-draft velocity may change. It is possible that that diversity would tend to average out the effects of postures and cross-draft velocities when 8-hour time-weighted sampling is done.

The dramatic effects of subjects, velocities, and postures suggest that exposure studies should consider multiple postures and cross-draft velocities. The lapels and chest samples were poor surrogates for the mouth, but concentrations measured adjacent to the nose, the forehead, and the collars generally fell within $\pm 20 \%$ of $\mathrm{C}_{\text {mouth }}$.

For humans, breathing through a tube had significant effect during sitting posture.

For humans, the collars, nose, and forehead were reasonably good surrogates for the mouth.

Based on results from the human studies, concentrations at the mouth can be estimated with reasonable precision using samples taken at the forehead, adjacent to the nose, or at the collars. Concentrations at the forehead were roughly $20 \%$ less concentrations at the mouth and concentrations at the nose were roughly $7 \%$ less than concentrations at the mouth. The forehead and nose locations provided ratios to $\mathrm{C}_{\text {mouth }}$ with the lowest geometric standard deviations. They were affected by the independent variables in similar behavior as of the $\mathrm{C}_{\text {mouth }}$. Thus both can provide reasonably good estimates of $\mathrm{C}_{\text {mouth }}$ by adding a fixed percentage correction to their values. 


\subsection{Impact of the Study}

The outcomes of the study raise serious concerns about the accuracy of sampling on the chest, especially at the lapels when the source is near the worker and airflow is from the back. It is particularly important to note that the resulting sampling errors may vary greatly if the subject is sitting rather than standing and may depend strongly on the airflow velocity, which generally is difficult to characterize in the field. For 8-hour sampling, the level of error may be substantially reduced if the worker both sits and stands and if the velocity varies from low to high levels (the errors will "average out" to a degree). For 15-minute or shorter samples, it is unlikely that these conditions would vary a great deal, so sampling concentrations taken on the chest could vary from $50 \%$ to $200 \%$ of the inhaled value.

The impact of this research work is to raise concerns about use of lapel and chest locations as surrogates for inhaled concentrations and to suggest that variability in sampling results could be strongly affected by using these surrogates for different conditions.

\subsection{Recommendations for Future Work}

This study found important differences between the results for four human subjects and one manikin. It would be highly desirable to use manikins instead of human subjects for future research, but given these results, it would be difficult to do so with confidence. It would be very useful to determine what changes to the manikin are necessary to narrow the differences. Given that the manikin was heated and breathed like a normal human and was anthropometrically proportioned and had a lifelike face, the 
only obvious improvement would be to roboticize the manikin so that it moved like the human subjects while doing the same task they did. It may also be helpful to have a more diverse range of manikin body sizes and shapes (including diverse degrees of simulated obesity) hairstyles, and clothing.

In addition, laboratory studies could be improved by incorporating the results from field observations of the actual ranges of postures, cross-drafts velocities, and task movements that occur in real work. Finally, sampling workers during a diverse range of tasks at a diverse range of work places could shed light on the true magnitude of the errors actually experienced during sampling from using samples taken at the torso.

As the results of this study, are considered important for laboratory research as well as for industrial hygiene practices. Further investigations is needed to be conducted for the effects of these variables on more number of human subjects and determine the relations between the human body and the concentration at the locations.

Subject-to-subject differences were substantial. There were not enough subjects to determine if subject physiological measurements, gender, or hair length substantially affected concentrations at the mouth or at the surrogate locations that was due to the study-limited budget

It is recommended to study the effects of wider range of wind tunnel velocities, the effect of mouth breathing, and breathing rates at moderate and heavy activities that are present in industrial applications. In addition, in any industrial environment, workers wear glasses, helmets, caps, and goggles. These variables may have an effect on inhaled concentrations for workers. In another word, more variability in future experiments is needed. 


\section{APPENDIX A: LOW FLOW PUMPS CALIBRATION SHEET}

\begin{tabular}{|l|l|l|l|l|l|}
\hline Record\# & Line Name & $\begin{array}{l}\text { Pump } \\
\#\end{array}$ & $\begin{array}{l}\text { Pump } \\
\text { Model }\end{array}$ & $\begin{array}{l}\text { Pump } \\
\text { Serial \# }\end{array}$ & $\begin{array}{l}\text { Average Flow Rate of } \\
\text { 3 measures }\end{array}$ \\
\hline $\mathbf{1}$ & C. chest & 1 & $222-3$ & 0205708 & 0.149 \\
\hline $\mathbf{2}$ & L. lapel & 2 & $222-3$ & 0205709 & 0.153 \\
\hline $\mathbf{3}$ & R. lapel & 4 & $222-3$ & 0212101 & 0.154 \\
\hline $\mathbf{4}$ & Neck & 5 & $222-3$ & 0212102 & 0.155 \\
\hline $\mathbf{5}$ & L. collar & 6 & $222-3$ & 0217515 & 0.153 \\
\hline $\mathbf{6}$ & R. collar & 13 & $222-3$ & 0217504 & 0.148 \\
\hline $\mathbf{7}$ & Inhale/Mouth & 14 & $222-3$ & 0217507 & 0.149 \\
\hline $\mathbf{8}$ & Adj.Nose & 12 & $222-3$ & 0217510 & 0.148 \\
\hline $\mathbf{9}$ & Forehead & 9 & $222-3$ & 0316010 & 0.153 \\
\hline $\mathbf{1 0}$ & Exhale/Mouth & 3 & $222-3$ & 0316832 & 0.154 \\
\hline
\end{tabular}

This calibration was carried by Mingyu \& AES. 


\section{APPENDIX B: Ambient Conditions During Sampling}

\begin{tabular}{|c|c|c|c|c|c|c|}
\hline & Mean & S & CV & Max & Min & Range \\
\hline Pressure $\mathbf{~ m m H g}$ & 756 & 9.92 & $1.3 \%$ & 780 & 737 & 43 \\
\hline Rh Indoor \% $^{\text {Rh Outdoor \% }}$ & $24 \%$ & 0.05 & $21.5 \%$ & $28 \%$ & $18 \%$ & $10.0 \%$ \\
\hline WT Temp $^{\circ} \mathbf{F}$ & $25 \%$ & 0.01 & $3.0 \%$ & $26 \%$ & $24 \%$ & $2.0 \%$ \\
\hline WT Right wall $^{\circ} \mathbf{F}$ & 76 & 0.88 & $1.2 \%$ & 77 & 75 & 2 \\
\hline WT Left wall $^{\circ} \mathbf{F}$ & 73.4 & 2.05 & $8.9 \%$ & 77 & 65.8 & 11.2 \\
\hline Subject Center Head Temp $^{\circ} \mathbf{F}$ & 73.4 & 2.10 & $9.1 \%$ & 77 & 65.8 & 11.2 \\
\hline
\end{tabular}




\section{APPENDIX C: Sampling lines Leaks \& losses}

\begin{tabular}{|l|l|l|}
\hline & & $\begin{array}{l}\text { \% losses in sampling with } \\
\text { respect to Source bag } \\
\text { concentration Before testing } \\
\text { lines }\end{array}$ \\
\hline Source Before Testing & 2607 & $8.32 \%$ \\
\hline Right Lapel & 2390 & $4.45 \%$ \\
\hline Left Lapel & 2491 & $4.49 \%$ \\
\hline Center Chest & 2490 & $6.37 \%$ \\
\hline Neck & 2441 & $7.06 \%$ \\
\hline Inhale / Mouth & 2423 & $7.83 \%$ \\
\hline Nose & 2403 & $8.02 \%$ \\
\hline Forehead & 2398 & $8.21 \%$ \\
\hline Left Collar & 2393 & $2.69 \%$ \\
\hline Right Collar & 2537 & $1.76 \%$ \\
\hline Exhale / Mouth 2 & 2561 & $1.00 \%$ \\
\hline Source After Testing & 2581 & \\
\hline
\end{tabular}




\section{References}

Kim, T. and Michael R. Flynn.: Airflow Pattern around A Worker in a Uniform Free stream. Am Ind Hyg.Assoc.J.52: 287-296 (1991).

Flynn, M.R. and Dennis K.George.: A Filed Evaluation of a Mathematical Model to Predict Worker Exposure to Solvent Vapors. Appl.Occup.Environ.Hyg. 11(10): 1212-1216; (1996).

OSHA Technical Manual Section II: Chapter 1, General; II. Sampling procedures, Starting Sampling. www.osha.gov :Dated 03/31/2003

Cohen, B.S.; Harley, N.H.; Lippman, M.: Bias in Air Sampling Techniques Used to Measure Inhalation Exposure. Am Ind Hyg.Assoc.J.44: 187-192 (1984).

Chatterjee, B.B., M.K. Williams, J. Walford and E. King: The Location of Personal Samplers Filter Heads. Am.Ind Hyg.Assoc.J.30: 643-645 (1969).

Donaldson, H.M. and W.T. Stringer: Beryllium Sampling Methods.: Am Ind Hyg.Assoc.J.41: 85-90 (1980).

Martenelli, C.A.; Harley, N.H.; Cohen, B.S.: Monitoring Real-time Aerosol Distribution in the Breathing Zone. Am Ind Hyg.Assoc.J.44: 280-285 (1983).

Van Der Wal, J.F.; Moerkerken, A.: The Performance of Passive Diffusion Monitors for organic Vapors for Personal Sampling of Painters.

Ann.Occup.Hyg. 28: 39-47 (1984).

Cohen, B.S.; Malek R.: Measurement of Workers Exposure to Styrene. Final Report. NIOSH-00182755.Grant No. 1 RO3 OHO2180.

Kim, T. and Michael R. Flynn.: The Effect of Contaminant Source Momentum on a Workers Breathing Zone Concentration In a Uniform Freestream. Am Ind Hyg.Assoc.J.53: 757-766 (1992).

Rodes, C.E., Kamens, R.M., Wiener, R.W.: Experimental Consideration for the Study of Contaminant Dispersion near the Body Am Ind Hyg.Assoc.J.56: 535-545 (1995).

Kulmala, I., Saamanen, A., Enbom, S.: The Effect of Contaminant Source Location on Worker Exposure in the Near-Wake Region. Ann.Occup.Hyg. 40: 511-523 (1996).

Johnson, A.E., Fletcher, B., Saunders, C.J.: Air Movement Around a Worker in a Low-Speed Flow Field. Ann.Occup.Hyg. 40: 57-64 (1996).

Flynn, M.R., and Bengt Ljungqvist: A Review Of Wake Effects On a Workers Exposure. Ann.Occup.Hyg. 39: 211-221 (1995).

Malek, R.F., Daisy, J.M., Cohen, B.S.: Breathing Zone Concentrations Variations in the Reinforced Plastic Industry; Field measurements in a Boat Manufacturing Plant. Appl.Occup.Environ.Hyg. 14(11): 777-784; (1996). 
Welling, I., Andersson, I., Rosen, G., Raisanen, J., Mielo, T., Marttien, K., Niemela, R.: Contaminant Dispersion in the Vicinity of a Worker in a Uniform Velocity Field. Ann.Occup.Hyg. 44: 219-225 (2000).

Guffey, S. E., Flanagan, M.E., Belle van G.: Air Sampling at the Chest and Ear as Representative of the Breathing Zone. Am Ind Hyg.Assoc.J.62: 416427 (2001).

Space craft Maximum Allowable Concentrations for Selected Airborne Contaminants: Volume 3(1997)

www.nap.edu/openbook/0309056292/html/171-199 dated 03/31/2003.

El Nahass W.,: Effects of Heating, Breathing, Hair Style, Posture, and Air Velocity on Breathing Zone Concentrations for an AnthropometricallyCorrect Manikin in a Wind Tunnel. Doctoral Dessertaion, West Virginia University, (2005) 